University of Rhode Island

DigitalCommons@URI

Open Access Master's Theses

2017

\title{
Conserving Milkweed: The Effects of Environmental Change and Viral Prevalence on Asclepias syriaca
}

Courtney Devoid

University of Rhode Island, cdevoid@uri.edu

Follow this and additional works at: https://digitalcommons.uri.edu/theses

\section{Recommended Citation}

Devoid, Courtney, "Conserving Milkweed: The Effects of Environmental Change and Viral Prevalence on Asclepias syriaca" (2017). Open Access Master's Theses. Paper 1068.

https://digitalcommons.uri.edu/theses/1068

This Thesis is brought to you for free and open access by DigitalCommons@URI. It has been accepted for inclusion in Open Access Master's Theses by an authorized administrator of DigitalCommons@URI. For more information, please contact digitalcommons-group@uri.edu. 
CONSERVING MILKWEED: THE EFFECTS OF

ENVIRONMENTAL CHANGE AND VIRAL

PREVALENCE ON ASCLEPIAS SYRIACA

BY

COURTNEY DEVOID

A THESIS SUBMITTED IN PARTIAL FULFILLMENT OF THE

REQUIREMENTS FOR THE DEGREE OF

MASTER OF SCIENCE

IN

BIOLOGICAL AND ENVIRONMENTAL SCIENCES

UNIVERSITY OF RHODE ISLAND

2017 


\section{MASTER OF SCIENCE THESIS}

OF

\section{COURTNEY DEVOID}

\section{APPROVED:}

Thesis Committee:

\begin{tabular}{|c|c|}
\hline Major Professor & Nathaniel Mitkowski \\
\hline & Brian Maynard \\
\hline & Jose Amador \\
\hline & $\begin{array}{l}\text { Nasser H. Zawia } \\
\text { N OF THF GRADUATE SCHOOL }\end{array}$ \\
\hline
\end{tabular}

UNIVERSITY OF RHODE ISLAND

2017 


\begin{abstract}
Monarch butterflies (Danaus plexippus L.) undergo a cross-continental migration each year, depending on the presence of common milkweed (Asclepias syriaca L.), both as a food source and for breeding purposes. The past two decades have seen a marked decline in monarch populations. These declines are partially attributed to a loss of milkweed plants in agricultural areas. To prevent monarch butterfly extinction, conservation efforts are working to increase milkweed prevalence.

Common milkweed is able to grow in a variety of habitat types and environmental conditions; however, the plants response to environmental change has not been extensively studied. The first chapter in this thesis examined the response of northeastern milkweed populations to changes in temperature and precipitation. In addition, the response of plants to increasing levels of soil salinity was investigated, as milkweed plants in the northeast are particularly vulnerable to exposure to high salt levels. Growth patterns were captured by the following response variables: plant height, number of nodes and leaves, stem diameter, stem, root, and whole plant biomass, and leaf area. We found a mixed response of growth characteristics to elevated temperature; leaf area and root biomass were smaller, while node count was larger, and all other variables did not have consistent trends across trials. Across variables, drought conditions reduced plant growth compared to control and excess precipitation treatments, while excess was generally larger than control, although not consistently across response variables. As soil salinity increased, plant growth characteristics decreased, but low salt levels did not differ significantly from the control; therefore we concluded that common milkweed is moderately salt tolerance.
\end{abstract}


These findings indicate that common milkweed populations may experience decreased growth rate with changing environmental conditions; however, the changes we observed will not likely result in an overall significant decrease.

Conservation initiatives are currently focusing on planting milkweed near agricultural areas. While this is helpful for monarch butterflies, common milkweed can act as a host to many viral plant pathogens, which is problematic for growers. The second chapter of this thesis surveyed wild populations of northeastern common milkweed for the presence of cucumber mosaic virus (CMV). Tissue samples were tested for CMV using Immunostrip and ELISA methods. Seed samples were subsequently collected from plants testing positive for the virus and grown up to determine the rate of seed transmission. We found low levels (2.5\%) of CMV positive plants throughout the northeast, with most field sites testing negative for the disease. Seed transmission studies were all negative, indicating that common milkweed seeds do not transmit CMV. These results demonstrate that common milkweed does not substantially contribute to the spread of CMV in the northeastern United States.

The final chapter of this thesis presents methods for propagating common milkweed in tissue culture. Common milkweed has a high level of genetic variation, due to outcrossing, complex pollination methods, and incompatibility in selfpollination. Callus induction was obtained on Murashige and Skoog media containing $10 \mu \mathrm{M} \mathrm{BAP}+5 \mu \mathrm{M}$ NAA; shoot proliferation was obtained on media containing 1.25 $\mu \mathrm{M} \mathrm{BAP}+5 \mu \mathrm{M} \mathrm{NAA}$; and root production occurred on media with $1.25 \mu \mathrm{M}$ BAP and $2.5 \mu \mathrm{M}$ NAA. The formulations in this thesis allow for the production of in vitro plantlets for future research efforts. 


\section{ACKNOWLEDGMENTS}

I would like to thank my advisor Dr. Nathaniel Mitkowski for his invaluable guidance and support throughout this project. Thank you to the staff at the greenhouse facilities, Lisa Tewksbury and Nick Castrataro, for their support and advice. I also thank Arielle Chaves, for her guidance and instruction in countless lab procedures. I would also like to thank my committee members, Dr. Brian Maynard and Dr. Jose Amador for their instruction and assistance throughout my graduate studies.

I would like to thank my office mate, Sarah Schweig for her continual encouragement and support. Thank you to my parents for their help and reassurances along the way. Finally, to my husband, Thomas Dickerson, for his patience, kindness, and willingness to be a sounding board for problem solving. 


\section{PREFACE}

The manuscript format outlined by the Graduate School at the University of Rhode Island will be utilized for this thesis. Three chapters will make up the thesis, prefaced by a Review of the Literature.

The first chapter is entitled "Conserving Milkweed for Monarchs: The effects of elevated temperature, water stress, and soil salinity on northeastern common milkweed (Asclepias syriaca) morphology."

The second chapter is entitled "Evaluation of Asclepias syriaca as a viral host for Cucumber Mosaic Virus in the northeastern United States"

The third chapter is entitled "In vitro clonal plantlet induction of Asclepias syriaca through callus tissue." 


\section{TABLE OF CONTENTS}

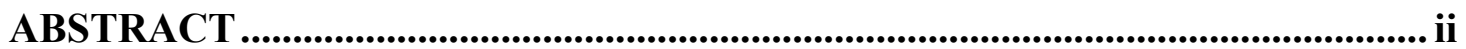

ACKNOWLEDGMENTS ............................................................................................... iv

PREFACE

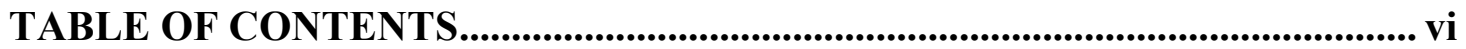

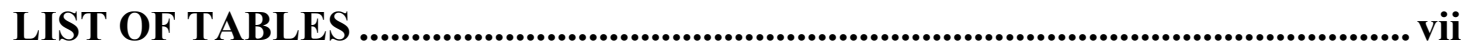

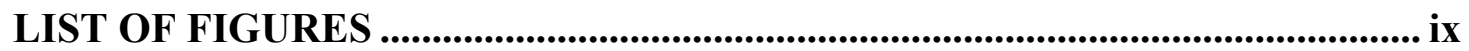

CHAPTER 1: INTRODUCTION............................................................................... 1

CHAPTER 2: REVIEW OF THE LITERATURE.............................................. 4

CHAPTER 3: CLIMATE AND SALINITY............................................................... 27

CHAPTER 4: VIRAL PREVALENCE ............................................................66

CHAPTER 5: IN VITRO PROPAGATION ........................................................ 90

CHAPTER 6: CONCLUSION......................................................................................... 105

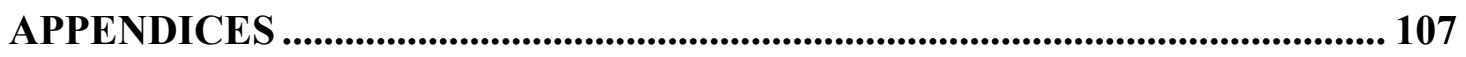

BIBLIOGRAPHY .......................................................................................................... 119 


\section{LIST OF TABLES}

TABLE

PAGE

\section{CHAPTER 3}

Table 1. Pairwise comparisons between water treatments and total change in response variables for height $(\mathrm{cm})$, diameter $(\mathrm{mm})$, nodes, leaves, leaf:node ratio, and leaf area $(\mathrm{cm})$ 57

Table 2. Table 2. Pairwise comparisons between water treatments and total change in response variables for plant biomass (lbs) and wet:dry biomass ratio..... 57 Table 3. Difference between $30^{\circ} \mathrm{C}$ and $25^{\circ} \mathrm{C}$ treatments for total change in response variables.

Table 4. Pairwise comparisons between water treatments for response variables measured over time. Height $(\mathrm{cm})$, nodes, leaves, and leaf:node ratio were all measured weekly to show the divergence of treatments. 58

Table 5. Difference between $30^{\circ} \mathrm{C}$ and $25^{\circ} \mathrm{C}$ temperature treatments for response variables measured over time. 58

Table 6. Total change in response variables for soil salinity study. 58

Table 7. Main effects for change over time for soil salinity study. 59 


\section{CHAPTER 4}

Table 1. Initial screening of $A$. syriaca plants after 7-weeks of growth using the Immunostrip testing method for three plant viruses: cucumber mosaic virus (CMV), tobacco mosaic virus (TMV), and tomato spotted wilt virus (TSWV)..................... 87

Table 2. Repeated tests of A. syriaca plants after 15-weeks of growth using the Immunostrip testing method for two viruses: cucumber mosaic virus (CMV), and tobacco mosaic virus (TMV)

Table 3. Field survey results from leaf samples of $A$. syriaca plants collected along a latitudinal gradient in the northeastern United States using the Immunostrip testing method to test for cucumber mosaic virus (CMV). Sites located near agricultural fields and away from any agriculture were collected at each location.

\section{CHAPTER 5}

Table 1. The development of callus from stem node and internode explants of Asclepias syriaca on nine different media combinations 102 


\section{LIST OF FIGURES}

FIGURE

PAGE

\section{CHAPTER 3}

Figure 1. The relationship between temperatures $\left(25^{\circ} \mathrm{C}\right.$ and $\left.30^{\circ} \mathrm{C}\right)$, water treatments (drought (D), control (C), and excess (E)) and total change in response variables: height $(\mathrm{cm})$, biomass $(\mathrm{lbs})$, leaf area $(\mathrm{cm})$, diameter $(\mathrm{mm})$, wet:dry biomass ratio, and number of leaves. Legend: blue line represents $30^{\circ} \mathrm{C}$, red line represents $25^{\circ} \mathrm{C}$, drought (D), control (C), and excess (E) 60

Figure 2. The relationship over time between water treatments (drought (D), control (C), and excess (E)) and response variables: height $(\mathrm{cm})$, nodes, leaves, and leaf:node ratio. Legend: blue line represents excess water, red line represents control, and green line represents drought conditions. 61

Figure 3. The relationship over time between temperatures $\left(25^{\circ} \mathrm{C}\right.$ and $\left.30^{\circ} \mathrm{C}\right)$ and response variables: height $(\mathrm{cm})$, nodes, leaves, and leaf:node ratio. Legend: blue line represents $30^{\circ} \mathrm{C}$, red line represents $25^{\circ} \mathrm{C}$ 62

Figure 4. The relationship between soil salinity level (ppm) and total change in response variables: height $(\mathrm{cm})$, biomass $(\mathrm{lbs})$, leaf area $(\mathrm{cm})$, diameter $(\mathrm{mm})$, wet:dry biomass ratio, and number of leaves. 63

Figure 5. The relationship over time between soil salinity level $(0,2,000,6,000$, and $12,000 \mathrm{ppm})$ and height $(\mathrm{cm})$, nodes, leaves, and leaf:node ratio 


\section{CHAPTER 4}

Figure 1. Geographic distribution of field sites in the northeastern United States where surveys were conducted to determine the prevalence of cucumber mosaic virus (CMV) in and away from agricultural areas. Symbols portray the approximate location of both field sites. Each triangle represents two sites: one near a crop field and one isolated from agriculture. Exact coordinates can be found in the appendix. Base map was

obtained from Wikimedia Commons (2010).

\section{CHAPTER 5}

Figure 1. Developing callus tissue at two different stages. The left plate has been growing for 3 weeks old, while the right plate has been growing for 6 weeks. Callus development occurred most quickly on media containing $10 \mu \mathrm{M}$ BAP $+5 \mu \mathrm{M}$ NAA.

Figure 2. Shoot formation from an adventitious bud on a nodal explant. Callus

formation was substantially reduced.

Figure 3. Shoot formation from callus tissue. Photos depict multiple shoots

proliferating from one piece of callus.

Figure 4. Flower produced on shoot induction media.

Figure 5. Shoots with attached root systems. The attachment point between roots and shoots was extremely fragile. Plants were transferred to media without any hormones, where roots grew profusely. 104 


\section{CHAPTER 1}

\section{INTRODUCTION}

Monarch butterfly (Danaus plexippus L.) populations have been in decline for the past two decades (Flockhart et al. 2015). This decline is due to several factors, including extreme weather events, habitat loss in central Mexico, and reduction in host-plant availability (Brower et al. 2012, Flockhart et al. 2015). To survive their annual cross-continental migration, monarchs require common milkweed (Asclepias syriaca L.) along migration routes. Milkweed serves as both a food source and larvalhost plant for monarch caterpillars. After overwintering in central Mexico, populations must rebuild during their spring migration, making milkweed presence essential.

Recent declines in monarch populations have been attributed to decreased milkweed prevalence in agricultural areas. The advent of herbicide resistant crops and subsequent large-scale herbicide application has substantially reduced milkweed populations (Pleasents and Oberhauser 2012). To decrease the likelihood of monarch butterfly extinction, conservation initiatives are being implemented throughout the United States. Initiatives include: planting hedgerows of milkweed along agricultural fields, developing "monarch way stations" along migration routes, roadside planting projects, and working with community members to plant pollinator gardens (Borders and Lee-Mader 2014). These conservation efforts are important; however, current knowledge about how common milkweed will be impacted by future environmental change is limited. 
Climate change has the potential to alter species distributions, reduce population size, and decrease overall plant growth. Near-term climate models predict temperature increases of as must as $4.8^{\circ} \mathrm{C}$ by 2100 , accompanied by extreme weather events (IPCC 2013). Previous work looking at the effects of climate change on milkweeds has focused on Midwestern populations. Increased temperature has been shown to increase milkweed growth, while drought conditions decreased growth (Couture et al. 2015). Since milkweeds are a genetically diverse species that have been shown to be locally adapted, research on populations throughout the migration area is essential. Examination of the impacts of other weather patterns will also be important, particularly because increases in precipitation are predicted in the northeast. The first objective of this thesis is to study how increased temperature, drought, and excess precipitation alter the growth patterns of northeastern A. syriaca populations.

In addition to climate change, human mediated environmental changes have the potential to significantly affect common milkweed populations. Increased soil salinity is an important factor to consider when examining the growth of common milkweed. Common milkweed grows in fields, meadows, along roadsides, and agricultural edges (Hartzler 2010). Roadsides are particularly vulnerable to salinization in the northeastern United States, due to the application of de-icing salts during winter months. Irrigation and intensive agricultural can also result in increased soil salinity; the build-up of salts can occur as water is used by plants or evaporates, leaving behind salts. Since many conservation projects are focused on roadsides and agricultural areas, it is important to examine the salt tolerance of $A$. syriaca. Germination studies have shown a decrease in germination rates and root length when 
seeds are grown in saline solutions (Beaton and Dudley 2004). The second objective of this thesis is to examine how common milkweed plants respond to increasing levels of soil salinity, in order to assess the salt tolerance of this species.

Conservation projects based in agricultural fields are important for monarchs, but they the potential to increase the prevalence of crop viruses. Common milkweed is a host-plant for an array of crop viruses, often acting as the source of inoculum for insect transmission vectors. As a long-lived perennial, common milkweed has deep root systems where viruses are able to overwinter. Cucumber mosaic virus (CMV) is spread from perennial weeds via non-persistent transmission by over 86 aphid species (Francki et al. 1979a, Ali and Kobayashi 2010). CMV has a large host range, infecting as many as 1200 species in 100 families (Ali and Kobayashi 2010). Milkweed is a know host to CMV; however, the extent of infection in wild populations is currently unknown (Doolittle and Walker 1925). The third objective of this thesis is to survey wild milkweed populations in the northeast and assess the abundance of CMV infection in plants.

It is clear that research on common milkweed is critical for conservation of monarch butterflies. Common milkweed is a genetically diverse species, making research challenging, as a high level of variation among individual plants can occur. The propagation of $A$. syriaca in tissue culture has had limited success. In order to create genetically identical clones to be used in future research efforts, formulations need to be developed for successful plantlet production in vitro. The final objective of this thesis is to develop methods for in vitro propagation of $A$. syriaca. 


\section{CHAPTER 2}

\section{REVIEW OF LITERATURE}

\section{Common Milkweed Life History:}

Species Characteristics: Common milkweed (Asclepias syriaca L.) is a longlived, perennial herb that grows from a deep rhizome (Bhowmik 1994). Plants have simple stems ( $2 \mathrm{~m}$ high) and propagate from seeds and root buds formed from the previous years growth. The species is colony-forming, often growing in dense stands from adventitious buds (Borders and Lee-Mader 2014). In the spring, aerial shoots emerge from underground root buds; root extension starts mid-summer, and terminates in September. Seedlings are capable of producing new shoots from buds, and therefore becoming perennial, 21 days after germination; however, seedlings rarely flower until their second year (Bhowmik et al. 1970). Flowering occurs during the following growing season for shoots formed from adventitious root buds (Bhowmik 1994).

Plants are largely self-incompatible, depending on insects to carry pollinia for reproduction (Wyatt and Broyles 1994). The milkweed pollination process is extremely complex, requiring insects to come in contact with a pollen bearing gland (corpusculum), the pollinia to attach to the insect, and then be inadvertently transferred into the stigmatic slit of a non-related milkweed flower (Borders and LeeMader 2014). As a result, fruit set is very low in natural populations (between 1-5\%), due in part to plants having limited resources to produce mature fruits and insufficient numbers of compatible pollinia (Wyatt and Broyles 1994). Plants produce ovoid seed 
pods, filled with brown, flat seeds that have a tuft of silky hair (pappus) to aid dispersal (Bhowmik 1994, Borders and Lee-Mader 2014). Intact seeds are dormant at maturity; seeds require a short period of cold, moist stratification to break dormancy (Baskin and Baskin 1977). One week of stratification and germination in warm temperatures $\left(30^{\circ} \mathrm{C}\right)$ has proved effective in overcoming dormancy (Baskin and Baskin 1977).

Distribution: Common milkweed is adapted to a wide range of soil and climactic conditions, making its distribution area large (Cramer and Burnside 1982). Common milkweed is native to southern Canada and the central and eastern United States. The United States Department of Agriculture plant profile has this plant listed throughout the eastern United States, excluding Florida. The western bound of the range includes Montana, South Dakota, Nebraska, Kansas, Oklahoma, and Texas; Oregon is also included from the west coast. In Canada, Quebec, Ontario, Manitoba, and Saskatchewan make up the native range. Distribution is limited by $18-32{ }^{\circ} \mathrm{C}$ mean July temperatures and a minimum of $50 \mathrm{~m}$ of rain during summer months, but soil type, $\mathrm{pH}$, and altitude are not limiting factors (Bhowmik 1994).

Habitats: Milkweed can be found in a diverse range of habitats, such as prairies, plains, open woods, and meadows (Woodson 1954). Common milkweed has been extremely successful in colonizing disturbed areas, including roadsides, agricultural fields, and railroads (Bhowmik 1994, Cramer et al. 1994, Pleasents and Oberhauser 2012). Growing in agricultural fields has made milkweed a target for irradiation, as this plant can infest croplands (Cramer and Burnside 1982). Common 
milkweed is a weak competitor in cultivated land, but both dense milkweed stands and allelopathic effects play a substantial role in crop reduction (Rasmussen 1975).

Chemical Ecology: Milkweeds get their name from the "milky" latex sap that is released in response to herbivore damage (Borders and Lee-Mader 2014). The latex acts as a defense against herbivores by drowning the instar larvae in the sticky sap (Borders and Lee-Mader 2014). An additional response to feeding damage is to increase cardenolide concentrations in leaves (Malcolm and Zalucki 1996). Cardenolides are glycoside steroids that defend plants from herbivores, parasites, and pathogens (Malcolm 1991). Monarch butterflies are adapted specialists that sequester cardenolids as larvae, thereby becoming chemically defended against predators (Malcolm and Zalucki 1996). Monarchs are known to sequester cardenolids from common milkweed most effectively; studies using cardenolide fingerprinting analysis have shown that $85-92 \%$ of monarchs overwintering in Mexico fed on common milkweed as larvae (Malcolm et al. 1993). Cardenolides make milkweeds bittertasting and unpalatable to herbivores; however, the plants are toxic to livestock, therefore careful management in grazing areas must be undertaken to avoid poisoning (Panter et al. 2011, Borders and Lee-Mader 2014).

\section{Monarch Butterfly Conservation and Milkweed Limitation:}

Each spring, monarch butterflies undergo a multi-generational, crosscontinental migration from central Mexico to eastern North America (Pleasents and Oberhauser 2012). This unique migration and overwintering biology has made eastern monarch butterflies one of the best known examples of long-range migration (Malcolm et al. 1993). Over the last two-decades, annual counts of the overwintering 
population in Mexico indicate that the eastern population has been declining (Brower et al. 2012, Vidal and Rendón-Salinas 2014, Pleasants et al. 2016). Declines have been attributed to three factors: loss of habitat in central Mexico, severe weather events, and decreased host-plant availability (Brower et al. 2012, Flockhart et al. 2015).

In January 1975, researchers located the first colonies of monarchs in the mountains of central Mexico (Slayback et al. 2007). Over the next four decades, researchers have located 12 mountain massifs that host overwintering butterfly colonies in Mexico (Slayback et al. 2007). Colonies are ecologically and geographically constrained to high elevations (2900-3300 m) and densely forested areas, aggregating on oyamel fir (Abies relegiosa (Kunth) Schltdl. \& Cham., 1830) trees with as many as 5,000 butterflies per square meter (Brower et al. 2004). Habitat degradation is caused by industrial logging, charcoal production, domestic use, and agricultural expansion (Brower et al. 2002). Illegal logging has eliminated several overwintering habitats with 44\% of high quality forest degraded between 1971-1999 and 10\% degraded and clear cut between 2001-2009 (Brower et al. 2012). Multiple wildlife reserves and refuges have been designated to protect overwintering habitat, but illegal logging, failure to enforce laws, and general ineffectiveness of protection have caused diminished conservation success (Brower et al. 2002)

Severe weather events can threaten monarch populations by decreasing survivorship in overwintering areas and lowering breeding season survivorship (Brower et al. 2012). Several events have led to declines in recent years. Between $2009-2011,115$ hectares of forest in the monarch reserve have been impacted by 
flooding, wind, drought, and fires, with 29 hectares more being affected by drought and parasitic plants (Vidal and Rendón-Salinas 2014, Vidal et al. 2014) During the spring of 2009, high temperatures impacted first-generation monarchs in Texas, and subsequent low temperatures in the Midwest limited the growth of summer populations. In 2009-2010, extreme amounts of precipitation fell on overwintering habitats: $577 \mathrm{~mm}$ compared to $40 \mathrm{~mm}$ in the previous year (Brower et al. 2012). This high level of precipitation was accompanied by severe windstorms that decimated oyamel fir trees in the core monarch reserve. Storms like this scatter butterflies from their tree colonies and result in mass mortality (Brower et al. 2012). It is important to note that severe precipitation events like this one are likely to increase with climate change (Pleasents and Oberhauser 2012, IPCC 2013).

Declines in plant-host availability are the final factor attributed to loss of monarch populations. Monarch butterflies depend on milkweed presence along migration routes. Overwintering adults migrate north and reproduce in the spring on milkweed plants. Their offspring moving farther north and this breeding-migration phenomenon continues for two or three generations until mid-August, when adults that emerge then migrate south (Pleasents and Oberhauser 2012, Flockhart et al. 2015). The sole food source for monarch larvae is milkweeds, with $92 \%$ of those plants being Asclepias syriaca (Malcolm et al. 1993, Hartzler 2010).

Large reductions of common milkweed populations have occurred, especially in the Midwestern United States. This is problematic because monarchs have been shown to heavily use milkweeds in corn and soybean fields (Oberhauser et al. 2001). In an initial survey in 1999, Hartzler et al. (2010) found common milkweed presence 
in $50 \%$ of Iowa corn and soybean fields. In 2009, common milkweed was found in just $8 \%$ of fields, and areas once infested with the plant were reduced by up to $90 \%$ (Hartzler 2010). These reductions are linked to adoption of crops genetically modified for glyphosate resistances, which became widely used by 1999 (Dill et al. 2008). Milkweed presence in agricultural fields is a concern for farmers, as it can infest agricultural areas and reduce crop yields (Bhowmik 1994). With the advent of herbicide resistant crops, large scale application of herbicides can occur, resulting in significantly reduced levels of milkweed (Pleasents and Oberhauser 2012). These reductions in agricultural areas have important implications because larval densities on common milkweed plants have been shown to be higher in agricultural fields than non-agricultural areas (Oberhauser et al. 2001).

Pleasants and Oberhauser (2012) estimate a 58\% decline in milkweeds and an $81 \%$ decline in monarch production in the Midwest. They demonstrate that monarch production during the summer breeding season is positively correlated with overwintering populations in Mexico, and conclude that a loss of agricultural milkweeds is a primary contributor to the decline (Pleasents and Oberhauser 2012, Pleasants et al. 2016). Modeling by Flockhart et al. (2015) has also demonstrated that a reduction in milkweed host plants, caused by genetically modified crops and landuse change, is responsible for monarch reduction. Therefore, reducing the negative effects of host plant loss has become the top conservation priority for halting future population declines (Flockhart et al. 2015). 


\section{Climate Change:}

Research has established the critical role that milkweed plays in monarch survival along migration routes. In conjunction with conservation efforts being taken to reduce destruction of overwintering habitat, organizations are working to increase milkweed prevalence in summer breeding areas. The future impacts of climate change, both for monarch butterflies themselves and for their host plant, become a critical point to consider when planning conservation efforts today. Climate change can alter species distributions, caused by changes in temperature, precipitation, and seasonality (Lemoine 2015). These altered growing conditions can modify both the plants themselves and plant insect interactions (Couture et al. 2015). Near-term climate models predict increases of as much as $4.8^{\circ} \mathrm{C}$ by 2100 , accompanied by increased extreme weather events (IPCC 2013). Precipitation changes will not be uniform, with both drought and increased precipitation predicated, depending on the geographic area and the climate model (IPCC 2013). In the northeastern United States, the focus of this thesis, model projections suggest a 5-20\% increase in winter precipitation and increased frequency of heavy downpours and seasonal drought episodes (Horton et al. 2014). Climate change will therefore effect monarchs in multiple ways, including: reduced overwintering habitat, breeding range shifts, and changes in host plant abundance (Lemoine 2015).

Monarch population reductions at overwintering sites are expected to occur with climate change, due to altered distributions of winter host species and increased prevalence of extreme weather events. Sáenz-Romero et al. (2012) modeled the effect of climate change on oyamel fir, the preferred plant host in Mexico. The model 
mapped the climactic niches for oyamel fir for future climates and found that the current niche should decrease rapidly in the next century; a decrease of $69.2 \%$ by $2030,87.6 \%$ by 2060 , and $96.5 \%$ by 2090 (Sáenz-Romero et al. 2012). This will cause upward migration of oyamel fir to higher altitudes (Sáenz-Romero et al. 2012). These findings have important implications for monarch conservation, as suitable habitat could move outside the current reserve area. Changes in weather patterns are also likely to cause population declines at overwintering sites. Using ecological niche modeling, Oberhauser and Peterson (2003) found that precipitation and temperature are key factors for monarch survival in winter habitat, and increased cool-weather precipitation could cause increased mortality.

Warming temperatures are predicted to shift the breeding range of monarch butterflies, due to the specialization between monarchs and milkweeds (Davis and Dyer 2015, Lemoine 2015). Since monarchs are specialists, the rate of range expansion depends on their host plant; therefore, if monarchs are unable to shift their distributions northward, climate change can impose severe bottlenecks (Lemoine 2015). Species distribution models have demonstrated that climate change may drive northward both the northern and southern range of monarchs (Lemoine 2015). Lemonie (2015) found that distributions are projected to extend northward through most of Canada. The models also found that Asclepias distributions are an important predictor for current monarch distributions, therefore monarch ranges are likely constrained by milkweed availability (Lemoine 2015). Early evidence of range shifts is already being reported: first sightings of fall roosts have been shown to be father 
north and monarch arrival to overwintering sites is showing delays (Davis and Dyer 2015, Howard and Davis 2015).

Climate change will further impact monarch populations by altering the growing conditions of milkweed plants. Both changes in precipitation and temperature can have severe impacts on plant survival and overall growth. Drought stress can impede cell division and elongation, resulting in stunted growth of plant organs (Medeiros et al. 2012). Findings that drought stress hinders growth are consistent across many species (Nezami et al. 2008, Aslam et al. 2015, Couture et al. 2015). Couture et al. (2015) found water stress decreased plant growth by $\sim 76 \%$ in common milkweed.

The effects of flooding and increased precipitation must also be considered in the context of climate change, specifically for the northeastern United States. Saturated soils result in reduced respiration, decreased root volume, less transport of water and nutrients, and a buildup of toxic compounds (Lauer 2014). Soil inundation can suppress leaf formation and expansion, as well as accelerate leaf senesce (Kozlowski 2000). Decaying roots and decreased root production are also common occurrences in saturated soils (Heinrichs 1970). Further, excess moisture can increase plant susceptibility to fungi, pathogens, and insects (Rosenzweig et al. 2001). Increased moisture conditions result in environments where certain diseases and pests can thrive and plants growing in stressed conditions therefore become more susceptible in infestation (Rosenzweig et al. 2001).

Responses to increased temperature vary substantially, depending on the species examined. Elevated temperature has been found to increase plant growth in 
several studies (Veteli et al. 2002, Nybakken et al. 2012, Lavola et al. 2013, Couture et al. 2015). In woody perennials, plant growth characteristics, including biomass, diameter, and height have been found to increase with elevated temperatures (Veteli et al. 2002, Nybakken et al. 2012, Lavola et al. 2013). Other variables, including diameter, number of leaves, and leaf area have been shown to decrease with elevated temperatures (Lavola et al. 2013). For common milkweed specifically, Couture et al. (2015) concluded that elevated temperature "marginally" increased plant growth $(\mathrm{p}=$ 0.07). It is important to note that Couture et al. (2015) state that elevated temperature increases plant growth; however, all cited literature supporting this statement in the paper pertains to woody perennials and multiple growth variables showed no signs of increased growth with elevated temperature (eg. Lavola et al. 2013).

Primary research on the effects of elevated temperature on agricultural crops has found no difference in total plant biomass under increased temperature regimens (Hatfield and Prueger 2015). Warming temperatures had no effect on leaf area or vegetative biomass in corn (Hatfield and Prueger 2015). In later work, Hatfield (2016) found rising temperatures significantly reduced agricultural crop yields. This research focused on extrapolation of crop models combined with future climate scenarios (Hatfield 2016). Primary research has found plant height, number of tillers, and total biomass were reduced in response to elevated temperature in rice cultivars (Mitra and Bhatia, 2008). It is clear that varying responses to elevated temperature have been demonstrated; therefore species and population level research must be conducted to determine how a given plant will respond. Additionally, most work pertains to either 
woody perennials or monocot species, and studies on the effects of elevated temperature on common milkweed are limited.

Given that both changes in temperature and weather patterns are predicted, the interactive effects between these variables must also be considered. Hatfield and Prueger (2015) subjected corn plants to normal or elevated temperatures and three precipitation levels: normal, excess, and deficit conditions. Normal precipitation produced the highest biomass and grain yield, regardless of temperature treatment (Hatfield and Prueger 2015). Further, water deficit and excess water reduced biomass and grain yield under the normal temperature, and extreme temperatures had a significant reduction under any water regime (Hatfield and Prueger 2015). This experiment shows that the effects of increased temperature are amplified by water stress, demonstrating the interactive effect of these climate variables (Hatfield and Prueger 2015).

Couture et al. (2015) examined temperature and water stress on four populations of $A$. syriaca. They found no interactive effects of temperature and water stress when populations were combined; however, there was a significant interaction when plant origin was taken into account (Couture et al. 2015). This finding brings up the importance of local adaptation when examining the role of climate change. For $A$. syriaca specifically, multiple studies have shown geographic variation between populations (Agrawal 2005, Woods et al. 2012, Wason et al. 2013, Couture et al. 2015). Woods et al. (2012) found that plants from northern populations produced less aboveground biomass, more root buds and clonal growth, higher root-to-shoot ratio, and more latex production, then southern populations. Couture et al. (2015) found that 
plants from northern populations were less affected by water stress than southern populations. These studies demonstrate that examination of variable interactions will be important in predicting the impacts of climate change on A. syriaca.

\section{Soil Salinity:}

Soil salinity is an environmental factor that significantly limits plant productivity (Shrivastava and Kumar 2015). Intensified agriculture, drought, roadside salt application, conversion of wetlands to agricultural fields, and irrigation can cause increases in soil salinity (Jamil et al. 2011, Shrivastava and Kumar 2015). Jamil et al. (2011) estimate that $20 \%$ of cultivated lands and $33 \%$ of irrigated agricultural lands have high salinity levels, and salinized areas are increasing at an annual rate of $10 \%$ (Cabot et al. 2014). Further, under global climate models, salinity is expected to increase in the near future, as temperature and drought increase (Cabot et al. 2014).

In general, salt stress can reduce plant growth, inhibiting leaf and stem elongation and decreasing plant yields (Bartels and Sunkar 2005). Major constraints associated with salt-stress include: water deficit, ion toxicity, and ion imbalance (Cabot et al. 2014). A decrease in soil osmotic potential results in reduced water availability and subsequent loss of cell turgor pressure (Cabot et al. 2014). Excessive anions then compromise plant growth, as sodium and chlorine are toxic to many plants, inhibiting enzymatic activity (Cabot et al. 2014, Renault et al. 2016). Root growth may continue as an effort to obtain additional surfaces to sequester toxic ions (Bartels and Sunkar 2005).

Decreased growth rates and changes in leaf area have been demonstrated in many species as a result of salt stress (Cramer et al. 1994, Abdul Qados 2011, Renault 
et al. 2016). Renault et al. (2016) exposed Brassica juncea to salt treatments using a hydroponic system. This study found that after two weeks, biomass of plants exposed to 50 and $100 \mathrm{mM}$ sodium chloride $(\mathrm{NaCl})$ were 24 and $35 \%$ smaller than control, respectively (Renault et al. 2016). In another study on corn plants, salinity significantly reduced dry matter and leaf area, and caused calcium deficiency (twisting and curling leaves with necrotic margins) in plants treated with sodium (Cramer et al. 1994). Long-term exposure to increased salinity limits plant growth when it reaches the maximum tolerated concentration, causing leaf senescence and decreased photosynthetic area (Munns and Termaat 1986).

In addition to changes in plant growth, stress responses can occur that result in altered plant morphology. Salt induced epinasty has been observed. Epinasty occurs when cells elongate on the upper surface of a plant organ faster than the lower surface, resulting in leaf bending and curling. This is caused by the increased production of ethylene (Jones and El-Beltagy, 1989). Salt-induced epinastic growth of petioles has been seen in tomatoes under moderately high levels of salt stress (Jones and ElBeltagy, 1989). El-iklil et al. (2000) also found that increasing levels of salt stress resulted in increased epinasty and that the severity increased over time. Such a phenomena demonstrates that salt stress can cause both morphological and physiological changes in plants. Epinasty in particularly is an important symptom because it can act as an indicator of salt-tolerances amount different genotypes (Jones and El-Beltagy 1989).

The current habitat distribution of common milkweed makes it particularly vulnerable to increased soil salinity. Common milkweed frequently grows in fields, 
meadows, along roadsides, and agricultural edges (Hartzler 2010, Dumroese and Luna 2013). These habitats are particularly vulnerable to increased soil salinity. In agricultural fields, irrigation causes a buildup of salts, as plants use water or water evaporates, trace amounts of salt are left behind. Roadsides are also subject to high salt levels due to the use of de-icing salts during winter months (Beaton and Dudley 2004). Predicted increases in soil salinity under climate change will mean increased exposure to high salinity levels. Further, conservation efforts are focused on increasing milkweed prevalence in salt prone areas. For example, the Roadsides program in Minnesota is using native prairie plants (including common milkweed) for roadside revegetation to increase pollinator habitat (Borders and Lee-Mader 2014). Another common conservation project is planting milkweed and other wildflowers along field boarders of agricultural fields and in "pollinator hedgerows," to increase on-farm access of insects to native plants (Borders and Lee-Mader 2014).

Several studies have examined how soil salinity levels effect germination and seedling development of $A$. syriaca. Common milkweed was germinated alongside four other species (honeyvine milkweed (Ampelamus albidus (Nutt.) Britt), kochia (Kochia scopari (L.) Schrad), sunflower (Helianthus annuus L.), and sorghum (Sorghum bicolor (L.) Moench)) in sodium chloride $(\mathrm{NaCl})$ solutions that ranged from 0-10,000 ppm (Evetts and Burnside 1972). Sorghum and kochia were not affected by concentrations less than 5,000 ppm $\mathrm{NaCl}$ and sunflower germination was not reduced at the highest concentration of 10,000 ppm. Common milkweed and honeyvine milkweed germination was significantly reduced at 5,000 ppm, but the germination rate index (accounting for the speed and total number of germinated seeds) of common 
milkweed was unaffected by salt concentrations. Radical lengths of common milkweed were significantly shorter when germinated at 2,500 ppm NaCl.

Beaton and Dudley (2004) examined whether local adaptation to high soil salinity had occurred in A. syriaca. Seeds from roadsides (high salt exposure) and oldfield populations (low salt exposure) were treated with $70 \mathrm{mM} \mathrm{NaCl}$; both populations had shorter roots when exposed to salt levels compared to control. An important finding from this paper was that roadside populations were not better adapted to high salt levels than old-field populations. Lack of adaptation was attributed to the life history of A. syriaca. It's adventitious root bud reproduction and low seedling recruitment result in most plants being a part of long-lived clones, which can buffer the species against environmental variation (Bhowmik 1994, Beaton and Dudley 2004). A next step in this research should be germination studies looking at the interactive effects of soil medium and salinity, which may produce different results than the previous work described above, since seeds were germinated seeds in saltwater solutions without soil medium.

\section{Viral Host Potential:}

A. syriaca presence in agricultural fields is a significant concern for crop farmers, both because of its fast growing, weedy properties that can reduce yields and because it acts as an reservoir for crop diseases (Bhowmik 1994, Kazinczi et al. 2002). Weed plants are alternative hosts for agricultural viruses; the plants are a food source for insect vectors and the seeds, vegetative shoots, and deep root systems serve as overwintering sites for the viruses (Kazinczi et al. 2002). Common milkweed's presence in agricultural areas, its rapid distribution ability, and alleopathic nature, 
make it a particular problem. Common milkweed is a known host to a variety of plant pathogenic viruses, including: alfalfa mosaic virus, arabis mosaic virus, cucumber mosaic virus, prunus necrotic ringspot virus, strawberry mottle virus, tobacco mosaic virus, and tobacco streak virus (Kazinczi et al. 2002). Cucumber mosaic virus (CMV) is a devastating virus with an extremely large host range (1200 plant species in 100 families) (Ali and Kobayashi 2010). Management of CMV is difficult and the virus is widespread throughout the United States, therefore it will be the focus of this thesis.

CMV is a single-stranded RNA virus that is transmitted from perennial weeds via non-persistent transmission by over 86 aphid species (Francki et al. 1979b, Ali and Kobayashi 2010). The virus is made up of a single-stranded RNA genome, surrounded by isometric particles (Escriu et al. 2000). Non-colonizing, transient winged aphids are responsible for spread from host plants to crops (Tomlinson 1987). Most of the aphids species responsible for transmission have a narrow host range; however, they will often test-probe non-host species and spread the virus (Mueller et al. 2012). Massive flights of winged aphids have lead to viral epidemics in non-host agricultural crops. Rusty plum aphids (Hysteroneura setariae Thomas, 1878) caused an outbreak of CMV in sugar beets (Beta vulgaris L.) (Duffus 1971, Mueller et al. 2012). The aphids grew on grain sorghum, acquired the virus from infected weeds growing in and around the field, and then infected sugar beet fields, despite feeding poorly on sugar beets (Duffus 1971). Hobbs et al. (2000) conducted aphid transmission experiments with oleander aphids (Aphis nerii Boyer de Fonscolombe, 1841), which were observed on milkweed near CMV-infected clammy groundcherry (Physalis heterophylla Nees) plants. A. nerri was found to be able to transmit CMV from P. heterophylla to pepper 
plants (Hobbs 2007). The non-persistent transmission method, in combination with a wide range of weedy host species, makes CMV particularly problematic for farmers.

CMV can cause considerable crop losses through reductions in both yield and plant growth (Bruckart and Lorbeer 1975). Once a plant is infected, numerous foliar symptoms occur, including: leaf blistering, pod distortion, vein clearing, and leaf mottling (Mueller et al. 2012). Fruits often become mottled and distorted, making them unsellable (Zitter and Banik 1984). Infected milkweed plant symptoms are similar to crops, including dwarfed growth, mottled leaves, and leaves with irregular patches of green/yellow color (Doolittle and Walker 1925). Leaves of infected milkweeds are often distorted in shape and smaller than non-infected plants. Dwarfed plants seldom reach 12-inches, compared to a normal 3-4 feet; this feature, accompanied by leaf abnormalities, make the disease easily recognizable (Doolittle and Walker 1925).

Doolittle and Walker (1925) first established the importance of weeds as hosts for infection and subsequent spread within CMV infected crops. Mosaic disease on milkweed was first observed in the 1920's in Madison, Wisconsin. Approximately 20 mosaic milkweeds were found in rows of cucumber plants, and over the summer months, the disease developed and spread to the cucumbers. All early infection of cucumbers was found to occur within 6-10 feet of mosaic milkweeds. Then, the cucumber aphid (Aphis gossyppi Glover, 1877) was present in July in large quantities, resulting in $75 \%$ of the cucumber plants becoming diseased by August. Further evidence of the connection between milkweeds and CMV was found in Rockland, Wisconsin, where experiments were being done to control CMV by removing wild 
cucumber plants. Fields where wild cucumbers were removed (to prevent infection) were found to be $90 \%$ mosaic diseased. Researchers found 100 mosaic milkweed plants heavily infected with cucumber aphids growing between the cucumber plants. After this discovery, cross-inoculation experiments were conducted between aphids feeding on mosaic milkweeds and healthy cucumber plants. Mosaic appeared on all plants exposed to the aphids, and control plants with aphids taken from healthy milkweeds had no sign of mosaic.

Since the initial confirmation of milkweed as a CMV host, several other studies have been done to test these findings. Bruckart and Lorbeer (1976) collected samples from weeds growing in and around lettuce and celery fields that had previously been infected with CMV. A. syriaca samples were found to be infected with CMV, but only at a 3\% frequency (Bruckart and Lorbeer 1975). All infected samples were collected during September, when lettuce samples were also commonly infected (Bruckart and Lorbeer 1975). Infected plants were observed to be symptomless (Bruckart and Lorbeer 1975).

Mueller et al. (2012) tested crop and non-crop plants as potential reservoirs for CMV by surveying plants that are abundant in agricultural landscapes. Samples were taken along the border of snap bean (Phaselous vulgaris L.) fields and within $5 \mathrm{~m}$ of the adjacent field (which included unmanaged areas). During 2007, 86 plants boarding Phaselous vulgaris fields were tested with 0 positive hits; however, in 2008, 371 plants were tested and $7 \%$ were found to be CMV positive. Samples taken within $5 \mathrm{~m}$ of field edges tested positive for CMV, with 457 samples tested and 5\% being positive. 
Various aphid species have been confirmed as transmission vectors for CMV, but seed transmission is another possibility (Ali and Kobayashi 2010, Mueller et al. 2012). Seed-born viruses are an importance source of initial infection, that can subsequently be spread via insects (Tomlinson 1987). Seed transmission of CMV has been documented in crop plants, including peppers (Capsicum annum L.) and spinach (Spinacia oleracea L.) (Yang et al. 1997, Ali and Kobayashi 2010). Whole dry pepper seeds were found to have infection rates of $95-100 \%$ per plant, and in grow out tests, seed transmission averaged 12\% (Ali and Kobayashi 2010). CMV has been shown to be seed transmitted in chickweed, which can be particularly problematic because chickweed produced large numbers of seeds in the soil, therefore low rates of transmission (1-2\%) can result in outbreaks (Tomlinson 1987). Tomlinson and Carter (1970) inoculated 2-3 week old plants with CMV and tested the seeds of those plants. In addition, plants grown from naturally infected seed were also tested. Manual inoculation resulted in a mean of $11 \%$ infection, while natural infection had $28 \%$ mean infection (Tomlinson and Carter 1970). Much lower rates of seed transmission were found by Jones and Coutts (1996). Samples of seed from infected crops of both chickpeas and lentils were germinated and $0.1-2 \%$ of plants tested positive for CMV (Jones and Coutts 1996). Seed transmission in A. syriaca has not yet been documented and will be tested in this thesis.

The ability of $A$. syriaca as a viral host makes it a risky plant to keep in agricultural areas. Coupled with its toxicity to livestock and reduction of crop yields, it is important that agricultural producers be aware of the possible problems associated with common milkweed presence in fields. At the same time, the presence of common 
milkweed in agriculture fields is a critical part of monarch butterfly habitat.

Conservation efforts focused on increasing milkweed populations in agricultural areas must consider the risks to producers before projects are initiated.

\section{Tissue Culture:}

Asclepias syriaca is a genetically outcrossing species that depends on insects for reproduction. Plants are nearly self-incompatible: several studies have reported total self-incompatibility, while others report low levels $(<5 \%)$ (Wyatt and Broyles 1994). Self-incompatibility, coupled with very low levels of fruit set (1-5\%) and long periods before plants are reproductively mature ( $\sim 2$ years $)$ makes $A$. syriaca difficult and time consuming to carry out experiments designed to assess breeding systems (Wyatt and Broyles 1994). The reproductive system also makes $A$. syriaca genetically diverse, which can result in experiments with large variability and low statistical power. As such, A. syriaca is a candidate for vegetative production via tissue culture, to produce genetically identical clones, removing the high levels of genetic variation.

Multiple media options are available to initiate morphogenesis. Reddy et al. (2013) examined the effect of Murashige and Skoog media (MS) and L2 media, accompanied by various concentrations of growth regulations, on $A$. curassavica (L.) regeneration. MS media was better than L2 media for callusing, but L2 proved better for shoot multiplication and shoot length (Reddy et al. 2013). Reddy et al. (2013) also

found that nodal explants produced a greater organogenic response than shoot tips, and that basal nodal explants produced more shoots than terminal explants.

Tideman and Hawker (1982) successfully produced latex-producing plants in tissue culture, including Asclepias rotundifolia (Mill.). Using shoot apex fragments, 
callus was produced on MS media and a combination of benzyladenine (BA) and naphthalene acetic acid (NAA). Shoots were successfully produced after callus had aged 2-4 weeks. Shoots were grown and rooted with low concentrations of NAA and $1 / 2$ strength MS. Roots formed after approximately two weeks and were transferred to peat blocks and hardened off. Regeneration methods from stem explants were also successfully developed for $A$. rotundifolia. Nodal segments produced the most callus and shoots, with a combination of $10 \mathrm{uMBA}$ and $5 \mu \mathrm{M}$ NAA producing profuse callus, while $2.5 \mathrm{uM} \mathrm{BA}$ and $10 \mathrm{uM}$ BA produced shoots on both full and half strength MS media. Callus also developed from leaf explants on $10 \mathrm{uM} \mathrm{BA}+5 \mu \mathrm{M}$ NAA MS media. These methods give a starting point from which $A$. syriaca can be produced in culture. Rosu et al. (2011) developed a method to produce A. syriaca shoots using an internode segment with attached bud. All tested cytokinins stimulated the elongation of the main shoot, which then developed multiple buds that could be transferred to fresh media to make more shoots. Benzylaminopurine (BAP) and thidiazuron (TDZ) resulted in the most morphogenesis, compared to kinetin $(\mathrm{KN})$ and isopentenyl adenine (2-ip) (Rosu et al. 2011). Reddy et al. (2013) support this finding for Asclepias curassavica: BAP was shown to be better than $\mathrm{KN}$ for improving shoot number and shoot length. In contrast, Pramanik and Datta (1985) found BAP and KN were equally effective for shoot initiation.

After shoot initiation, rhizogenesis must be achieved. Rosu et al. (2011) did not develop methods for $A$. syriaca rhizogenesis; however, a small proportion of shoots did develop roots on MS media supplemented with indole-3-acetic acid (IAA) and KN. Additional testing to determine optimal formulations was suggested by Rosu et 
al. (2011). Pramanik and Datta (1986) found IAA and NAA were both successful at root induction in $A$. curassavica and that a combination of KN and NAA induced both roots and shoots after 30 days of culture. Both root and shoot initiation occurred for Wilson and Mahlberg (1977) in A. syriaca from callus; however, this organogenesis only occurred after long periods of growth (up to 1 year). Methods must still be developed to produce plantlets in a shorter period of time. A combination of previous work by Tideman and Hawker (1982), Wilson and Mahlberg (1977), Pramanki and Datta (1985), and Rosu et al. (2011) will be used to develop methods to produce $A$. syriaca in tissue culture. By developing these methods, $A$. syriaca clones can be created to quickly produce large numbers of genetically identical plants for research. 
“CONSERVING MILKWEED FOR MONARCHS: THE EFFECTS OF ELEVATED

TEMPERATURE, WATER STRESS, AND SOIL SALINITY ON

NORTHEASTERN COMMON MILKWEED (Asclepias syriaca) MORPHOLOGY"

BY

Courtney Devoid

Master of Science Candidate, Department of Plant Science and Entomology,

University of Rhode Island, Kingston, R.I. Email: cdevoid@uri.edu 


\title{
CHAPTER 3
}

CONSERVING MILKWEED FOR MONARCHS: THE EFFECTS OF ELEVATED

TEMPERATURE, WATER STRESS, AND SOIL SALINITY ON

NORTHEASTERN COMMON MILKWEED (Asclepias syriaca) MORPHOLOGY

\begin{abstract}
:
Monarch butterflies depend on the presence of common milkweed (Asclepias syriaca L.) along migration routes. Conservation efforts are working to increase monarch populations by increasing milkweed availability. This study examines the effects of temperature, water stress, and soil salinity on the growth and morphological characteristics of common milkweed; in order to understand how future environmental changes will impact conservation efforts. Milkweed was collected from population sources located along a latitudinal gradient in the northeastern United States. Plants were grown under ambient or elevated temperatures and subject to drought stress, optimum (control) water conditions, or excess precipitation stress. Plants were also subject to increasing levels of soil salinity, to determine salt tolerance levels. Elevated temperature and drought stress were found to significantly decrease growth; while excess water stress only marginally increased growth compared to control conditions. Increasing levels of soil salinity caused decreased growth rates, but milkweed was found to be moderately salt tolerant. Findings from this study suggest that common milkweed populations are expected to show a decline in growth when temperatures become elevated and during drought conditions. Differences in population locations indicate that locally adapted species will be important for conservation efforts aimed at increasing milkweed populations for monarch conservation.
\end{abstract}




\section{Introduction:}

Monarch butterflies (Danaus plexippus L.) are one of the most recognized species on earth, acting as a flagship species for global pollinator conservation. Significant population declines over the past two decades have resulted in conservation efforts being launched across the United States to save monarch butterflies from extinction (Flockhart et al. 2015). Declines are attributed to: habitat loss, increased herbicide use, decreased nectar sources, and intensified weather events. To counteract declines, conservation organizations are working to increase milkweed (Asclepias sp.) populations along monarch migration routes. Each year, monarchs undergo an annual multi-generational cross-continental migration (Shlizerman et al. 2017). To complete this long journey, monarchs depend on milkweed as an important source of nectar and for reproduction during migration. During this migration, monarchs are most vulnerable, as they must rebuild their populations by laying eggs on milkweed, the primary food source for larval insects (Davis and Howard 2005). Milkweed presence along spring migration corridors is therefore critical for the success of monarch migration.

Due to the difficulty in tracking cross-continental migrations, the exact reasons for monarch decline are currently unknown. The complex, multi-generational lifecycle of monarch butterflies means that changes at any stage can result in population fluxuations that put the species at risk for extinction (Inamine et al. 2016). A long-held theory is the milkweed limitation hypothesis, which hypothesizes that monarch decline is due to a reduction in the availability of milkweed as a host plant for monarch larvae (Pleasents and Oberhauser 2012). This theory has resulted in projects across the 
United States, centered on planting and conserving existing milkweed populations. Examples include adding milkweed hedgerows to the edges of agricultural fields, design of pollinator gardens that include native milkweed species, and milkweed friendly roadside management efforts (Borders and Lee-Mader 2014). The goal of this study is to examine how environmental changes will impact these conservation efforts. To accomplish this, controlled experiments were conducted that assess how elevated temperature, water stress, and soil salinity impact common milkweed (Asclepias syriaca L.) growth.

Global environmental change results in altered growing conditions that can modify the growth patterns of locally adapted plants. We have seen dramatic temperature increases over the past century and near-term climate models predict an increase of as much as $4.8^{\circ} \mathrm{C}$ by the end of the $21^{\text {st }}$ century (IPCC 2014). Under current Intergovernmental Panel on Climate Change (IPCC) models, precipitation events are also predicted to change; however, changes in precipitation will not be uniform. In dry regions, mean precipitation will likely decrease, while in wet regions, precipitation will likely increase (IPCC 2014). In the northeastern U.S., the geographical focus for this study, model projections for the end of the century suggest a $5-20 \%$ increase in winter precipitation (Horton et al. 2014). The frequency of heavy downpours and seasonal drought episodes are also projected to increase in the northeast. Given the current IPCC predictions, this paper will examine the interactive effects of temperature and precipitation conditions, including both drought and increased water levels.

In addition to climate change, landscape-level physical changes will cause 
additional environmental stress on milkweed conservation initiatives, and must also be considered. An important issue is soil salinity, a devastating environmental stress that can cause major reductions in plant yield and quality (Jamil et al. 2011). Soil salinity increases are attributed to roadside salt application, conversion of wetlands and forests to agricultural land, salt-buildup from irrigation, and increased temperatures caused by climate change. It is estimated that $20 \%$ of cultivated lands and $33 \%$ of irrigated agricultural lands have high salinity levels, and salinized areas are increasing at an annual rate of 10\% (Jamil et al. 2011). This is particularly important because agricultural fields are a primary habitat for common milkweed and a target for pollinator hedgerow conservation initiatives. Roadsides, another primary habitat, are also subject to increased soil salinity, as they are inundated with de-icing salt in the northern United States. High salt levels complicate roadside management efforts that are currently being implemented to increase milkweed populations. Soil salinity, taken in combination with climate change, has the potential to result in severe impediment of milkweed conservation efforts.

In order for conservation measures to be most effective, it is important that scientists are able to understand and predict the response of milkweeds to climate change throughout the United States. As previously mentioned, monarchs migrate along corridors located in both the central and eastern United States. Existing literature, focused on Midwestern common milkweed populations, found that elevated temperature and drought alter the growth and quality of common milkweed (Couture et al. 2015). We sought to expand Couture et al.'s (2015) work by focusing on milkweed populations from the northeastern United States, and comparing these 
results to Midwest populations. This work also looks at a how a range of morphological parameters will be impacted by environmental change, as only biomass had been previously examined by Couture et al. (2015). Comparing northeastern and Midwestern populations is critical because common milkweed is self-incompatible; therefore it depends on insects to transfer pollen between non-related plants. Differing responses between populations due to local adaptation have been demonstrated in common milkweed (Woods et al. 2012). By looking at environmental variables specifically targeted at northeastern common milkweed populations, this study allows conservation initiatives to be tailored to geographical areas.

Results from this study are intended help enhance efforts already underway by conservation organizations across the country. Our primary objectives are to assess how increased temperature, water stress, and soil salinity alter the growth characteristics of common milkweed, to determine how local adaptation impacts treatment responses, and to compare the results of this study to previous work completed in the Midwest.

\section{Methods:}

\section{Plant propagation:}

For the climate change study, seeds of $A$. syriaca were collected from four open-field locations, located along a latitudinal gradient in the northeastern United States. Pods were collected in fall 2015 from Georgia, Vermont $\left(44.74136^{\circ} \mathrm{N}\right.$, $\left.73.12911^{\circ} \mathrm{W}\right)$, Lewiston, Maine (44.1073 $\left.\mathrm{N},-70.21911^{\circ} \mathrm{W}\right)$, North Oxford, Massachusetts $\left(42.18906^{\circ} \mathrm{N},-71.9059^{\circ} \mathrm{W}\right)$, and North Stonington, Connecticut $\left(41.4684^{\circ} \mathrm{N},-71.94448^{\circ} \mathrm{W}\right)$. For the soil salinity study, seeds of $A$. syriaca were 
collected in fall 2015 and 2016 from four open-field locations, located at increasing distances from salt-water sources. Collections originated in Kingston, Rhode Island $\left(41.4804^{\circ} \mathrm{N}, 71.5226^{\circ} \mathrm{W}\right)$, Gloucester, Rhode Island $\left(41.9043^{\circ} \mathrm{N}, 71.6911^{\circ} \mathrm{W}\right)$, and North Stonington, Connecticut $\left(41.4409^{\circ} \mathrm{N}, 71.8812^{\circ} \mathrm{W}\right)$. The fourth population was obtained from the USDA Germplasm Resources Information Network (GRIN) from a collection originating in Pennsylvania (accession number: W6 48816). To collect enough plants for appropriate replication, seeds were obtained from closely positioned plants (possibly clones) to decrease genetic variation. Prior to germination, seeds were placed on moistened perlite and subject to cold, moist stratification for one week (Baskin and Baskin 1977). Seeds were germinated for ten days in $10 \times 15 \mathrm{~cm}$ trays using a greenhouse MetroMix potting medium \#830 (SunGrow, Agawam, Massachusetts). Seedlings were transferred to $10 \mathrm{~cm}$ pots, grown for 30 days, and fertilized twice-weekly using Peter's 20-10-20 Peatlite special fertilizer (JR Peters Inc, Allentown, Pennsylvania), which contained 230 PPM nitrogen. After the initial growth period, plants were transferred to $15 \mathrm{~cm}$ pots and initial morphological measurements were taken. Fertilizing was decreased to once weekly during the treatment period, which ensured that the drought stress condition was not overwatered.

\section{Experimental design:}

\section{Climate Change Study}

The climate change study was conducted using two identical Plant Growth Chambers (Conviron, model: CMP6050; Manitoba, Canada). A standardized, average temperature of $25: 18^{\circ} \mathrm{C}$ day/night was selected as the ambient control temperature. Due to logistical the constraints of using growth chambers, it was not possible to grow 
each population at its average summer temperatures. The $25: 18^{\circ} \mathrm{C}$ day/night temperature combination was selected based on average summer temperatures in the mid-range of the latitudinal gradient (Boston, Massachusetts from 1981-2010) and because it matched the ambient temperature used by Couture et al. (2015). To simulate increased temperatures, plants were subject to $30: 23{ }^{\circ} \mathrm{C}$ day/night as the elevated temperature treatment condition, corresponding both to Couture et al. (2015) and the mean annual increase predicted in the IPCC RCP8.5 scenario (IPCC 2014). Three water treatments were tested to simulate changes in precipitation patterns predicted for the northeast: control, drought, and elevated water levels. Water levels were monitored daily using a soil moisture meter (Delta-T Devices, model: SM150; Cambridge, United Kingdom) and plants were watered with 400 milliliters of water when moisture reached $10 \%(\mathrm{~g} / \mathrm{g})$ moisture for drought, $20 \%(\mathrm{~g} / \mathrm{g})$ for control, and $30 \%(\mathrm{~g} / \mathrm{g})$ for excess water. The timing of watering varied between treatments and chambers. Given that water flowing through the soil and into the tray underneath was likely, a block design was implemented, where water treatments were grouped into blocks. Each chamber was separated into nine blocks, with three blocks of water treatments per chamber, and six plants per block.

All plants were initially grown for four weeks at the ambient temperature; then 46 plants per population were selected for homogeneity. Of the selected plants, 10 were weighed and dried to obtain mean initial biomass measurements and 36 were randomly assigned to one of six possible treatment combinations: elevated temperature, control water; elevated temperature, drought stress; elevated temperature, excess water stress; ambient temperature, control water; ambient temperature, drought 
stress; ambient temperature, excess water stress $(n=$ six plants/population/treatment $)$.

Plants were grown under assigned treatment conditions for eight weeks. Initial measurements were taken at the start of the experiment that included: height, stem diameter, total number of leaves, number of nodes, number of nodes with leaves, and largest leaf area. Weekly measurements of height, number of nodes, and nodes with leaves were also recorded. At the conclusion of the experiment, the same initial measurements were taken and plants were harvested to determine the weight of the stems, leaves, and roots. Each plant was bagged and dried at $50{ }^{\circ} \mathrm{C}$ for two weeks to calculate dry weights of stems, leaves, and roots. Total plant growth was determined by calculating the final dry biomass minus the initial dry biomass. Leaf area was found by multiplying length $\mathrm{x}$ width measurements from the largest leaf on each plant (Smith and Kliewer 1984).

\section{Salinity Study}

In 1985, the Food and Agriculture Organization (FAO) published extensive lists of salt tolerance data, which was used to classify crop tolerance to soil salinity levels (Tanji et al. 2002). Salt tolerance has been classified into four categories (sensitive, moderately sensitive, moderately tolerant, and tolerant), which correspond to electrical conductivity values (EC dS/m). For this study, values that correspond to sensitive, moderate (between moderately sensitive and moderately tolerant), and tolerant to salinity were chosen, with $80 \%$ plant survivability at these levels. The electrical conductivity values were converted into parts per million (ppm) and salt water solutions were made that contained 0, 2000, 6000, 12000 ppm sodium chloride ( $\mathrm{NaCl}$; Fischer scientific, catalog number: BP358-1; Hampton, NH). After plants were 
grown for the initial four-week growth period, they were randomly assigned a salinity treatment condition and 200 milliliters of the appropriate solution was added to the soil weekly. For the first two weeks, salt water was diluted to avoid shocking the plants, at $1 / 4$ strength in the first week, $1 / 2$ strength in the second week, and full strength for the remaining eight weeks of the experiment. The data collection methodology was identical to those described in the previous experiment. At the conclusion of the experiment, electrical conductivity was measured using an electrical conductivity meter (Vetus Industrial Co., model: CD-4303; Anhui, China) to verify soil salinity levels.

Statistical Analysis:

For the climate change study, a three-way ANOVA was used to determine the effects of temperature, water treatment, and population location on morphological growth characteristics. With the soil salinity study, a two-way ANOVA was used to determine the effects of soil salinity and population location. Response variables were analyzed as delta values (final - initial) and included: change in height, diameter, number of leaves, number of nodes, leaf to node ratio, leaf area, biomass, and wet to dry biomass ratio. Height, number of nodes, number of leaves, and leaf to node ratio were measured weekly to determine the role of time on the divergence of treatment effects. For both experiments, time was added as an additional factor to analyze these four variables, therefore a four-way ANOVA was used for the climate change study and a three-way ANOVA was used for the soil salinity study. 


\section{Results:}

There were significant effects of water treatment, temperature, and soil salinity on plant growth characteristics. In general, plants exposed to drought conditions were smaller than both control and excess water treatments. Plants at elevated temperatures were found to have more nodes and leaves, but less leaf area, root biomass, and a smaller wet:dry biomass ratio. Interactive effects were not observed consistently across all trials. For the soil salinity experiment, increasing soil salinity showed a decrease in plant growth. No significant interaction between population and soil salinity was observed for total change measurements, but when time was a factor, nodes and leaves did show a significant interaction.

\section{Climate Change Study: total change}

Temperature and water treatment had variable effects across trials (Figure 1). The effect of water treatment was generally consistent across trials for measured variables, with drought conditions resulting in less growth than excess and control treatments, and excess water resulting in more growth than control. The effect of temperature was not consistent across variables.

Total change measurements had varying responses to water treatments (Table 1). Looking at the total change in plant height and stem diameter, plants experiencing drought conditions were smaller than both control and excess water treatments (Figure 1a). Plants receiving excess water were also larger than control. The number of nodes was consistently less in drought treatments compared to control (Figure 1d). We see the same trend for total number of leaves on each plant and for leaf area: plants in drought conditions had less leaves than control and plants in excess water conditions 
had more leaves than drought (Figure 1c,e). Looking at the leaf:node ratio, we see no effect of water treatment (Figure 1f).

Change in plant biomass again showed similar trends as described above (Table 2). Plant biomass (stem + root) and total plant biomass (final - initial) was consistently smaller for drought treatments compared to both control and excess water, while excess water was found to be larger than control. These trends were consistent for both stem and root biomass when analyzed separately. Wet:dry biomass ratios were examined for total plant biomass, and stem and roots individually. No consistent trends of the effects of water treatment were observed across all wet:dry ratios.

The effect of temperature was not consistent across response variables (Table 3; Figure 1). For height, plants experiencing elevated temperature grew larger than ambient temperature in trial two $(\mathrm{p}<0.001)$ and three $(\mathrm{p}<0.05)$; however, plants were significantly smaller in trial $1(\mathrm{p}<0.10)$. Stem diameter was smaller for elevated temperature conditions. Across all three trials, plants in elevated temperature environments had more nodes. No consistent effect of temperature was observed for the number of leaves a plant produced or leaf:node ratio. Temperature did have a significant effect on leaf area for all trials; plants at elevated temperatures had significantly smaller leaves.

The effect of temperature was not consistent for total biomass and stem biomass; however, root biomass was found to be smaller for the elevated temperature conditions (Table 3). Looking at final - initial, both roots and total (stems + roots) were smaller when exposed to an elevated temperature. The ratios of total and stem 
wet:dry biomass were consistently smaller at the elevated temperature compared to ambient. No temperature effect was observed for the wet:dry biomass ratio of roots.

\section{Climate Change Study: change over time}

Height, node count, number of leaves, and leaf:node ratio were all measured over time (Table 4; Figure 2). Between drought treatments, we found drought stressed plants grew at a slower rate than both control and excess water plants for height, nodes, and leaf measurements. Excess water plants were significantly larger than control for the aforementioned measurements. The only significant difference for leaf:node ratio was between excess and drought plants. In all cases, drought stress significantly decreased the rate of growth and visibly diverges from the other two treatments (Figure 3). Within water treatments and between temperatures, we found the same result, where plants at the ambient temperature had a higher growth rate over time.

There was not a consistent effect of temperature across all three trials for plant height or leaf:node ratio (Table 5; Figure 3). Nodes and number of leaves were found to be greater for plants experiencing elevated temperature conditions, in trials 1 and 2.

Interactions between variables were observed in several instances when time was added as a factor. All interactions were evaluated to ensure that they did not interfere with the main effect (Appendix A). Several interesting interactions did emerge. We found that for height, when population and temperature were observed together (i.e. plants from Vermont subject to $30^{\circ} \mathrm{C}$ compared to those from Vermont at $25^{\circ} \mathrm{C}$ ), plants at $30^{\circ} \mathrm{C}$ were found to be larger than those at $25^{\circ} \mathrm{C}$ for plants originating 
in Vermont, Maine, and Connecticut. This result is important because we did not find that temperature had an effect for height when populations were pooled.

\section{Population level differences:}

Several population level differences were observed. Plants from Vermont and Massachusetts were consistently smaller than Maine and Connecticut in pairwise comparisons. Plants from Vermont were also consistently smaller than those from Massachusetts. The trends described above did not vary substantially based on population; however, populations did exhibit localized differences.

\section{Soil salinity study: total change}

Soil salinity had a significant effect across all variables measured (Table 6). For height, biomass, diameter, and number of leaves, we found that as salt level increased, growth measurements decreased (Figure 4). Wet:dry biomass ratio also increased with salt level, indicating that plants add less physical biomass when levels of salinity are high. With leaf area, we see the same trend, except at $2000 \mathrm{ppm}$ salt water, where leaf area is higher for $2000 \mathrm{ppm}$ than control (0 ppm salt); however, post-hoc analysis shows that this difference is not significant (Figure 4c).

\section{Soil salinity study: change over time}

Looking at change over time, a clear divergence can be seen between salt treatments (Table 7; Figure 5). All plants start at similar values, but growth decelerates over time based on treatment. Plants at the highest salt level (12000 ppm) have significantly lower growth rates than the other three treatments. Importantly, there is no significant difference between the control ( 0 ppm), moderately sensitive (2000 ppm) and moderately tolerant (6000 ppm) salt levels for any measured variables. This 
lack of significance demonstrates moderate tolerance to soil salinity levels in common milkweed.

\section{Differing response to salt treatment by population:}

Gloucester, RI was significantly smaller than the other three populations for total change in height and diameter. Looking at the results over time, we find that this size difference holds for all variables. Importantly, this result is consistent across salinity treatments; therefore local adaptation of this population to soil salinity is not demonstrated.

\section{Discussion:}

This study examined how temperature, water stress, and soil salinity alter the morphological growth characteristics of $A$. syriaca. By determining how environmental stress conditions affect $A$. syriaca, conservation initiatives will be able to use this information to make informed decisions about pollinator protection projects. Our study demonstrates that both temperature and water treatments effect milkweed growth; however, the response varied across measurements. In general, plants were smaller under drought stress than excess water and control conditions, and increased temperature resulted in decreased plant growth. These results indicate that we can expect milkweed plants to be smaller as temperatures rise and during periods of drought. Where flooding and increased precipitation are predicted, we can expect plants to be larger than those in drought prone environments.

Water Stress:

Drought stress can result in different morphological responses, depending on the plant organ examined (French and Turner 1991). As prolonged low soil-water 
availability occurs, cell division and elongation are impeded, and therefore plants are smaller (Medeiros et al. 2012). This trend was observed in our plants, where height and diameter were smaller in drought conditions, which is consistent with the literature (Nezami et al. 2008, Medeiros et al. 2012, Aslam et al. 2015). Low soil moisture levels resulted in smaller plants that had less growth over time. Because repeated measurements were made over the course of the experiment, we can clearly see a divergence of the treatment effects for plants under drought stress. All plants started at the same height and with the same number of nodes and leaves, but after two weeks, we see a clear separation between drought and control or excess water stress. This same trend was observed in the literature for soybean (Glycine max), which showed significant signs of drought stress after 12 days for plant height and leaves per plant (Mak et al. 2014).

The finding that $A$. syriaca growth decreases significantly under drought stress is particularly interesting, as this plant is well-known and marketed for its drought tolerance (Borders and Lee-Mader 2014). An important caveat is that milkweed species are drought tolerant once they have become established and they often require high soil moisture during the first year of growth (Borders and Lee-Mader 2014). Wild milkweed plants have deep root systems that support the plant under drought conditions (Phippen 2007). Tap roots commonly grow $2 \mathrm{~m}$ deep within the first two years, laying down minimal root structures in the first $15 \mathrm{~cm}$ of soil (Phippen 2007). Our experiments were carried out in growth chambers with $15 \mathrm{~cm}$ pots over 12 weeks, which means that plants did not have the opportunity to develop deep taproot systems. Such conditions likely made the effects of drought more severe in our study. Despite 
this limitation, plants were likely still exhibiting drought tolerance, given the high survival rate. This result suggests that climate change induced periods of drought will have minimal impact on established milkweed plants. Our experiments found smaller first year seedlings during drought stress, but these results do not indicate that the population itself will be in jeopardy due to precipitation decreases, especially in wellestablished populations. Further research should be conducted to measure the effect of drought stress in less confined growing conditions and over a longer period of time.

Excess precipitation either resulted in larger plants or no significant difference from control conditions. It was expected that excess water would decrease plant growth characteristics, due to depleted soil-dissolved oxygen levels. Saturated soils can result in reduced respiration, decreased total root volume, less transport of water and nutrients, and a buildup of toxic compounds (Lauer 2014). No significant difference was found between root volumes for excess versus control plants; however, root rot was observed when roots were cleaned at the conclusion of the experiment. Adaptation to high water levels is one explanation; Wenkert et al., (1981) found shortterm reductions in corn root and leaf growth immediately following waterlogged conditions, but plants recovered quickly (within 2-3 days). Given that, for this experiment, plants experienced excess water conditions for the entire course of the experiment, our plants likely adapted after the initial high water levels. It is also probable that divergent treatment effects between excess and control would have been observed if moisture levels were higher. A trade-off had to be made between an amount of moisture that would provide excess water stress and water levels where the plants would experience massive die-off. In future iterations of this experiment, a 
water level gradient should be implemented, where a range of moisture conditions are tested. Implementing a spectrum of moisture conditions would allow for the lower and upper bounds of water tolerance to be examined.

The effects of excess water would also likely be observed in less controlled growing conditions. An important effect of excess moisture is plant susceptibility to fungi, pathogens, and insects (Rosenzweig et al. 2001). Increased moisture conditions result in environments where certain diseases and pests can thrive and plants growing in stressed conditions therefore become more susceptible in infestation (Rosenzweig et al. 2001). Given that this was a controlled experiment, plants were intentionally kept isolated from any contact with insects and pathogens, in an attempt to decrease variability. Plants were also treated bi-monthly with insecticides to prevent any insect infection. The controlled growth environment likely prevented any consequences of increased susceptibility. Further research is needed to determine whether plants experiencing excess moisture conditions are likely to show decreased growth due to increased susceptibility to infection.

\section{Temperature}

Varying responses of plant growth to elevated temperature have been reported. Several studies have found that elevated temperature results in an increase in plant growth (Nybakken et al. 2012, Lavola et al. 2013, Couture et al. 2015). Couture et al. (2015) found that elevated temperature "marginally" increased plant growth $(\mathrm{p}=0.07)$ in common milkweed. It is important to note that with the exception of Couture et al. (2015), most studies concluding that elevated temperature increased growth are focused on woody species. Primary research on the effects of elevated temperature on 
agricultural crops found no difference in total plant biomass under increased temperature regimens (Hatfield and Prueger 2015). In later work, Hatfield (2016) found rising temperatures to significantly reduce agricultural crop yields (Asseng et al. 2015, Tack et al. 2015). This research is primarily focused on extrapolation of crop models combined with future climate scenarios (Hatfield 2016). Primary research has found plant height, number of tillers, and total biomass were reduced in response to elevated temperature in rice cultivars (Mitra and Bhatia, 2008). The results of our study did not demonstrate a clear trend across variables in response to temperature. We found that the number of nodes and stem biomass increased with temperature, while leaf area and root biomass decreased, and all other variables did not show a significant trend.

Given that the results of this study differ from the findings of Couture et al., (2015) it is important to look further at possible causes of this difference. Local adaptation is a critical factor to consider when comparing these results. Couture et al. (2015) demonstrate high levels of local adaptation, which indicates that the responses to climatic variables can be different based on population origin. Multiple studies have reported geographic and population level variation in A. syriaca (Agrawal 2005, Woods et al. 2012, Wason et al. 2013) The goal of this study was to compare the responses to climatic variables in common milkweed originating in the northeast to plants from the Midwest. We found that northeastern plants had a mixed response to an increase in temperature, while Midwest plants had a marginally positive response.

When looking at the post hoc analysis, there were several population level differences in treatment effects by population for temperature and water treatments. 
We observed that northern and southern populations had different growth rates in response to treatments. This indicates that variation in response to climate exists in milkweed, based on local adaptation to longitudinal positions. Such a finding is critical for conservation efforts aimed at creating local pollinator projects, as it demonstrates the importance of locally sourced seeds. Projects like monarch waystations, which provide habitat along migration routes, are already using sourceidentified and locally adapted seeds and nursery stock to account for local adaptation (Landis 2014).

Changes in plant leaf characteristics were particularly informative in regards to the effects of both temperature and water stress. Leaf area and total number of leaves have been shown to be important indicators of plant stress (Milthorpe 1959, Potrer and Jones 1977 , Dennett et al. 1978). We found that plants at $30^{\circ} \mathrm{C}$ had significantly less leaf area than leaves at $25^{\circ} \mathrm{C}$. Milthorpe (1959) reported the same result for cucumber leaves, where the relative rate of leaf expansion increased with temperature up to $24^{\circ} \mathrm{C}$, but leaf expansion as lower at $30^{\circ} \mathrm{C}$. In this study, despite having smaller leaves, plants at $30^{\circ} \mathrm{C}$ had a significantly larger quantity of leaves in trial 1 , demonstrating that plants were growing smaller leaves, but keeping those leaves longer. This result is interesting, as morphological symptoms of heat stress usually include leaf senescence and abscission (Hasanuzzaman et al. 2013). As a possible explanation, we observed that plants exposed to the hotter temperature were holding onto wilted leaves, as opposed to continuously dropping and re-growing new leaves, which was observed in non-heat stressed control plants. It is important to note that this trend was only 
observed for the total change in leaf number (final leaf count - initial count), and not over time.

Interactive effects:

It has been demonstrated that temperature effects are increased by water deficits and excess soil water, which shows the importance in understanding the interactions of temperature and water stress (Hatfield 2015). No significant interaction was found between temperature and water stress for variables looking at the total change in growth. This result is consistent with those found for Midwestern milkweed populations (Couture et al. 2015). However, when looking at temperature and water stress over time, this experiment showed several significant interactions. Plants experiencing drought and control conditions were significantly smaller at a higher temperature. We also found that time played an important role in the divergence of treatment effects. The effects of temperature must therefore be examined parallel to the effects of moisture stress and across time, which is likely another reason that our temperature results differ from Couture et al. (2015).

\section{Soil Salinity:}

Since the use of de-icing salts became common, high soil salinity has become an important selecting agent for roadside plant species (Beaton and Dudley, 2004). Roadside salt concentrations are often highest in the spring, when seeds are germinating and seedlings are establishing (Thompson et al. 1986). Such conditions can jeopardize conservation projects focused on roadside management, such as the Roadsides Program in Minnesota, which is using native prairie plants for roadside revegetation (Borders and Lee-Mader 2014). Nurseries often advertise the Asclepias 
genus as salt tolerant; however, little primary research is available to back these claims. This study has concluded that milkweed has moderate salt tolerance; with plant growth decreasing as salt level increases above moderate levels. No significant difference was found between sensitive, moderately sensitive, and moderately tolerant soil salinity levels.

Salt stressed plants had less overall growth than non-stressed plants for the highest level of salt water. This result is consistent with the literature, where salt treatment has been shown to decrease root length in germinating seeds of $A$. syriaca (Beaton and Dudley 2004). Decreased growth rates, as a result of salt stress, have also been demonstrated in many other species (Renault et al. 2016). Mild osmotic stress has been shown to quickly inhibit the growth of leaves and stems (Bartels and Sunkar 2005). Bartels and Sunkar (2005) report that the timescale of response is associated with the degree of growth inhibition due to osmotic stress. Over time, we observed a clear compounding effect between salt concentrations. Plants all started at the same point when the experiment commenced, which can be seen in weeks 1-3, where there is no difference between treatments (Figure 5). As exposure continued, we see that plants exposed to higher salt levels have a severe decrease in growth rate. Looking at leaf count, we actually see a negative growth rate starting at time point 6 (Figure 6b). This shows that plants were losing leaves as a result of high levels of salt, which has implications for overall plant productivity and photosynthetic capacity.

In addition to measured variables, important physiological stress responses to high salt levels were observed. Salt stress resulted in decreased leaf expansion, as well as a decreased number of leaves. Reduction in relative growth rate and leaf area, as a 
response to salinity, have been demonstrated in multiple species (Cramer et al. 1994, Abdul Qados 2011). Furthermore, salinity induced epinasty was also observed in this study for plants subject to the highest salt levels. Epinasty occurs when cells elongate on the upper surface of a plant organ, causing the leaf to bend downward and curl. Stress imposed by environmental factors can increase the production of ethylene, which results in epinastic growth of leaf petioles (Jones and El-Beltagy, 1989; Yang and Hoffman, 1984). Salt-induced epinastic growth of petioles has also occurred in tomatoes under moderately high levels of salt stress (Jones and El-Beltagy, 1989). Just like number of leaves, such physiological changes in leaf characteristics have important implications for overall plant growth, as salt stressed plants can experience decreased photosynthetic activity due to decreased leaf health.

Local adaptation between populations was not observed in this study. This result is consistent with Beaton and Dudley (2004), who concluded that seed germination for roadside populations were not more adapted to high salt levels than old-field populations. Given the strong level of local adaption that has been demonstrated with temperature (see above discussion), this result is surprising. We predicted that plants would exhibit population level differences, based on local adaptation at each collection site (Woods et al. 2012). A. syriaca's life history likely contributes to this finding, as it is a long-lived perennial that often reproduces by adventitious root buds (Bhowmik 1994). This trait can result in a majority of roadside plants being part of long-lived clones, which buffer the species against environmental variation and limit adaptation in a short-time scale (Beaton and Dudley 2004). Lack of local adaptation could limit the future abundance of this species along the roadside, if 
other species gain an ability to outcompete in high salt environments (Beaton and Dudley 2004). Long-lived asexually reproducing species may be excluded from roadsides by rapidly evolving exotics, unless roadside management efforts are taken. However, we have shown that $A$. syriaca does exhibit moderate salt tolerance, and it's fast growing weedy nature will likely boost it's competitive ability. Regardless, roadside management projects that support native species plantings will be critical to the success of $A$. syriaca along roadsides.

\section{Conservation Implications:}

The findings from this study indicate that elevated temperature and water stress will alter the growth of common milkweed. Drought and elevated temperature will decrease the size of milkweed plants; however, the populations are not likely in danger of eradication. These conclusions demonstrate that milkweed projects will likely be successful with any climate changes, especially if large colonies of plants are able to establish. Such findings are extremely positive, as they show that research and efforts being made to increase monarch butterfly habitat will not be hindered by future environmental changes, as predicted by the IPCC models. Our second experiment showed that milkweed was moderately sensitive to soil salinity levels. These conclusions are also important for conservation efforts, where investments are being made to create monarch habitat along roadsides and in agricultural fields. Increased soil salinity levels may decrease the growth and quality of milkweed populations, especially when combined with climate change variables. Again, despite the decreased growth, a tolerance to soil salinity indicates that plants may be smaller, but they will continue to persist at moderate salinity levels and be available for monarchs. 
Conservation efforts should take soil salinity into account when creating milkweed rich habitat, but our overall results present a positive picture for monarch conservation success. 


\section{Literature Cited:}

Abdul Qados, A. M. S. 2011. Effect of salt stress on plant growth and metabolism of bean plant Vicia faba (L.). Journal of the Saudi Society of Agricultural Sciences $10: 7-15$.

Agrawal, A. 2005. Natural selection on common milkweed. Evolutionary Ecology Research 7:651-667.

Aslam, M., M. Maqpool, and R. Cengiz. 2015. Drought stress in maize (Zea Mays L.): effects, resistance mechanisms, global achievements, and biological strategies. Springer Briefs in Agriculture 8:5-18.

Asseng, S., F. Ewert, P. Martre, R. P. Rotter, D. B. Lobell, D. Cammarano, B. A. Kimball, M. J. Ottman, G. W. Wall, J. W. White, M. P. Reynolds, P. D. Alderman, P. V. V Prasad, P. K. Aggarwal, J. Anothai, B. Basso, C. Biernath, A. J. Challinor, G. De Sanctis, J. Doltra, E. Fereres, M. Garcia-Vile, S. Gayler, G. Hoogenboom, L. A. Hunt, R. C. Izaurralde, M. Jabloun, C. D. Jones, K. C. Kersebaum, A. K. Koehler, C. Muller, S. N. Kumar, C. Nendel, G. O’Leary, J. E. Olesen, T. Palosuo, E. Priesack, E. E. Rezaei, A. C. Ruane, M. A. Semenov, I. Shcherbak, C. Stockle, P. Stratonovitch, T. Streck, I. Supit, F. Tao, P. J. Thorburn, K. Waha, E. Wang, D. Wallach, I. Wolf, Z. Zhao, and Y. Zhu. 2015. Rising temperatures reduce global wheat production. Nature Climate Change $5: 143-147$.

Bartels, D., and R. Sunkar. 2005. Drought and salt tolerance in plants. Critical Reviews in Plant Sciences 24:23-58.

Baskin, J. M., and C. C. Baskin. 1977. Germination of common milkweed (Asclepias 
syriaca L.) seeds. Bulletin of the Torrey Botanical Club 104:167-170.

Beaton, L., and S. Dudley. 2004. Tolerance to salinity and manganese in three common roadside species. International Journal of Plant Science 165:37-51.

Bhowmik, P. C. 1994. Biology and control of common milkweed (Asclepias syriaca). Review in Weed Science 6:227-250.

Borders, B., and E. Lee-Mader. 2014. Milkweeds: A conservation practitioner's guide.

Couture, J. J., S. P. Serbin, and P. A. Townsend. 2015. Elevated temperature and periodic water stress alter growth and quality of common milkweed (Asclepias syriaca) and monarch (Danaus plexippus) larval performance. Arthropod-Plant Interactions 9:149-161.

Cramer, G., G. Alberico, and C. Schmidt. 1994. Leaf expansion limits dry matter accumulation of salt-stressed maize. Functional Plant Biology 21:663-674.

Davis, A. K., and E. Howard. 2005. Spring recolonization rate of monarch butterflies in eastern North America: new estimates from citizen-science data. Journal of the Lepidopterists' Society 59:1-5.

Dennett, M. D., J. Elston, and J. R. Milford. 1978. The effect of temperature changes on the expansion of individual leaves of Vicia faba L. Annals of Botany 42:877888.

Flockhart, D. T. T., J.-B. Pichancourt, D. R. Norris, and T. G. Martin. 2015. Unravelling the annual cycle in a migratory animal: breeding-season habitat loss drives population declines of monarch butterflies. Journal of Animal Ecology $84: 155-165$.

French, R. J., and N. C. Turner. 1991. Water deficits change dry matter partitioning 
and seed yield in narrow-leafed lupins (Lupinus angustifolius L.). Australian Journal of Agricultural Research 42:471-484.

Hasanuzzaman, M., K. Nahar, M. M. Alam, R. Roychowdhury, and M. Fujita. 2013. Physiological, biochemical, and molecular mechanisms of heat stress tolerance in plants. International Journal of Molecular Sciences 14:9643-9684.

Hatfield, J. L. 2016. Increased temperatures have dramatic effects on growth and grain yield of three maize hybrids. Agricultural \& Environmental Letters 1:150006.

Hatfield, J. L., and J. H. Prueger. 2015. Temperature extremes: Effect on plant growth and development. Weather and Climate Extremes 10:4-10.

Horton, R., G. Yohe, W. Easterling, R. Kates, M. Ruth, E. Sussman, A. Whelchel, D. Wolfe, and F. Lipschultz. 2014. Ch. 16: Northeast. Pages 371-395in J. M. Melillo and T. C. Richmond, editors.Climate Change Impacts in the United States: The Third National Climate Assessment.

Inamine, H., S. P. Ellner, J. P. Springer, and A. A. Agrawal. 2016. Linking the continental migratory cycle of the monarch butterfly to understand its population decline. Oikos 125:1081-1091.

IPCC. 2014. Climate Change 2014: Synthesis Report. Contribution of Working Groups I, II and III to the Fifth Assessment Report of the Intergovernmental Panel on Climate Change. Page (R. K. P. and L. A. Meyer, Ed.). Geneva, Switzerland.

Jamil, A., S. Riaz, M. Ashraf, and M. R. Foolad. 2011. Gene expression profiling of plants under salt stress. Critical Reviews in Plant Sciences 30:435-458.

Jones, R. A., and A. S. El-Beltagy. 1989. Epinasty promoted by salinity or ethylene is 
an indicator of salt sensitivity in tomatoes. Plant, Cell \& Environment 12:813817.

Landis, T. 2014. Monarch waystations: propagating native plants to create travel corridors for migrating monarch butterflies. Native Plants Journal 15:5-16.

Lauer, J. 2014. Flooding effects on corn. University of Wisconsin Crop Manager $21: 42-47$.

Lavola, A., L. Nybakken, M. Rousi, J. Pusenius, M. Petrelius, S. Kellomäki, and R. Julkunen-Tiitto. 2013. Combination treatment of elevated UVB radiation, CO 2 and temperature has little effect on silver birch (Betula pendula) growth and phytochemistry. Physiologia Plantarum 149:499-514.

Mak, M., M. Babla, S. C. Xu, A. O’Carrigan, X. H. Liu, Y. M. Gong, P. Holford, and Z. H. Chen. 2014. Leaf mesophyll $\mathrm{K}+, \mathrm{H}+$ and $\mathrm{Ca} 2+$ fluxes are involved in drought-induced decrease in photosynthesis and stomatal closure in soybean. Environmental and Experimental Botany 98:1-12.

Medeiros, D. B., E. Ciriaco, H. Rafael, B. Santos, C. M. Pacheco, S. Musser, R. Jurema, and M. Custódio. 2012. Physiological and biochemical responses to drought stress in Barbados cherry. Brazilian Society of Plant Physiology 24:181192.

Milthorpe, F. L. 1959. Studies on the expansion of the leaf surface: I. The influence of temperature. Journal of Experimental Botany 10:233-249.

Mitra, R., and C.R. Bhatia. 2008. Bioenergetic cost of heat tolerance in wheat crop. Current Science 94:1049-1053.

Nezami, A., H. R. Khazaei, Z. B. Rezazadeh, and A. Hosseini. 2008. Effects of 
drought stress and defoliation on sunflower (Helianthus annuиs) in controlled conditions. Desert 12:99-104.

Nybakken, L., R. Hörkkä, and R. Julkunen-Tiitto. 2012. Combined enhancements of temperature and UVB influence growth and phenolics in clones of the sexually dimorphic Salix myrsinifolia. Physiologia Plantarum 145:551-564.

Phippen, W. B. 2007. Production variables affecting follicle and biomass development in common milkweed. Pages 82-88in J. Janick and A. Whipkey, editors.Issues in new crops and new uses. ASHS Press, Alexandria, VA.

Pleasents, J. M., and K. S. Oberhauser. 2012. Milkweed loss in agricultural fields because of herbicide use: effect on the monarch butterfly population. Insect Conservation and Diversity 6:135-144.

Potrer, J. R., and J. W. Jones. 1977. Leaf area partitioning as an important factor in growth. Plant Physiology 59:10-14.

Renault, S., S. Wolfe, J. Markham, and G. Avila-Sakar. 2016. Increased resistance to a generalist herbivore in a salinity-stressed non-halophytic plant. AoB Plants 8:110.

Rosenzweig, C., A. Iglesius, P. R. Epstein, and E. Chivian. 2001. Climate change and extreme weather events - Implications for food production, plant diseases, and pests. Global Change \& Human Health 2:90-104.

Shlizerman, E., J. Phillips-Portillo, D. B. Forger, and S. M. Reppert. 2017. Neural integration underlying a time-compensated sun compass in the migratory monarch butterfly. Cell Reports 15:683-691.

Smith, R. J., and W. M. Kliewer. 1984. Estimation of Thompson seedless grapevine 
leaf area. American Journal of Enology and Viticulture 35:16-22.

Tack, J., A. Barkley, and L. L. Nalley. 2015. Effect of warming temperatures on US wheat yields. Proceedings of the National Academy of Sciences of the United States of America 112:6931-6.

Wason, E. L., A. A. Agrawal, and M. D. Hunter. 2013. A genetically-based latitudinal cline in the emission of herbivore-induced plant volatile organic compounds. Journal of Chemical Ecology 39:1101-1111.

Wenkert, W., N. R. Fausey, and H. D. Watters. 1981. Flooding responses in Zea mays L. Plant and Soil 62:351-366.

Woods, E. C., A. P. Hastings, N. E. Turley, S. B. Heard, and A. A. Agrawal. 2012. Adaptive geographical clines in the growth and defense of a native plant. Ecological Monographs 82:149-168.

Yang, S. F., and N. E. Hoffman. 1984. Ethylene biosynthesis and its regulation in higher plants. Annual Review of Plant Physiology 35:155-189. 
Table 1: Pairwise comparisons between water treatments and total change in response variables for height $(\mathrm{cm})$, diameter $(\mathrm{mm})$, nodes, leaves, leaf:node ratio, and leaf area (cm). Comparisons are made between drought $(10 \%$ soil moisture $(\mathrm{g} / \mathrm{g}))$, control $(20 \%$ soil moisture $(\mathrm{g} / \mathrm{g}))$, and excess $(30 \%$ soil moisture $(\mathrm{g} / \mathrm{g}))$ conditions. The difference is shown between each pair, negative values indicate the first mean is smaller than the second and positive values indicate the opposite trend. Data was analyzed by individual trials but pooled below; full ANOVA tables for each trial can be found in Appendix A. Significance codes: $\mathrm{p} \leq 0.001^{\text {' } * * * ', ~} \mathrm{p} \leq 0.01^{\prime} * *$ ' $, \mathrm{p} \leq 0.05^{\text {'*', }}, \mathrm{p} \leq 0.10$

\begin{tabular}{lllllll}
\hline & Height & Diameter & Nodes & Leaves & Ratio & Leaf Area \\
\hline $\begin{array}{l}\text { Drought- } \\
\text { Control } \\
\text { Excess- }\end{array}$ & $-6.626 * * *$ & $-0.413 * * *$ & $-1.943 * * *$ & $-1.944 *$ & -0.030 & -7.531 \\
$\begin{array}{l}\text { Control } \\
\text { Excess - }\end{array}$ & 2.672 & 0.186 & 0.403 & -0.308 & -0.019 & $12.408 * * *$ \\
Drought & $9.299 * * *$ & $0.599 * * *$ & $2.346 * * *$ & 1.636 & 0.011 & $19.939 * * *$ \\
\hline
\end{tabular}

Table 2: Pairwise comparisons between water treatments and total change in response variables for plant biomass (lbs) and wet:dry biomass ratio. Significance codes: $\mathrm{p} \leq$

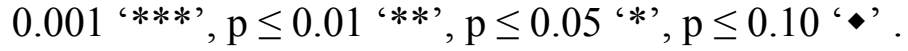

\begin{tabular}{lllllll}
\hline & $\begin{array}{l}\text { Stem } \\
\text { Biomass }\end{array}$ & $\begin{array}{l}\text { Root } \\
\text { Biomass }\end{array}$ & $\begin{array}{l}\text { Total } \\
\text { Biomass }\end{array}$ & $\begin{array}{l}\text { Wet:dry } \\
\text { Stem }\end{array}$ & $\begin{array}{l}\text { Wet:dry } \\
\text { Roots }\end{array}$ & $\begin{array}{l}\text { Wet:dry } \\
\text { Total }\end{array}$ \\
\hline $\begin{array}{l}\text { Drought- } \\
\text { Control } \\
\text { Excess- }\end{array}$ & $-1.374 * * *$ & $-0.826 .$. & $-2.201 * * *$ & 0.192 & 0.058 & 0.015 \\
$\begin{array}{l}\text { Control } \\
\text { Excess - }\end{array}$ & $0.910 *$ & 0.584 & $1.495 *$ & -0.041 & 0.233 & 0.127 \\
Drought & $2.284 * * *$ & $1.411 * * *$ & $3.696 * * *$ & -0.233 & 0.175 & 0.111 \\
\hline
\end{tabular}

Table 3: Differences between $30^{\circ} \mathrm{C}$ and $25^{\circ} \mathrm{C}$ treatments for total change in response variables by trial. Negative values indicate plants at $30^{\circ} \mathrm{C}$ were smaller than $25^{\circ} \mathrm{C}$, and positive values depict the opposite trend. Significance codes: $\mathrm{p} \leq 0.001^{\text {' }} * * *$ ', $\mathrm{p} \leq 0.01$

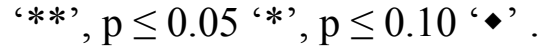

\begin{tabular}{llll}
\hline & \multicolumn{1}{c}{ Trial 1 } & \multicolumn{1}{c}{ Trial 2 } & \multicolumn{1}{c}{ Trial 3 } \\
\hline Height & $-3.937 *$ & $10.286 * * *$ & $3.181^{*}$ \\
Diameter & -0.438 & -0.2622 & -0.2069 \\
Nodes & $1.013 *$ & $3.152 * * *$ & $1.569 * * *$ \\
Leaves & $2.402 * * *$ & 0.361 & -0.069 \\
Leaf:node ratio & $0.143 * * *$ & -0.0418 & -0.019 \\
Leaf Area & $-28.353 * * *$ & $-16.861 * * *$ & $-9.791 *$ \\
Stem Biomass & $-1.322 *$ & 0.556 & 0.173 \\
Root Biomass & $-2.934 * * *$ & -0.025 & $-0.776 * * *$ \\
Total Biomass & $-4.256 * * *$ & 0.532 & -0.602 \\
Wet:dry Stem & $-0.729 * * *$ & -0.141 & -0.721 \\
Wet:dry Roots & 0.143 & 0.0404 & 0.151 \\
Wet:dry Total & -0.143 & -0.100 & $-0.282 *$ \\
\hline
\end{tabular}


Table 4: Pairwise comparisons between water treatments for response variables measured over time. Height $(\mathrm{cm})$, nodes, leaves, and leaf:node ratio were all measured weekly to show the divergence of treatments. Significance codes: $p \leq 0.001^{\text {' } * * * ', p} \leq$ $0.01^{\prime * *} *, \mathrm{p} \leq 0.05^{\prime *},, \mathrm{p} \leq 0.10^{\prime} \bullet '$.

\begin{tabular}{lllll}
\hline & Height & Nodes & Leaves & $\begin{array}{l}\text { Leaf:node } \\
\text { Ratio }\end{array}$ \\
\hline $\begin{array}{l}\text { Drought- } \\
\text { Control } \\
\text { Excess- }\end{array}$ & $-3.611^{* * *}$ & $-1.018^{* * *}$ & $-0.847^{* * *}$ & -0.011 \\
$\begin{array}{l}\text { Control } \\
\text { Excess - }\end{array}$ & $2.034 * * *$ & $0.258 *$ & 0.146 & -0.001 \\
Drought & $5.645^{* * *}$ & $1.277^{* * *}$ & $0.993 * * *$ & 0.010 \\
\hline
\end{tabular}

Table 5: Differences between $30^{\circ} \mathrm{C}$ and $25^{\circ} \mathrm{C}$ temperature treatments for response variables measured over time. Columns represent individual trials. Significance codes:

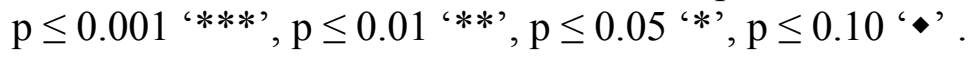

\begin{tabular}{llll}
\hline & \multicolumn{1}{c}{ Trial 1 } & \multicolumn{1}{c}{ Trial 2 } & \multicolumn{1}{c}{ Trial 3 } \\
\hline Height & $-3.755^{* * *}$ & $5.414^{* * *}$ & $1.358 * * *$ \\
Nodes & $0.244 *$ & $1.404 * * *$ & $1.033^{* * *}$ \\
Leaves & 0.168 & $0.818^{* * *}$ & $0.402 *$ \\
Leaf:node ratio & -0.010 & 0.002 & -0.012 \\
\hline
\end{tabular}

Table 6: Total change in response variables for soil salinity study. Degrees of freedom and mean squared error are shown for height $(\mathrm{cm})$, diameter $(\mathrm{mm})$, biomass $(\mathrm{lbs})$, wet:dry biomass ratio, leaf area (cm), and number of leaves for four Asclepias syriaca populations subject to four salt levels $(0,2000,6000$, and $12000 \mathrm{ppm} \mathrm{NaCl}$ solutions).

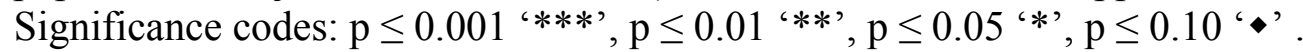

\begin{tabular}{llllllll}
\hline $\begin{array}{l}\text { Sources of } \\
\text { variance }\end{array}$ & df & Height & Diameter & Biomass & $\begin{array}{l}\text { Wet:dry } \\
\text { Ratio }\end{array}$ & Leaf Area $\begin{array}{l}\text { Number of } \\
\text { Leaves }\end{array}$ \\
\hline Population & 3 & $1364 * * *$ & $2.825 * * *$ & $1422 *$ & $1.0254 .$. & $1969 .$. & $649.2 * * *$ \\
Salt & 3 & $513.9 *$ & $5.905 * * *$ & $6386 * * *$ & $1.2011 *$ & $3174 * *$ & $668.2 * * *$ \\
Population x Salt & 9 & 52.5 & 0.122 & 240 & 0.6115 & 745 & 36.7 \\
Error & 103 & 137.5 & 0.303 & 459 & 0.423 & 742 & 73.7 \\
\hline
\end{tabular}


Table 7: Main effects for change over time for soil salinity study. Degrees of freedom and mean squared error are shown for height $(\mathrm{cm})$, nodes, number of leaves, and leaf:node ratio for four Asclepias syriaca populations growing over 9 time periods and subject to four salt levels $(0,2000,6000$, and $12000 \mathrm{ppm} \mathrm{NaCl}$ solutions). Full table with interactions can be found in Appendix A. Significance codes: $p \leq 0.001$ '***', $p$

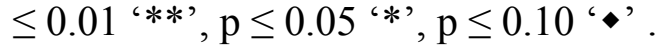

\begin{tabular}{llllll}
\hline Sources of variance & df & Height & Nodes & Leaves & $\begin{array}{l}\text { Leaf:node } \\
\text { Ratio }\end{array}$ \\
\hline Pop & 3 & $4639 * * *$ & $384.8 * * *$ & $338.7 * * *$ & 0.3187 \\
Salt & 3 & $3506 * * *$ & $198.4 * * *$ & $392.4 * * *$ & $0.5915 *$ \\
Time & 8 & $18348 * * *$ & $1566.1 * * *$ & $608.5 * * *$ & $0.605 * *$ \\
Residuals & 927 & 85 & 6.2 & 8.2 & 0.2043
\end{tabular}



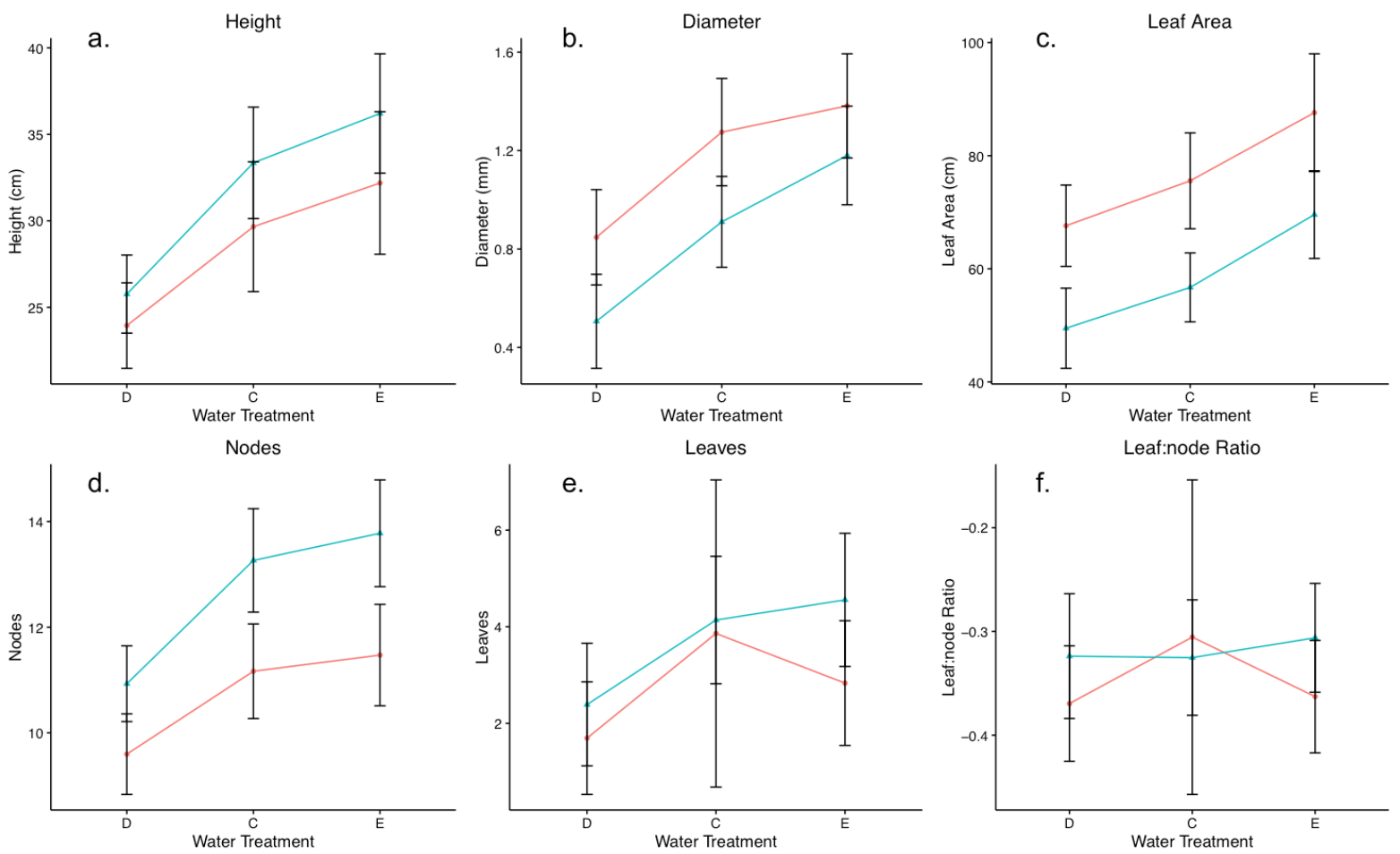

Figure 1: The relationship between temperatures $\left(25^{\circ} \mathrm{C}\right.$ and $\left.30^{\circ} \mathrm{C}\right)$, water treatments (drought (D), control (C), and excess (E)) and total change in response variables: height $(\mathrm{cm})$, diameter $(\mathrm{mm})$, leaf area $(\mathrm{cm})$, number of nodes, number of leaves, and leaf:node ratio.

Legend: blue line represents $30^{\circ} \mathrm{C}$, red line represents $25^{\circ} \mathrm{C}$, drought (D), control (C), and excess (E). 

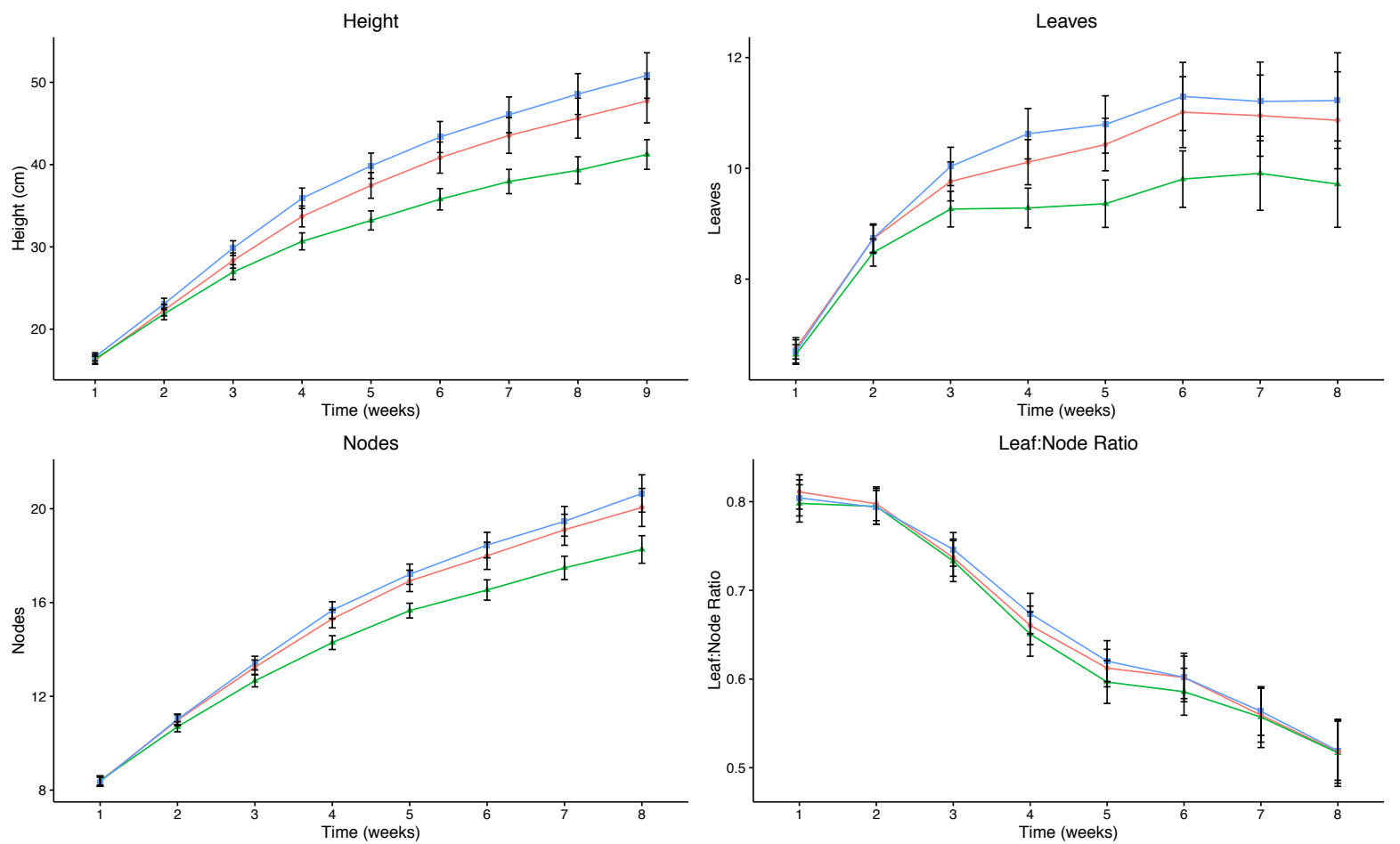

Figure 2: The relationship over time between water treatments (drought (D), control $(\mathrm{C})$, and excess $(\mathrm{E}))$ and response variables: height $(\mathrm{cm})$, nodes, leaves, and leaf:node ratio.

Legend: blue line represents excess water, red line represents control, and green line represents drought conditions. 

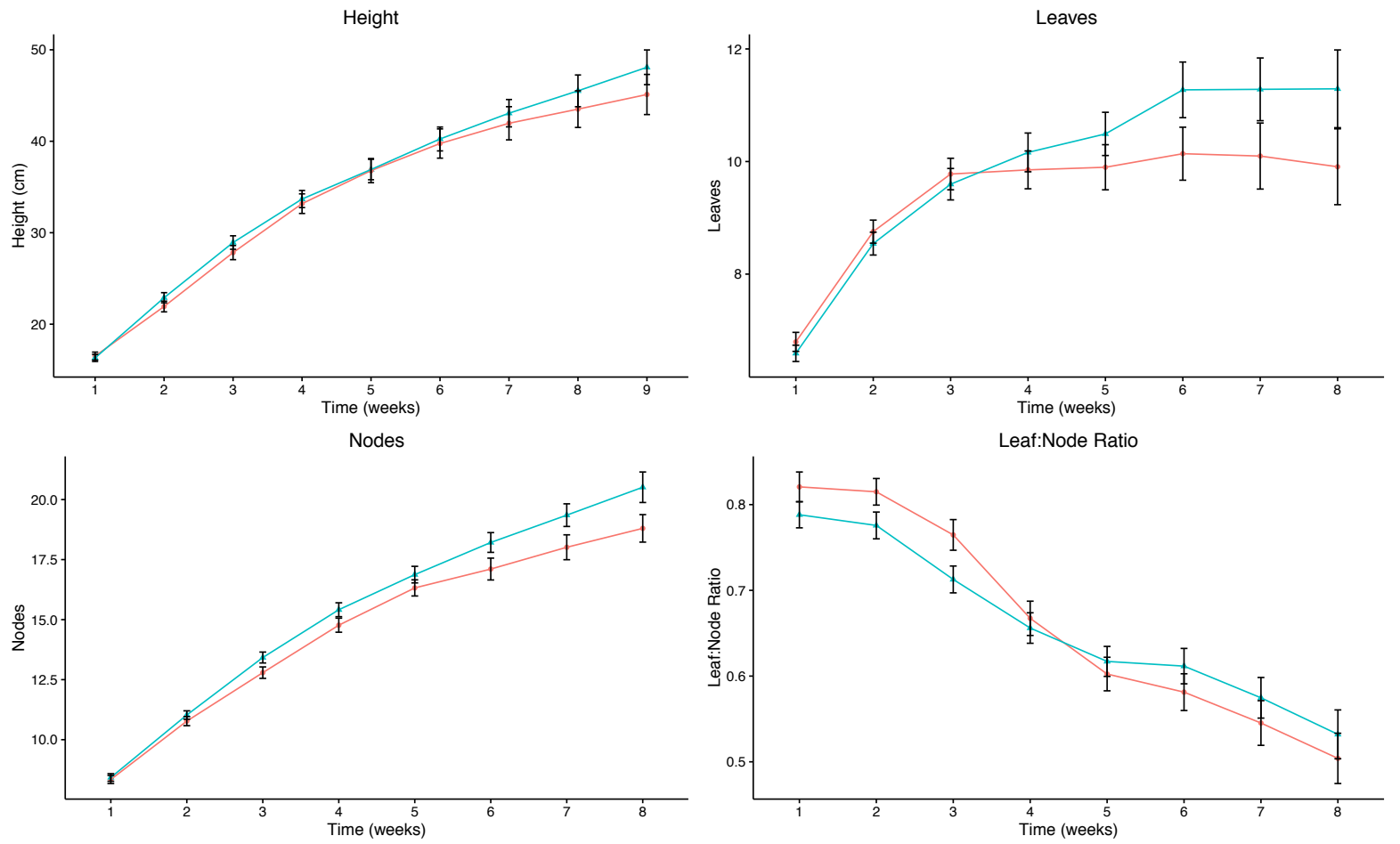

Figure 3: The relationship over time between temperatures $\left(25^{\circ} \mathrm{C}\right.$ and $\left.30^{\circ} \mathrm{C}\right)$ and response variables: height $(\mathrm{cm})$, nodes, leaves, and leaf:node ratio.

Legend: blue line represents $30^{\circ} \mathrm{C}$, red line represents $25^{\circ} \mathrm{C}$. 

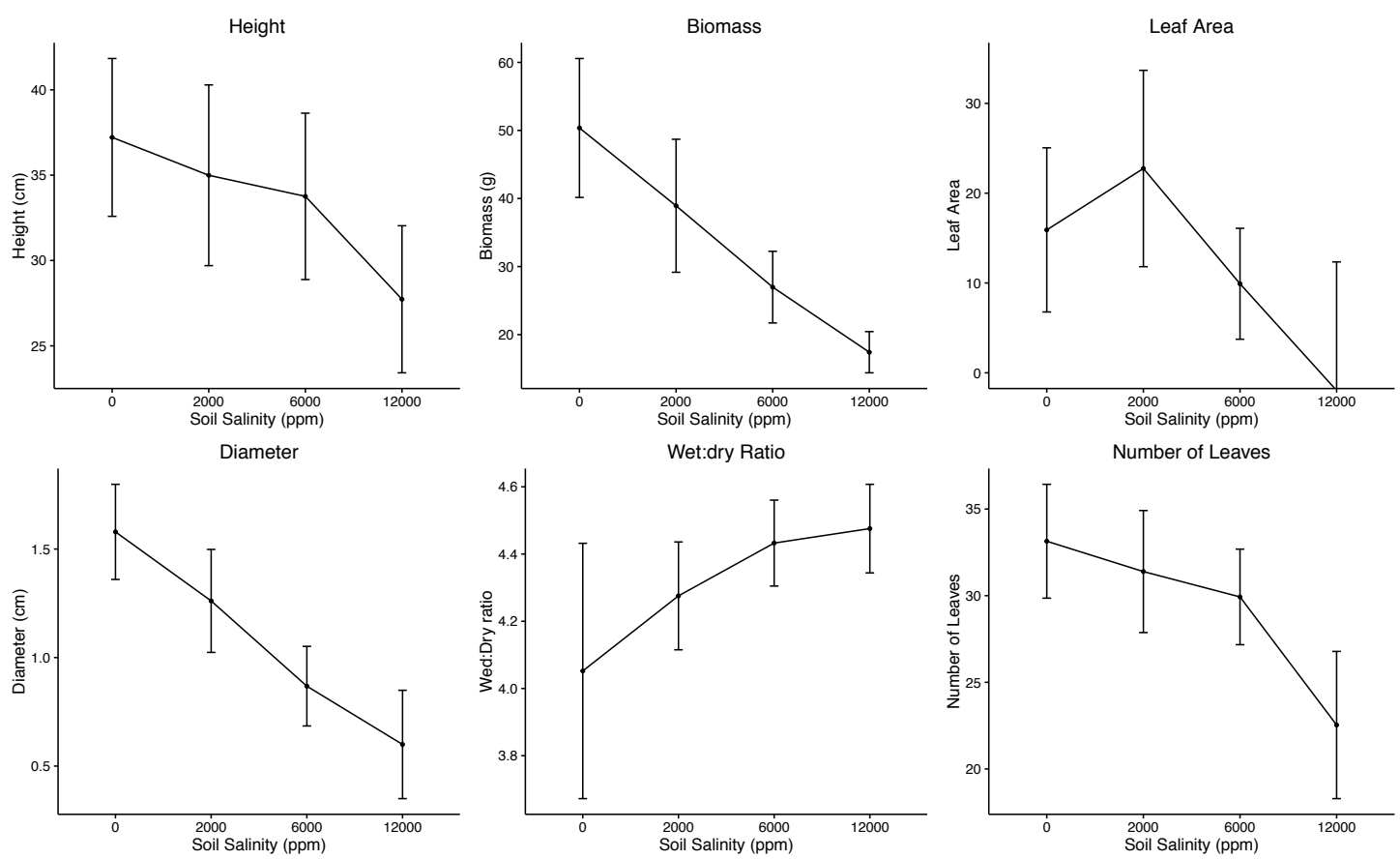

Figure 4: The relationship between soil salinity level ( $\mathrm{ppm}$ ) and total change in response variables: height $(\mathrm{cm})$, biomass $(\mathrm{lbs})$, leaf area $(\mathrm{cm})$, diameter $(\mathrm{mm})$, wet:dry biomass ratio, and number of leaves. 

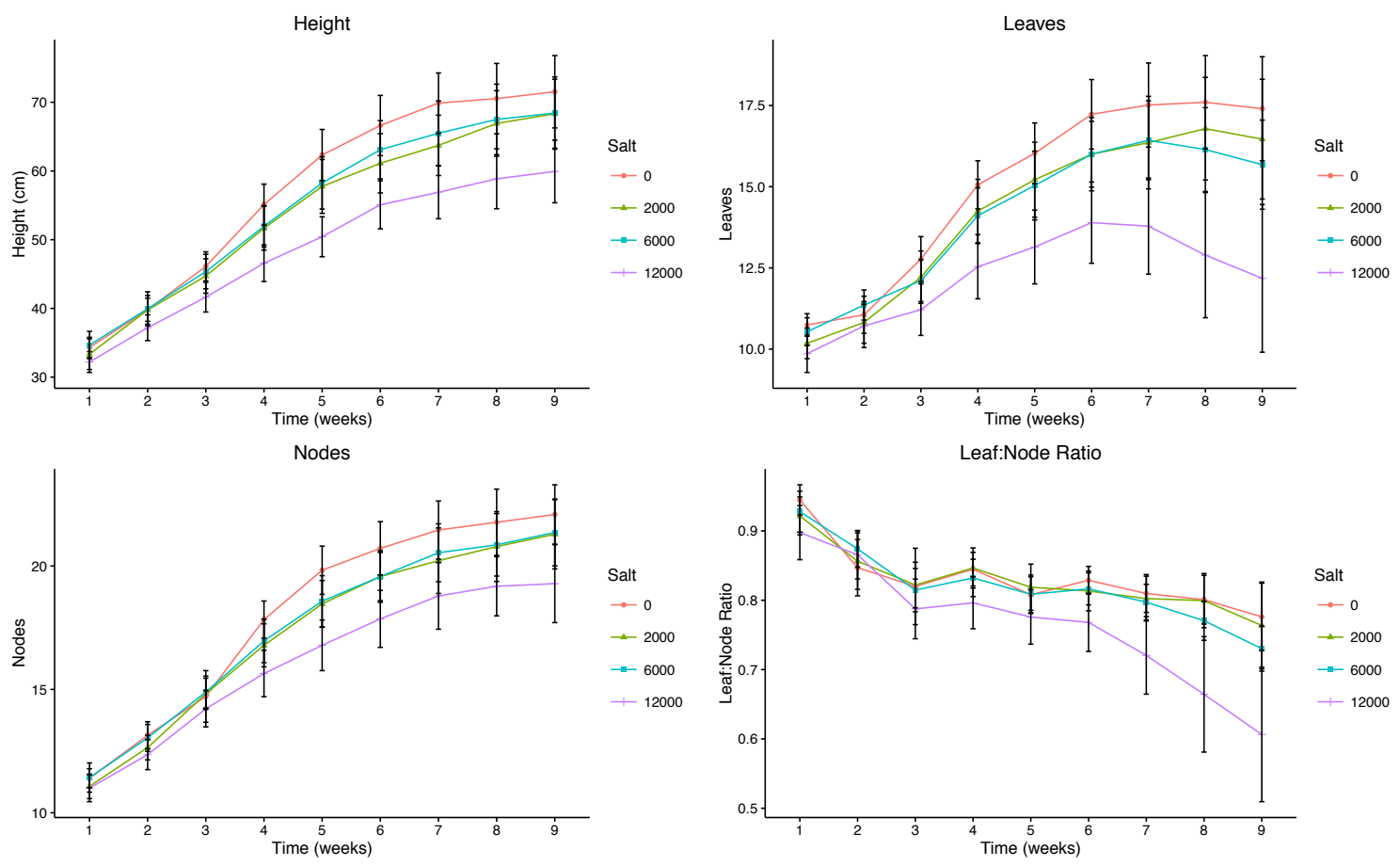

Figure 5: The relationship over time between soil salinity level $(0,2,000,6,000$, and $12,000 \mathrm{ppm})$ and height $(\mathrm{cm})$, nodes, leaves, and leaf:node ratio. 
"EVALUATION OF ASCLEPIAS SYRIACA AS A VIRAL HOST FOR CUCUMBER MOSAIC VIRUS IN THE NORTHEASTERN UNITED STATES"

\author{
BY \\ Courtney Devoid \\ Master of Science Candidate, Department of Plant Science and Entomology, \\ University of Rhode Island, Kingston, R.I. Email: cdevoid@uri.edu
}




\title{
CHAPTER 4
}

\author{
EVALUATION OF ASCLEPIAS SYRIACA AS A VIRAL HOST FOR \\ CUCUMBER MOSAIC VIRUS IN THE NORTHEASTERN UNITED STATES
}

\begin{abstract}
:
Plants surrounding agricultural fields can act as reservoirs for crop diseases, causing substantial economic losses for growers. Cucumber mosaic virus (CMV) is an aphid-transmitted virus that infects a wide host range. Common milkweed (Asclepias syriaca L.) can act as an alternative host for this crop disease, allowing the virus to overwinter in its perennial roots, serving as a primary inoculum for crops. Common milkweed is important for monarch butterfly conservation efforts aimed at increased milkweed presence in agricultural areas; therefore it is essential to establish its hostpotential for economically destructive viruses. A survey was conducted to determine the prevalence of CMV in common milkweed along a latitudinal gradient in the northeastern United States. Samples were collected from paired sites in agricultural and non-agricultural areas. Seeds from infected plants were grown in isolation to determine whether common milkweed seeds transmit the virus. Samples were tested using both ELISA and Immunostrip methods. In the field survey, low-levels of CMV $(2.5 \%)$ were detected using Immunostrips, while ELISA tests had no positive results. No plants were infected with CMV coming from positive maternal plants; therefore it is not likely that the virus is seed transmitted. This study found that level of infection in common milkweed is extremely low in the northeastern United States; making common milkweed presence in agricultural areas a low-risk for crop infection.
\end{abstract}




\section{Introduction:}

Vegetable crops incur considerable losses due to the spread of viral diseases. Weeds established in or near agricultural fields can act as natural hosts to these viruses, which can then be spread to crops. As alternative hosts, weeds serve as both food sources for virus vectors and reproductive aids to help spread the virus (Kazinczi et al. 2002). Aphids (Aphididae) serve as the primary vector for transmitting a variety of viruses and are particularly problematic for commercially grown crops in Midwest (Mueller et al. 2012). Aphids feed off both weedy species growing near crops and the crops themselves, resulting in rapid spread. Even through most aphid species tend to have narrow host ranges, they will often test-probe non-host species, which allows viruses to spread quickly and to a wide range of plants (Mueller et al. 2012). Weeds growing in agricultural fields act as reservoirs; viruses can overwinter in perennial plant roots and spread by seed transmission (Tomlinson and Carter 1970, Tomlinson et al. 1970, Mueller et al. 2012). To prevent crop infection, producers must be able to identify potential weedy hosts and the viral transmission vectors of those plants.

Common milkweed (Asclepias syriaca L.) is a fast-growing perennial weed that forms massive clonal colonies in and around agricultural fields, and is a known host to multiple crop viruses (Bhowmik 1994). Common milkweed has been especially prevalent in high yield cultivated areas in the Midwest, such as corn, soybean, and cereal fields, causing substantial yield losses (Evetts and Burnside 1972). The advent of genetically modified, herbicide resistant crops has resulted in significant reductions of common milkweed populations (Pleasents and Oberhauser 2012). While 
this may appear positive in the context of eliminating hosts of viral diseases, the situation is complicated when considering current conservation efforts being taken to keep milkweed in fields. The monarch butterfly (Danaus plexippus L.) depends on the presence of milkweed as it makes its annual migration from central Mexico to breeding grounds in the northeastern and central United States. Monarch populations have experienced significant declines in the past two decades, which have been attributed to losses of milkweed in agricultural fields (Pleasents and Oberhauser 2012, Flockhart et al. 2015, Pleasants et al. 2016). Modeling by Flockhart et al. (2015) has demonstrated that a reduction in milkweed host plants, caused by genetically modified crops and land-use change, is responsible for monarch population losses. Therefore, reducing host plant loss has become the top conservation priority for halting future monarch population declines (Flockhart et al. 2015).

Conservation efforts are being implemented to stop destruction of milkweed in agricultural areas and plant new populations in hedgerows along fields, making it imperative to understand the role of this weed in viral disease spread (Borders and Lee-Mader 2014). Currently, A. syriaca is known to host several economically impactful viruses. Cucumber mosaic virus (CMV), tomato spotted wilt virus (TSWV), and tobacco mosaic virus (TMV) are three known A. syriaca pathogens that can be particularly destructive to a wide range of agricultural crops (Kazinczi et al. 2002). CMV is one of the most devastating viruses that $A$. syriaca hosts; having created problems for growers throughout the world for many decades (Bruckart and Lorbeer 1975, Ali and Kobayashi 2010). For example, farmers in southern Illinois have 
stopped producing large volumes of pepper plants due to substantial losses from CMV infection (Hobbs et al. 2000).

CMV has the largest host range of any RNA virus, infecting over 1200 plant species in 100 families (Tomlinson 1987, Ali and Kobayashi 2010). This virus is spread by non-colonizing, transient winged aphids that move from host plants to crops (Tomlinson 1987). Once infected, numerous foliar symptoms occur, including: leaf blistering, pod distortion, vein clearing, and leaf mottling (Mueller et al. 2012). Additionally, fruits often become mottled and distorted, making them unsellable (Zitter and Banik 1984). Infected A. syriaca plants can have various symptoms including dwarfed growth, mottled leaves, and irregular green/yellow patches on leaves (Doolittle and Walker 1925). It is important to note that many of the symptoms of CMV can be caused by a variety of plant stresses, as well as other viruses. Since symptoms vary and are difficult to distinguish from other viruses, targeted removal of infected milkweed is not a viable option for growers.

In addition to insect vectors, seed transmission plays an important role in the survival and spread of viral diseases. Seed transmission can increase the overwintering potential and long range dissemination of the virus, as well as provide an initial source of inoculum for insect vector transmission (Ali and Kobayashi 2010). Seed transmission of CMV has been demonstrated in several weedy species, but transmission from A. syriaca has not yet been demonstrated. CMV has been found to be seed transmitted in chickweed (Stellaria media (L.) Vill.), another common weedy species that infests agricultural areas (Tomlinson and Carter 1970). Chickweed produces large numbers of seeds that end up in the soil; so low rates of transmission 
(1-2\%) can result in outbreak (Tomlinson 1987). Although common milkweed doesn't produce large numbers of seeds, seed transmission would be particularly problematic because seeds are wind-dispersed, often traveling long distances, which would result in substantial viral spread.

The goal of this work is to determine whether CMV is present in wild populations of $A$. syriaca, located along a latitudinal gradient in the northeastern United States. By sampling along a gradient, we can determine if CMV is more prevalent in certain areas, to aid both growers and conservation efforts. Several studies have already demonstrated that CMV is prevalent in agricultural areas in the Midwest, and this study aims to determine and compare northeastern abundance to previous findings.

\section{Methods:}

Initial screenings were conducted to test for the presence of CMV, TMV, and TSWV on A. syriaca leaves. The goal of these initial screens was to determine if any viruses were present and in what quantities, prior to large scale testing. A. syriaca seeds for these initial tests originated in Kingston, Rhode Island (41.48938 $\mathrm{N}$, $\left.71.54262^{\circ} \mathrm{W}\right)$, Glocester, Rhode Island $\left(41.90431^{\circ} \mathrm{N},-71.69106^{\circ} \mathrm{W}\right)$, Charleston, Rhode Island $\left(41.3832^{\circ} \mathrm{N},-71.6419^{\circ} \mathrm{W}\right)$, North Oxford, Massachusetts $\left(42.18906^{\circ} \mathrm{N}\right.$, $\left.-71.9059^{\circ} \mathrm{W}\right)$, and North Stonington, Connecticut (41.4684 $4^{\circ}$, $\left.-71.94448^{\circ} \mathrm{W}\right)$. Seeds originating in Kingston, RI were collected at the University of Rhode Island Agronomy farm from plants growing near multiple vegetable crops that had the potential to be infected with these viruses, including tomatoes, peppers, and cucumbers. 
Plants for initial screens were grown in Plant Growth Chambers (Conviron, model: CMP6050; Manitoba, Canada) set to $25: 18^{\circ} \mathrm{C}$ day/night temperature. Growth chambers were bleached and heat-treated before use, to ensure no insects or pathogens were present. Prior to germination, seeds were placed on moistened perlite and subject to cold, moist stratification for one week (Baskin and Baskin 1977). Seeds were germinated for ten days in $10 \times 15 \mathrm{~cm}$ trays using a greenhouse MetroMix potting medium \#830 (SunGrow, Agawam, Massachusetts). Seedlings were transferred to 10 $\mathrm{cm}$ pots, grown for four weeks, and then transferred to larger $15 \mathrm{~cm}$ pots. Plants were fertilized using Peter's 20-10-20 Peatlite special fertilizer (JR Peters Inc, Allentown, Pennsylvania), which contained 230 PPM nitrogen. Sticky traps were placed in the chamber to ensure monitor insect presence.

Initial testing was done with ImmunoStrip testing kits (Agdia, Elkhart, Indiana), which are used by growers as a rapid way to screen for a variety of pathogens. To perform the assay, $2.5 \mathrm{~cm}^{2}$ leaf segments were cut from the middle and outer edge of the leaf. Tissue was placed in sample extraction bags and macerated with a blunt object. Per instructions, each sample was allowed to settle for 3-minutes, then strips were immersed in homogenate for 30 minutes. A positive result was indicated if any intensity of pink/purple was present on the strip beneath the control line. Based on these initial results, tests were repeated for CMV and TMV after an additional 8 weeks, with plants being a total of 15 weeks old, allowing for an increased incubation period.

After the initial screening, a survey was conducted to estimate the incidence of CMV in A. syriaca plants in the northeastern United States. Samples were taken from 
wild A. syriaca plants growing along the edges of agricultural and non-agricultural areas. Site selection was based on a latitudinal gradient and the presence of both agricultural and non-agricultural fields in close proximity (Figure 1). Paired sites were located a minimum of $1.5 \mathrm{~km}$ apart, but close enough that plants experienced the same climactic conditions. A total of 25 leaf samples were collected from 11 sites (located in: Newport, Vermont $\left(44.81852^{\circ} \mathrm{N},-72.36408^{\circ} \mathrm{W}\right)$; Sugar Hill, New Hampshire $\left(44.24447^{\circ} \mathrm{N},-71.79239^{\circ} \mathrm{W}\right)$, Concord, New Hampshire (43.1861 $\left.\mathrm{N},-71.56446^{\circ} \mathrm{W}\right)$; Harvard, Massachusetts (42.5128 N, $\left.-71.50987^{\circ} \mathrm{W}\right)$; Glocester, Rhode Island $\left(41.90431^{\circ} \mathrm{N},-71.69106^{\circ} \mathrm{W}\right)$; and Kingston, Rhode Island $\left(41.48938^{\circ} \mathrm{N},-71.54262^{\circ}\right.$ W). One leaf per plant was taken from the center of the stem; wrapped in a damp paper towel, and kept in coolers for transport to the lab facility. All samples were collected within 24-hours, placed in a cooler at $4^{\circ} \mathrm{C}$ overnight, and tested the following day.

Samples from the field survey were tested using Triple Antibody Sandwich (TAS), enzyme-linked immunosorbent assay (ELISA) kits (Agdia Inc., Elkart, Indiana), containing polyclonal antibodies of CMV from subgroups I and II. Tests were performed according to the procedures dictated by the manufacturer's instructions. Leaf tissue was extracted from the middle, outer edge of the leaf. The remaining leaf tissue was stored at $-80^{\circ} \mathrm{C}$ for future tests. Tissue spiked with the antibody control, provided by Agdia, was used as a positive control to detect host reactions. Controls composed of buffer only were also included on each plate. Absorbance readings were measured at the conclusion of the protocol both by eye and using a $415 \mathrm{~nm}$ plate reader (Bio-Rad, iMark Microplate Reader; Hercules, 
California), which calculated absorbance values for each sample well compared to blank test well readings. Samples were considered positive results, and therefore virusinfected, if color developed in the well. Wells with no significant color indicated a negative result. Plates were read after 60 minutes and 180 minutes. Immunostrip tests were also conducted on field samples using the protocols outlined above, to compare/confirm the results from the ELISA tests.

Following serological analysis, additional tissue samples and seeds were collected in October 2016 from one field-site (located in Concord, NH) where plants tested positive for CMV. These samples were collected to demonstrate seed transmission of CMV. Because samples were collected late in the season, tissue was dry and therefore tested two ways: dry stems and roots were ground, placed in extraction buffer, and tested using the Immunostrip testing protocols described above; and samples were ground and placed in test tubes with distilled water to soak for 36 hours, at which time the extracted liquid was placed in extraction bags at a ratio of 1:20 dilution, per manufactures instructions.

Seeds from positive plants were cold stratified, germinated, and grown following the protocols outlined above. Plants were grown for a total of 15 -weeks (approximate length of a growing season in the northeastern United States). Plants were grown in isolation (in growth chambers) from any insects that could be carrying CMV. Plants were also sprayed bi-monthly with a combination of several insecticides to eliminate any possibility of insect presence. Insecticides included: Spinosad (Dow AgroSciences, Conserve SC; Indianapolis, Indiana), Spirotetramat (OPH, Inc., Kontos; Mainland, Pennsylvania), and azadirachtin (BioNEEM, Safer Brand; Lititz, 
Pennsylvania). Insect monitoring sticky traps were again placed in the growth chambers for the duration of the experiment to confirm lack of insect presence. Leaf samples were taken from the middle of each plant and tested using the Immunostrip methodology outlined above.

\section{Results:}

\section{Initial Screening:}

After an initial 7-weeks of growth, plants were tested for the three viruses. TSWV was negative for every plant $(n=25)$, while low levels of both CMV and TMV were detected. In populations originating in North Oxford, MA, North Stonington, CT, and Glocester, RI, 1/5 plants tested positive for CMV (Table 1). For TMV, 2/5 plants from North Stonington, CT tested positive, and 1/5 from Gloucester, RI (Table 1). Plants continued to grow and incubate the virus for 8 additional weeks. Viral tests were repeated for CMV and TMV, given that TSWV had no positive results for the initial test. Additional incubation time resulted in increased positive plants for both viruses. For CMV, $3 / 5$ plants from North Oxford, MA were positive after additional incubation, compared to the previous result of $1 / 5$ (Table 2). No additional positives were found for the other populations, which remained at $1 / 5$ positive plants. All populations became infected with TMV after the additional growth period (Table 2). This result is attributed to the transmission method of TMV. TMV is mechanically transmitted via human handling and because the virus is often present in tobacco products, we suspect that cross-contamination occurred. Although the growth chambers were isolated, we cannot rule out contamination from human vectors. Given the challenges of TMV isolation, CMV became the sole focus of this study, since it 
requires an aphid transmission vector and is therefore more easily isolated in growth chambers.

Leaf sampling location:

The five plants that tested positive for CMV were retested to determine whether there was a location on the plant where viral levels were highest. The lowest leaves on the plants had no positive results. All leaves sampled from the center of the stem tested positive and 2/5 plants tested positive for leaves sampled at the apex.

Based on these results, field samples were taken from the center of the stem.

Plant survey results: ELISA and Immunostrip

In total, 280 plants from 11 locations: 6 agricultural, 5 non-agricultural were sampled. All samples tested negative for CMV using the ELISA method. Samples were retested using Immunostrips and several positive plants were found. From Gloucester, RI, 3.3\% (1/30) of plants were infected; from the non-agricultural site in Massachusetts, $8 \%(2 / 25)$ of plants were infected, and from the agricultural site in Concord, NH 20\% (5/25) of plants were infected (Table 3).

\section{Seed transmission}

Plants collected along an agricultural field in Concord, NH had the highest incidence of CMV. Seeds were therefore collected from this site to demonstrate seed transmission of CMV in A. syriaca. Maternal plants were retested before seeds were grown to confirm CMV presence. A total of 10 plants were tested and 3 were found to be positive. Positive plants were retested a second time to confirm CMV presence. A total of 76 plants were grown from seeds originating from the 3 positive plants. Due to differing seed germination rates and seed availability levels at the time of collection, 
45 plants were grown from the first positive mother plant, 19 plants from the second positive mother plant, and 10 plants from third positive mother plant. No plants tested positive for CMV using the Immunostrip method, demonstrating that CMV is not transmitted via A. syriaca seeds. Mottled and distorted leaves were observed on several of the plants; however, this was attributed to other causes than CMV.

\section{Discussion:}

CMV has an extensive host range of both crop and weedy species, as well as numerous insect transmission vectors; however, we have shown this virus to be present in extremely low levels in the northeastern United States. Of the 280 plants sampled, $2.5 \%$ of plants were infected with CMV at three different sites, and these results were only observed using the Immunostrip testing method. These results indicate that $A$. syriaca does not substantially contribute to the spread of CMV from weedy hosts to crop species. Low levels of infection in A. syriaca are consistent with tests done in New York State. Bruckart and Lorbeer (1975) found a 3\% infection rate of A. syriaca located near commercial lettuce fields throughout New York State. Such low rates of infection are positive when considering the current efforts being taken to maintain milkweed populations in agricultural areas for monarch conservation.

In comparing the prevalence of CMV to agricultural versus non-agricultural areas, our survey did not find any difference between site locations. The goal of testing paired agricultural and non-agricultural sites was to see if $A$. syriaca was acting as an overwintering host independent of its location. This would allow us to determine if $A$. syriaca is a primary source of infection for crops or simply becomes infected due to its proximity to already infected crops. Our results showed positive plants at both 
agricultural and non-agricultural sites. We did find a much higher rate of infection at one site along a crop field in Concord, $\mathrm{NH}(20 \%$ infection, $\mathrm{n}=25)$, implying that proximity to crops could increase host plant infection. This is in agreement with Mueller et al. (2012), who found a higher percentage of CMV infection in A. syriaca bordering agriculture fields (7\%) than in the unmanaged areas on field edges (5\%). Since the number of positive plants was so low, it is hard to definitively say whether location plays a role in rate of infection; however, our highest rate of infection did occur next to a crop field.

The question of distance from crop sources should be examined further to determine the role of proximity to infected plants. This is an important question to answer when considering whether to eradicate $A$. syriaca populations located near a growers field. In one of the first papers linking A. syriaca to CMV, Doolittle and Walker (1925) concluded that overwintering weeds were the foci of infection for cucurbit crops. The first infected plants in spring plantings were found scattered around mosaic A. syriaca plants that had grown within the crop rows (Doolittle and Walker 1925). Sampling A. syriaca at increasing distances from fields where CMV is present is important future work to be done; unfortunately this was not possible at our site, since the populations were generally small and clumped in one patch. Such information will be critical for informing growers whether $A$. syriaca populations are putting their crops at risk of infection and for identifying plants that should be removed.

An important part of this work was finding a reliable way to test CMV in perennial host species. For this study, we used two methods: Immunostrip and ELISA 
kits. The Immunostrip kits are designed to rapidly and easily test plants, without any equipment or expertise. The ease of this method makes it optimal for growers looking to locate a source of infection within their fields. We ran into several problems with these tests. False positives were found to be a common occurrence in our samples, possibly due to a reaction with $A$. syriaca tissue. To determine if a plant is positive for the virus, a pink/purple test line will appear on the strip. A. syriaca tissue reacted to the strips by producing a faint grey/black line, which initially appears to be positive; however, we have determined it to be a false positive. To confirm that a plant was positive, we examine the strips under light-microscopy, where pink anti-body reactions were visible. Our results were light pink; therefore extremely low titer levels were present, making the potential of false positives greater. After several hours, the positive pink lines were visible to the naked eye; however, the dark grey false positives make this test potentially unreliable for growers, as the test results should be strongly pink after 30 minutes.

The presence of a host reaction is not surprising, as this seems to be a common occurrence with multiple other plants. In the user guide for Immunostrips, Agdia has identified both ivy geranium and begonia as presenting false positives. The essential finding here is that the host reaction we observed was a grey line, which was not the same color as the pink anti-body reaction. We therefore conclude that growers should beware of false positives from host plant interactions.

We also had discrepancies between the ELISA and Immunostrip tests, which was a surprising finding. At the start of this study, Immunostrips were used for the initial screens because they were a fast way to test small numbers of samples at a time. 
ELISA was used for the field samples, since it can be run in large batches using 96well plates. Given that all samples were negative with the ELISA method, yet we had several positives in initial screens, every sample was retested using Immunostrips to compare to ELISA. The positive Immunostrip samples indicate a discrepancy between these two testing methods. These differences are in agreement with Opina and Miller (2005), who tested tomato plants for bacterial wilt (Ralstonia solanacearum (Smith 1896) Yabuuchi et al. 1996); ELISA and Immunostrip results were the same for $91 \%$ of the samples, but for 9\%, Immunostrip results were positive and ELISA were negative. In our study, $2.5 \%$ of samples tested positive with Immunostrip. This is consistent with the findings from Opina and Miller (2005), and it is therefore likely that ELISA found false negatives or Immunostrip found false positives.

False negatives can occur if the viral agent is not present in the sampled tissue, which is a possibility because the tissue for the ELISA test uses a much smaller amount $\left(1 \mathrm{~cm}^{2}\right)$ compared to $\left(2.5 \mathrm{~cm}^{2}\right)$ for Immunostrips. CMV is known to have poor immunogenicity, therefore if the virus was present, it was likely in low levels that would be difficult to detect (Francki et al. 1979b). To counteract this problem, larger leaf tissue samples could be homogenized and a subsample taken to increase the likelihood of virus detection. There are several additional possibilities as to why we obtained false negatives for ELISA. Our samples were taken from the northeastern United States, which likely has a unique CMV ecotype. Although both tests include CMV isolates from the same two subgroups, the Immunostrip method may be better suited for the specific strain of CMV in our geographic region. Also, since $A$. syriaca has complex chemical compounds in its leaves, a low-level host reaction could be 
occurring that would result in false negatives for ELISA but not Immunostrips, due to differences in chemicals used for each test. One of the positive controls for our ELISA test was a leaf sample spiked with CMV antibodies to determine if a host reaction was occurring. Although there did not appear to be any interference in the control, we know that if the virus was present, it was in extremely low-levels and therefore an interaction that caused slight interference may not be picked up by the control. Low antibody titer levels could also be responsible for the differences. From our results, we know that the virus was present in approximately $2.5 \%$ of plants, indicating extremely low levels of CMV in the northeastern A. syriaca population. As such, the virus could have had a low-level of infection in the positive plants, and the Immunostrips method may have pick up that level but not the ELISA. As previously mentioned, increased sensitivity of Immunostrips over ELISA has been demonstrated for other viruses (Opina and Miller 2005).

False positives for Immunostrips are also a possibility, since $A$. syriaca did demonstrate a host reaction and our positive pink lines were faint. If this is the case, our conclusions are not significantly impacted. We found extremely low levels of wild plants infected with CMV, but cannot conclude that the positives we found were not actually false positives. Either way, if CMV is present in the northeast, it is in low quantities that are similar to the Midwest. In Wisconsin, Muller (2012), had 0 positive plants in 2007; while in $2008,7 \%$ of samples growing in fields and $5 \%$ of samples growing along field edges were found to be CMV positive. In southern Illinois, 0 of 169 plants tested positive for CMV adjacent to pepper fields where CMV has been particularly problematic (Hobbs et al. 2000). Hobbs et al. (2000) found that the 
primary weeds infected with CMV were eastern black nightshade (Solanum ptycanthum Dunal) and groundcherry (Physalis heterophylla Nees). The initial identification of CMV by Doolittle and Walker (1925) found high levels of infected milkweed in Wisconsin. Although an exact percentage was not calculated in this study, reports of 100 mosaic milkweeds plants in one field were described. Such high levels have not been subsequently reported in recent literature. These differences can be attributed to lower levels of $A$. syriaca in agriculture fields, diminished infection levels, or improved detection methods (Pleasents and Oberhauser 2012).

We did not demonstrate seed transmission of CMV in A. syriaca. This result is somewhat surprising, since our initial screens did show low levels of CMV present in plants that were grown from seed. Given the initial screens had positives, we assumed that the virus was seed transmitted, which would be consistent with the literature for other species, as CMV transmission has been demonstrated in other weedy species and in various crop plants. Our results agree with initial tests done by Doolittle and Walker (1925), who grew seeds from mosaic milkweeds and found that only healthy plants grew, concluding that CMV was not seed transmitted in A. syriaca. Since this research was done in 1925 and the method of determining CMV infection was by foliar symptoms, our goal was to test seed transmission via serological assay techniques.

There are three possible scenarios based on our results. We demonstrated that CMV is not seed transmitted and our initial screens were incorrect, either through failed plant isolation or false positives of Immunostrips. We could have had false positives from maternal seed sources, therefore negative seeds were collected and the subsequent outgrowth of plants was from a negative mother plant and not a positive 
one. Seed transmission could also have been in extremely low levels, which the Immunostrips didn't detect, whereas the initial screening seeds could have had higher rates of infection, based on either date of collection or seed origin. Regardless, we have concluded that $A$. syriaca does not likely transmit CMV via seed, and if it does, it is in extremely low levels that would have little consequence for growers. We have also concluded that CMV infection on $A$. syriaca plants in the northeastern United States is low and in most areas, non-existent.

There are several future research efforts that should be examined. Since high levels of CMV infection in crop plants in the northeast have been reported, identification of other weedy species host plants should be conducted. Additionally, more targeted surveys should also be undertaken on fields that have been identified to be positive for CMV. The goal of this study was to do an expansive survey of locations selected along a large geographical area, to gauge the general level of infection. Targeting infected fields would have biased this study; however, it is important that the rates of milkweed infection on CMV infected fields also be calculated, as well as studies on other weeds in those fields.

Further work should also be done on the rates of false positives and negatives when identifying infected plants. We have identified a potential problem with testing methods that could substantially skew conclusions for growers if false results are not considered. Additional testing methods, such as PCR can be used to compare to Immunostrip and ELISA tests, as well as determine the significance of a host reaction in A. syriaca. It is recommended that growers use Immunostrips over ELISA, due tot 
the ease of the testing method, but results should be carefully considered before action is taken and growers should aware that false positives can occur.

These findings have significant implications for monarch conservation efforts. Since $A$. syriaca is not an important host for CMV in the northeastern United States, milkweed presence in fields will not likely cause substantial harm to grower's crops. Conservation efforts focused on both maintaining current milkweed populations in fields and adding milkweeds by planting pollinator hedgerows along field edges will not be risky endeavors. Unless a grower experiences an outbreak of CMV, preemptive removal of A. syriaca is not necessary or recommended. Further, the presence of other weedy species, such as chickweed, eastern black nightshade, or ground cherry, should be the focus of host removal efforts (Tomlinson and Carter 1970, Hobbs et al. 2000). Our conclusion of lack of seed transmission is also positive, as $A$. syriaca seeds, which are able to travel long distances, will not be spreading the virus to adjacent fields. 


\section{Literature Cited:}

Ali, A., and M. Kobayashi. 2010. Seed transmission of cucumber mosaic virus in pepper. Journal of Virological Methods 163:234-237.

Baskin, J. M., and C. C. Baskin. 1977. Germination of common milkweed (Asclepias syriaca L.) seeds. Bulletin of the Torrey Botanical Club 104:167-170.

Bhowmik, P. C. 1994. Biology and control of common milkweed (Asclepias syriaca). Review in Weed Science 6:227-250.

Borders, B., and E. Lee-Mader. 2014. Milkweeds: A conservation practitioner's guide.

Bruckart, W. L., and J. W. Lorbeer. 1975. Cucumber moasic virus in weed hosts near commercial fields of lettuce and celery. Etiology 66:253-259.

Doolittle, S. P., and M. N. Walker. 1925. Further studies on the overwintering and dissemination of cucurbit moasic. Journal of Agricultural Research 31:1-58.

Evetts, L. L., and C. Burnside. 1972. Germination and seedling development of common milkweed and other species. Weed Science 20:371-378.

Ferreira, S. A., and R. A. Bloey. 1992. Cucumber mosaic virus. Univeristy of Habaii at Manoa.

Flockhart, D. T. T., J.-B. Pichancourt, D. R. Norris, and T. G. Martin. 2015. Unravelling the annual cycle in a migratory animal: breeding-season habitat loss drives population declines of monarch butterflies. Journal of Animal Ecology 84:155-165.

Francki, R. I. B., D. W. Mossop, and T. Hatta. 1979. Cucumber mosaic virus. Association of Applied Biologists 213.

Hobbs, H. A., D. M. Eastburn, C. J. D’Arcy, J. D. Kindhart, J. B. Masiunas, D. J. 
Voegtlin, R. A. Weinzierl, and N. K. McCoppin. 2000. Solanaceous Weeds as Possible Sources of Cucumber mosaic virus in Southern Illinois for Aphid Transmission to Pepper. Plant Disease 84:1221-1224.

Kazinczi, G., J. Horvath, and D. E. Lesemann. 2002. Perennial plants as new natural hosts of three viruses. Journal of Plant Diseases and Protection 109:301-310.

Mueller, E. E., A. Groves, R.L., and C. Gratton. 2012. Crop and non-crop plants as potential reservoir hosts of alfalfa mosaic virus and cucumber mosaic virus for spread to commercial snap bean. Plant Disease 96:506-514.

Opina, N. L., and S. A. Miller. 2005. Evaluation of immunoassays for detection of ralstonia solanacearum, causal agent of bacterial wilt of tomato and eggplant in the Philippines. Acta Horticulturae 695:353-356.

Pleasants, J. M., E. H. Williams, L. P. Brower, K. S. Oberhauser, and O. R. Taylor. 2016. Conclusion of no decline in summer monarch population not supported. Annals of the Entomological Society of America 109:169-171.

Pleasents, J. M., and K. S. Oberhauser. 2012. Milkweed loss in agricultural fields because of herbicide use: effect on the monarch butterfly population. Insect Conservation and Diversity 6:135-144.

Tomlinson, J. 1987. Epidemiology and control of virus diseases of vegetables. Annals of Applied Biology 110:661-681.

Tomlinson, J. A., and A. L. Carter. 1970. Studies on the seed transmission of cucumber mosaic virus in chickweed (Stellaria media $</ \mathrm{i}>$ ) in relation to the ecology of the virus. Annals of Applied Biology 66:381-386.

Tomlinson, J. A., A. L. Carter, W. T. Dale, and C. J. Simpson. 1970. Weed plants as 
sources of cucumber mosaic virus. Ann. appl. Biol. 66:11-16.

Wikimedia Commons. 2010. File:USA location map - counties.svg.

https://commons.wikimedia.org/wiki/File:USA_location_map_-_counties.svg.

Zitter, T. A., and M. T. Banik. 1984. Virus diseases of Cucurbits.

http://vegetablemdonline.ppath.cornell.edu/factsheets/Viruses_Cucurbits.htm. 
Table 1: Initial screening of $A$. syriaca plants after 7-weeks of growth using the Immunostrip testing method for three plant viruses: cucumber mosaic virus (CMV), tobacco mosaic virus (TMV), and tomato spotted wilt virus (TSWV).

\begin{tabular}{lccc}
\hline & CMV & TMV & TSWV \\
\hline North Oxford, MA & $1 / 5$ & $0 / 5$ & $0 / 5$ \\
North Stonington, CT & $1 / 5$ & $2 / 5$ & $0 / 5$ \\
Kingston, RI & $0 / 5$ & $0 / 5$ & $0 / 5$ \\
Glocester, RI & $1 / 5$ & $1 / 5$ & $0 / 5$ \\
Charleston, RI & $0 / 5$ & $0 / 5$ & $0 / 5$ \\
\hline
\end{tabular}

Table 2: Repeated tests of $A$. syriaca plants after 15-weeks of growth using the Immunostrip testing method for two viruses: cucumber mosaic virus (CMV) and tobacco mosaic virus (TMV)

\begin{tabular}{lcc}
\hline & CMV & TMV \\
\hline North Oxford, MA & $3 / 5$ & $4 / 5$ \\
North Stonington, CT & $1 / 5$ & $3 / 5$ \\
Kingston, RI & $0 / 5$ & $2 / 5$ \\
Glocester, RI & $1 / 5$ & $4 / 5$ \\
Charleston, RI & $0 / 5$ & $3 / 5$ \\
\hline
\end{tabular}

Table 3: Field survey results from leaf samples of $A$. syriaca plants collected along a latitudinal gradient in the northeastern United States using the Immunostrip testing method to test for cucumber mosaic virus (CMV). Sites located near agricultural fields and at least $1.5 \mathrm{~m}$ away from any agricultural activity were collected at each location.

\begin{tabular}{lll}
\hline & Agriculture & Non-Agriculture \\
\hline Newport, VT & $0 / 25$ & $0 / 25$ \\
Sugar Hill, NH & $0 / 25$ & $0 / 25$ \\
Concord, NH & $5 / 25$ & $0 / 25$ \\
Harvard, MA & $0 / 25$ & $2 / 25$ \\
Glocester, RI & $1 / 25$ & - \\
Kingston, RI & $0 / 25$ & $0 / 25$ \\
\hline
\end{tabular}




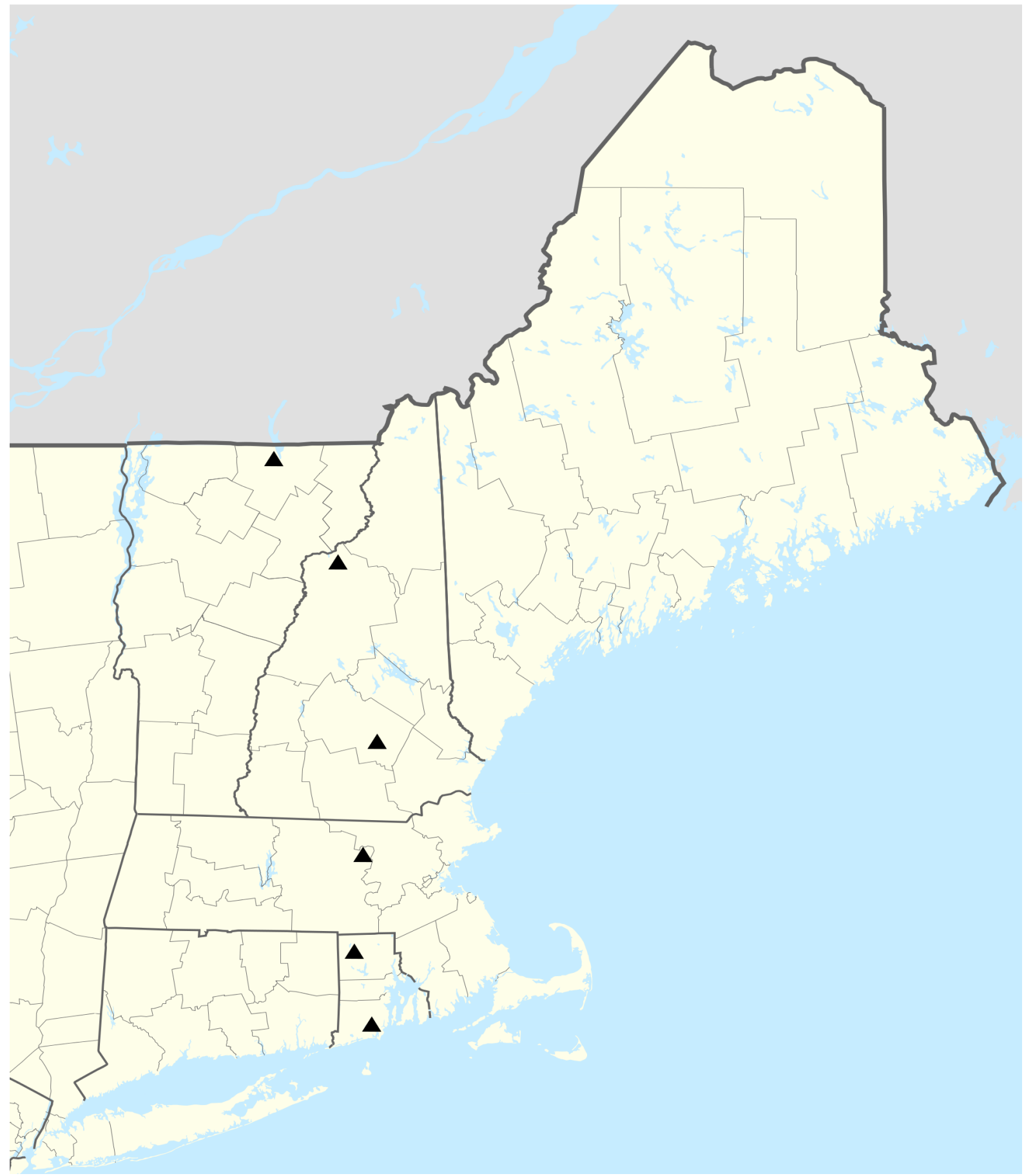

Figure 1: Geographic distribution of field sites in the northeastern United States where surveys were conducted to determine the prevalence of cucumber mosaic virus (CMV) in and away from agricultural areas. Symbols portray the approximate location of both field sites. Each triangle represents two sites: one near a crop field and one isolated from agriculture. Base map was obtained from Wikimedia Commons (2010). 
"IN VITRO CLONAL PLANTLET INDUCTION OF ASCLEPIAS SYRIACA THROUGH CALLUS TISSUE."

BY

Courtney Devoid ${ }^{1}$

Master of Science Candidate, Department of Plant Science and Entomology,

University of Rhode Island, Kingston, R.I. Email: cdevoid@uri.edu 


\title{
CHAPTER 5
}

\section{IN VITRO CLONAL PLANTLET INDUCTION OF ASCLEPIAS SYRIACA THROUGH CALLUS TISSUE.}

\begin{abstract}
Common milkweed (Asclepias syriaca L.) has a high level of genetic variation, due to outcrossing, complex pollination methods, and incompatibility in selfpollination. Research on A. syriaca can therefore be difficult and time consuming, but substantial effort is currently being made to study this plant, due to is importance to the monarch butterfly (Danaus plexippus L.). Different hormone formulations have been investigated to produce $A$. syriaca plantlets in vitro, in order to reduce genetic variation in research efforts. Cultures were established on Murashige and Skoog media, using various concentrations of phytohormones. For callus induction, $10 \mu \mathrm{M}$ $\mathrm{BAP}+5 \mu \mathrm{M}$ NAA produced profuse callus. Shoot proliferation was obtained on media containing $1.25 \mu \mathrm{M} \mathrm{BAP}+5 \mu \mathrm{M} \mathrm{NAA}$, and root production occurred on media with $1.25 \mu \mathrm{M}$ BAP and $2.5 \mu \mathrm{M}$ NAA. These combinations resulted in large amounts of callus production that could be subdivided to produce shoots and roots, for propagating genetically identical plantlets to assist current research efforts.

\section{Introduction}

Common milkweed (Asclepias syriaca L.) is a perennial plant that has been heavily researched due to its relationship with the monarch butterfly (Danaus plexippus L.). Monarch butterfly populations have been in decline for the past two decades, which has been attributed to reduced milkweed populations (Pleasents and Oberhauser 2012). As such, research on A. syriaca has become vital to prevent the extinction of monarch butterflies (Couture et al. 2015). Due to its complex pollination 
methods, $A$. syriaca is self-incompatible, making individual populations genetically diverse. Self-incompatibility, coupled with very low levels of fruit set (1-5\%), and long periods before plants are reproductively mature ( 2 years), makes $A$. syriaca a difficult and time consuming for carrying out experiments designed to assess breeding systems (Wyatt and Broyles 1994). Our goal is to propagate genetically identical clones in vitro, in order to remove genetic variation from experiments on $A$. syriaca. By determining hormone concentrations that will quickly produce genetically identical clones from stem explants, $A$. syriaca can be efficiently propagated for research use.

Previous attempts to propagate $A$. syriaca in tissue culture have had limited success (Tideman and Hawker 1982, Rosu et al. 2011). Members of the Asclepias genus are latex producing plants that contains low molecular weight hydrocarbons, therefore the focus of previous work has been using tissue culture for rapid vegetative production for use in cropping trials (Tideman and Hawker 1982). The success so far has been to produce plantlets from either embryoids or axillary shoot buds. Wilson and Mahlberg (1977) produced shoots in culture in order to observe the presence of laticifer systems. Shoots were produced of superficial origin on the callus; however, root initiation had little success. To obtain shoots, Wilson and Mahlberg (1977) cultured whole embryos to produce sterile plants, from which explants were excised to produce callus. Callus tissue was grown for five months before embryoids formed. These methods are not ideal, as they require a substantial time investment, sterile plant parent material, and resulted in little root formation. Additionally, whole embryoids were used, which are difficult to obtain. Based on this initial work, our goal is to 
develop the optimum sterilization methods and hormone concentrations so that $A$. syriaca plantlets can be produced quickly using stem explants.

In addition to Wilson and Mahlberg (1977), methods using nodal explants with axillary buds have been explored by Rosu at al. (2011) in an attempt to produce $A$. syriaca in culture. Shoot proliferation was achieved, with a main shoot developing from the initial bud, and multiple shoots and buds subsequently developing. Rosu et al. (2011) found that a high concentration of benzylaminopurine (BAP) was the most successful hormone to initiate numerous shoots. The development of roots was again achieved in a small proportion, and Rosu et al. (2011) concluded that additional testing was required to determine optimum formulations for in vitro rhizogenesis. With this in mind, an additional objective of this study is to use callus to develop high volumes of shoots, more than could be obtained with axillary buds, and to determine optimum hormone concentrations so that a large proportion of shoots will develop roots.

Latex producing plants have been shown to be difficult to produce in tissue culture. Our work will build on previous studies to produce genetically identical clones, which will reduce variability in research on this species. Optimization of hormone formulations will allow A. syriaca to be produced efficiently in tissue culture.

\section{Methods}

Explant source: experiments were conducted using explant sources grown in Plant Growth Chambers (Conviron, model: CMP6050; Manitoba, Canada) set to $25: 18^{\circ} \mathrm{C}$ day/night temperature. Seeds were subject to cold, moist stratification, and then germinated in $10 \times 15 \mathrm{~cm}$ trays using a greenhouse MetroMix potting medium 
\#830 (SunGrow; Agawam, Massachusetts). Seedlings were repotted as necessary in the same potting mix. Plants were fertilized weekly using Peter's 20-10-20 Peatlite Special Fertilizer (JR Peters Inc; Allentown, Pennsylvania), which contained 230 PPM nitrogen. Plants were sprayed bi-monthly with a combination of insecticides to prevent insect infestation.

Explant types: $1 \mathrm{~cm}$ nodal and internodal segments were excised from the top half of each plant. Any explants where woody fibers had developed were discarded.

Surface sterilization: Excised explants were placed in 10\% bleach solution with three drops of Tween and stirred for 15 minutes on a medium setting, to ensure all surfaces were sterilized. Explants were rinsed 3 times (5 minutes each), using sterile distilled water. Surface sterilization, implantation, and subsequent transfers were carried out aseptically in a laminar flow hood.

Culture Media: Explants were placed on media containing full or half strength Murashige and Skoog media (including vitamins) supplemented with $2 \%$ sucrose, solidified with $7 \mathrm{~g} / \mathrm{l}$ agar, and varying concentrations of BAP and naphthaleneacetic acid (NAA) (Murashige and Skoog 1962). Prior to autoclaving, $\mathrm{pH}$ was adjusted to 5.7-5.8. Flasks were autoclaved for 20 minutes at $121{ }^{\circ} \mathrm{C}$. Hormone concentrations were added after autoclaving, when media had cooled. Stock solutions $(10 \mathrm{ml})$ of hormones were prepared using sterile water, $0.01 \mathrm{~g}$ BAP or NAA, and a dissolving agent ( $0.5 \mathrm{ml}$ Potassium Chloride for BAP and $1.0 \mathrm{ml}$ Ethanol for NAA). Solutions were sterilized using $0.22 \mu \mathrm{m}$ pore size nylon syringe filters (CELLTREAT Scientific Products, product code: 229761; Pepperell, Massachusetts). Hormones were added after autoclaving to avoid heat destabilization. 
Culture Establishment: surface sterilized explants were cultured on solid media containing various concentrations of BAP and NAA. Media was placed in $100 \times 25$ $\mathrm{mm}$ Petri plates that contained $65 \mathrm{ml}$ of sterile autoclaved culture media. Plates were incubated in an incubator (Percival Scientific, model: 136LL; Perry, Iowa) at $27^{\circ} \mathrm{C}$ with a 16-hour photoperiod. Transfers were made onto fresh media at approximately three-week intervals.

\section{Results}

Callus tissue grew quickly and easily on several media variants (Table 1). Nodal segments produced the most callus on media with a combination of $10 \mu \mathrm{M}$ BAP $+5 \mu \mathrm{M}$ NAA (Figure 1). A combination of both BAP and NAA was required to obtain profuse callus production. Media with only BAP produced some callus, but at a slower rate and with higher levels of tissue die off. The addition of NAA kept the tissue healthy and alive longer than variants with BAP alone.

A comparison was made between node and internode explants. Axillary buds on nodal explants were removed to avoid shoot proliferation and increase callus production. Internodes were found to produce small amounts of callus and at a slower rate than nodal explants in all media combinations. Several plates also had internode explants that died before producing callus. Based on this result, nodal explants were used for shoot and root morphogenesis.

On several occasions, there were explants where axillary buds were insufficiently removed. These produced stems; however, callus formed in much smaller quantities than nodes without axillary buds. Only one main shoot grew from the axillary bud and shoot proliferation did not occur (Figure 2). 
Explants placed on media with $10 \mu \mathrm{M}$ BAP $+2.5 \mu \mathrm{M}$ NAA produced shoots. Several plates with $10 \mu \mathrm{M}$ BAP also produced roots, in addition to shoots. Previous work showed that high levels of BAP resulted in shoot proliferation with axillary bud explants (Rosu et al. 2011); however, we found that low levels of BAP and NAA resulted in profuse shoot proliferation. High levels of either phytohormone resulted in gradual die off of callus tissue. A combination of low levels of both BAP and NAA was required to keep callus tissue healthy, which then allowed shoots to form. After multiple combinations of root and shoot formulations, we found $1.25 \mu \mathrm{M} \mathrm{BAP}+5$ NAA produced the highest level of shoot proliferation (Figure 3).

In one instance, flowers were produced on shoot induction media. This was a surprising occurrence, but shows that this media combination was successful for producing viable plantlets (Figure 4).

Roots were formed most successfully on media containing $1.25 \mu \mathrm{M} \mathrm{BAP}+2.5$ $\mu \mathrm{M}$ NAA (Figure 5). Roots continued to grow and multiple shoots formed from the original shoot. The juncture between root and shoot was found to be extremely friable, making transfer out of culture difficult. It is recommended that transfers be made as soon as roots are formed, to reduce breakage.

Callus tissue was continually transferred to new media and kept viable for many months. After approximately 8 months, root and shoot tissue both began forming on callus indication media. This shows that, over time, viable plantlets will differentiate on $10 \mu \mathrm{M}$ BAP $+5 \mu \mathrm{M}$ NAA media due to the age of the callus tissue.

We recommend a combination of media formulations for plantlet formation. Callus induction was most prolific on media containing $10 \mu \mathrm{M}$ BAP $+5 \mu \mathrm{M}$ NAA. 
Following callus induction, media containing $1.25 \mu \mathrm{M}$ BAP $+5 \mu \mathrm{M}$ NAA produced prolific shoots, and media containing $1.25 \mu \mathrm{M} \mathrm{BAP}+2.5 \mu \mathrm{M}$ NAA produced roots.

\section{Discussion}

Hormone formulations for producing callus, shoots, and roots were determined in this study. The goal of this work was to establish morphogenic cultures from somatic explants, in order to produce genetically identical clones to reduce variation in research. A. syriaca plantlets were successfully developed in vitro; however, attempts were not made to transfer the plantlets out of culture. Data for $A$. syriaca production in vitro are limited, due to the difficulty of establishing latex-producing plants in culture (Wilson and Mahlberg 1977, Rosu et al. 2011). In addition to the previous work on $A$. syriaca, this discussion will compare our findings to studies that examined Asclepias rotundifolia (Mill.) and Asclepias curassavica (L.), which have been studied more frequently due to the medicinal properties of these species.

Our study concluded that explants originating from nodal tissue produced more callus than internodes. This finding is in agreement with Tideman and Hawker (1982), who studied the development of callus and shoots from stem internode and node explants in A. rotundifolia. For several concentrations tested on A. syriaca, callus was produced from nodal tissue, whereas no development occurred for internodes (Figure 1). In addition, Tideman and Hawker (1982) found the same formulation of hormones produced profuse callus (10 $\mu \mathrm{M} \mathrm{BAP}+5 \mu \mathrm{M}$ NAA) for A. rotundifolia as this study concluded was best for $A$. syriaca. For $A$. rotundifolia, the optimal combination resulted in profuse callus production for nodal tissue and moderate production for 
internodes; further demonstrating that nodal explants should be used for efficient callus production (Tideman and Hawker 1982).

BAP was the chosen cytokinin and NAA the chosen auxin for promoting morphogenesis in this study. Multiple studies have been done within the Asclepias genesis on what hormones should be used. Rosu at al. (2011) found all tested cytokinins stimulated the elongation of the main shoot, but BAP and TDZ (Thidiazuron) resulted in the most morphogenesis, compared to KN (Kinetin) and 2-ip (isopentenyl adenine). Reddy et al. (2013) support this finding for $A$. curassavica: BAP was shown to be better than $\mathrm{KN}$ for improving shoot number and shoot length, while Pramanik and Datta (1985) found BAP and KN to be equally effective for shoot initiation. For rhizogenesis, Pramanik and Datta (1986) found IAA and NAA were both successful at root induction in A. curassavica and that a combination of $\mathrm{KN}$ and NAA induced both roots and shoots after 30 days of culture. The chosen hormones in this study were use based on this previous work, as it is well established that both BAP and NAA promote morphogenesis effectively for the Asclepias genus.

We concluded that low levels of BAP resulted in more prolific shoot establishment than higher concentrations. This finding contrasts Rosu et al. (2011), who found that high concentrations of BAP produced more shoots $(3-5 \mathrm{mg} / \mathrm{l})$. We found that high levels resulted in callus die off and no shoot proliferation. The differences can be attributed to explant sources, as Rosu et al. (2011) used explants with adventitious buds where shoots would be much more prone to grow quickly from the existing meristem, whereas callus tissue would need to differentiate. 
A combination of auxin and cytokinins proved to be most effective when producing plantlets from callus tissue. The use of both phytohormones for in vitro propagation is consistent the literature. Pramanik and Datta (1986) found Kn + NAA from nodal explants was the most effective in inducing a high percentage of regenerates for A. curassavica. Interestingly, the combination of BAP + NAA was unsatisfactory for mass propagation for A. curassavica. Other studies, however, showed this combination to be optimal. Reddy et al. (2012) found maximum proliferation was obtained with a BAP + NAA combination for A. curassavica. Shoot number was found to occur in BAP containing media in combination with NAA, more than BAP alone, resulting in $82 \%$ shoot regeneration capacity (Reddy et al. 2013).

Callus size was found to be substantially smaller for nodal segments where axillary buds had not been removed. This is an important finding, given that one of the few other studies that examined $A$. syriaca propagation in vitro used axillary buds attached to nodes (Rosu et al. 2011). If the goal is to propagate a large numbers of shoots, anything that reduces callus production will result in less callus available for shoot proliferation. The methods of using axillary buds to produce shoots is likely much faster than growing shoots from callus, given that a meristem is already present. In future work, a comparison between these two types of explants should be conducted to determine differences in the rate of shoot proliferation.

The conclusions from this study have prompted several avenues for future work. The age of the tissue being studied was one issue that we came across. Callus tissue that had been continuously growing for long periods of time spontaneously produced roots and shoots. Wilson and Mahlberg (1977) successfully produced shoots 
in their paper; however, the tissue had been growing for a long period of time (up to a year). This calls into question whether their shoot production from callus was due to the age of the tissue, the hormones added, or some combination. Given that efficient propagation is important for research purposes, a study should be conducted to determine the role of time in these methods. If methods take months to develop, they will be ineffective for propagators seeking to quickly produce large volumes of plantlets.

By developing these formulations, we have found combinations that produce callus, shoot, and root morphogenesis. We have developed methods for producing genetically identical clones, to reduce variability in experimentation. Numerous research efforts on A. syriaca have been conducted for decades; therefore hopefully this information can be used to aid future efforts. 


\section{Literature Cited:}

Couture, J. J., S. P. Serbin, and P. A. Townsend. 2015. Elevated temperature and periodic water stress alter growth and quality of common milkweed (Asclepias syriaca) and monarch (Danaus plexippus) larval performance. Arthropod-Plant Interactions 9:149-161.

Murashige, T., and F. Skoog. 1962. A revised medium for rapid growth and bio assays with tobacco tissue cultures. Physiologia Plantarum 15:473-497.

Pleasents, J. M., and K. S. Oberhauser. 2012. Milkweed loss in agricultural fields because of herbicide use: effect on the monarch butterfly population. Insect Conservation and Diversity 6:135-144.

Pramanik, T. K., and S. K. Datta. 1986. Plant regeneration and ploidy variation in culture derived plants of Asclepias curcasavica L. Plant Cell Reports 3:219-222.

Reddy, S. H., M. Chakravarthi, and K. N. Chandrashekara. 2013. Effect of MS and L2 medium on callusing and regeneration from nodal explants of Asclepias curassavica ( L ). 3:294-301.

Rosu, A., S. Danaila-Guidea, R. Dobrinoiu, F. Toma, D. T. Rosu, N. Sava, and C. Manolache. 2011. Asclepias syriaca L . - an underexploited industrial crop for energy and chemical feedstock. Romanian Biotechnological Letters 16:131-138.

Tideman, J., and J. S. Hawker. 1982. In vitro propagation of latex-producing plants. Annals of Applied Biology 49:273-279.

Wilson, K. J., and P. G. Mahlberg. 1977. Investigations of laticifer differentation in tissue cultures derived from Asclepias syriaca L. Annals of Botany 41:10491054. 
Wyatt, R., and S. B. Broyles. 1994. Ecology and evolution of reproduction in milkweeds. Annual Review of Ecology and Systematics 25:423-441. 
Table 1: The development of callus from stem node and internode explants of Asclepias syriaca on nine different media combinations.

\begin{tabular}{lcc}
\hline & Nodes & Internodes \\
\hline $\mathrm{MS}+2.5 \mu \mathrm{m}$ BAP & $\mathrm{x}$ & - \\
$\mathrm{MS}+5 \mu \mathrm{m} \mathrm{BAP}$ & $\mathrm{x}$ & - \\
$\mathrm{MS}+10 \mu \mathrm{m} \mathrm{BAP}$ & $\mathrm{x}$ & - \\
$\mathrm{MS}+10 \mu \mathrm{m} \mathrm{BAP}+2.5 \mu \mathrm{m} \mathrm{NAA}$ & $\bullet$ & $\bullet$ \\
$\mathrm{MS}+10 \mu \mathrm{m} \mathrm{BAP}+5 \mu \mathrm{m} \mathrm{NA}$ & + & + \\
$1 / 2 \mathrm{MS}+2.5 \mu \mathrm{m} \mathrm{BAP}$ & - & $\mathrm{x}$ \\
$1 / 2 \mathrm{MS}+5 \mu \mathrm{m} \mathrm{BAP}$ & $\bullet$ & - \\
$1 / 2 \mathrm{MS}+10 \mu \mathrm{m}$ BAP $+2.5 \mu \mathrm{m}$ NAA & $\bullet$ & + \\
$1 / 2 \mathrm{MS}+10 \mu \mathrm{m} \mathrm{BAP}+5 \mu \mathrm{m}$ NAA & + & + \\
\hline
\end{tabular}

+ , profuse callus; $\bullet$ callus; - , limited development; $x$, tissue die-off or contamination

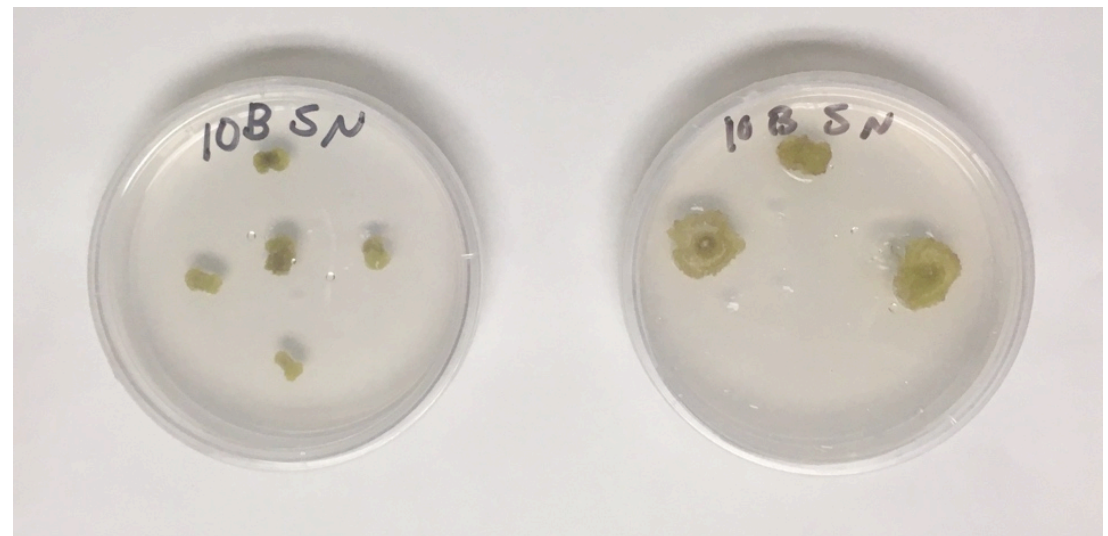

Figure 1: Developing callus tissue at two different stages. The left plate has been growing for 3 weeks, while the right plate has been growing for 6 weeks. Callus development occurred most quickly on media containing $10 \mu \mathrm{M}$ BAP $+5 \mu \mathrm{M}$ NAA.

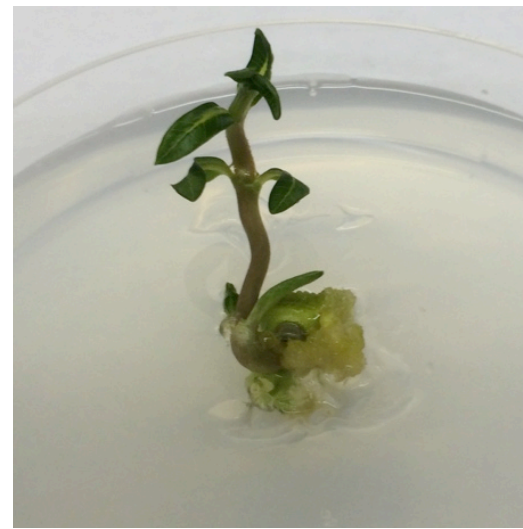

Figure 2: Shoot formation from an axillary bud on a nodal explant. Callus formation was substantially reduced. 

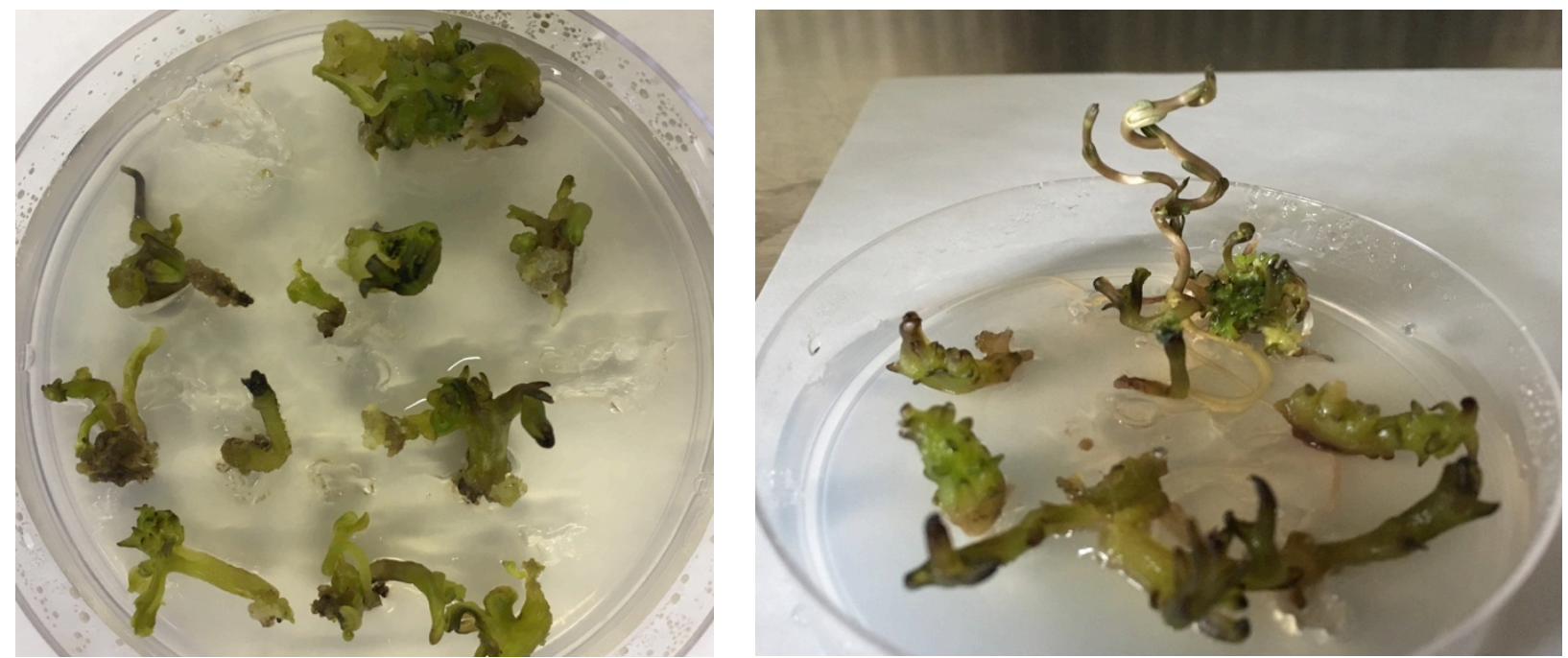

Figure 3: Shoot formation from callus tissue. Photos depict multiple shoots proliferating from one piece of callus.

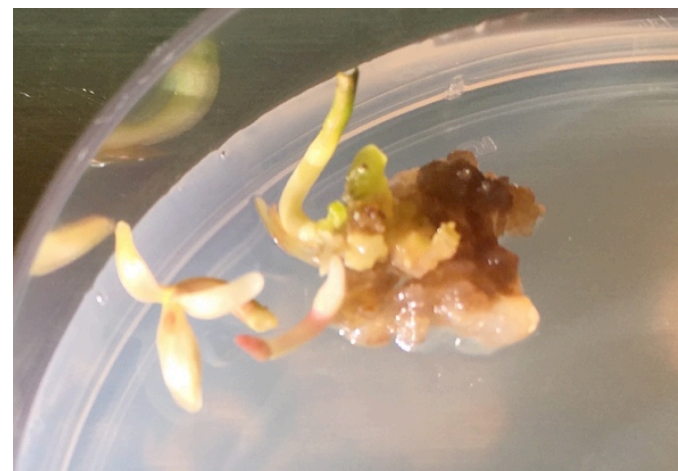

Figure 4: Flower produced on shoot induction media. 

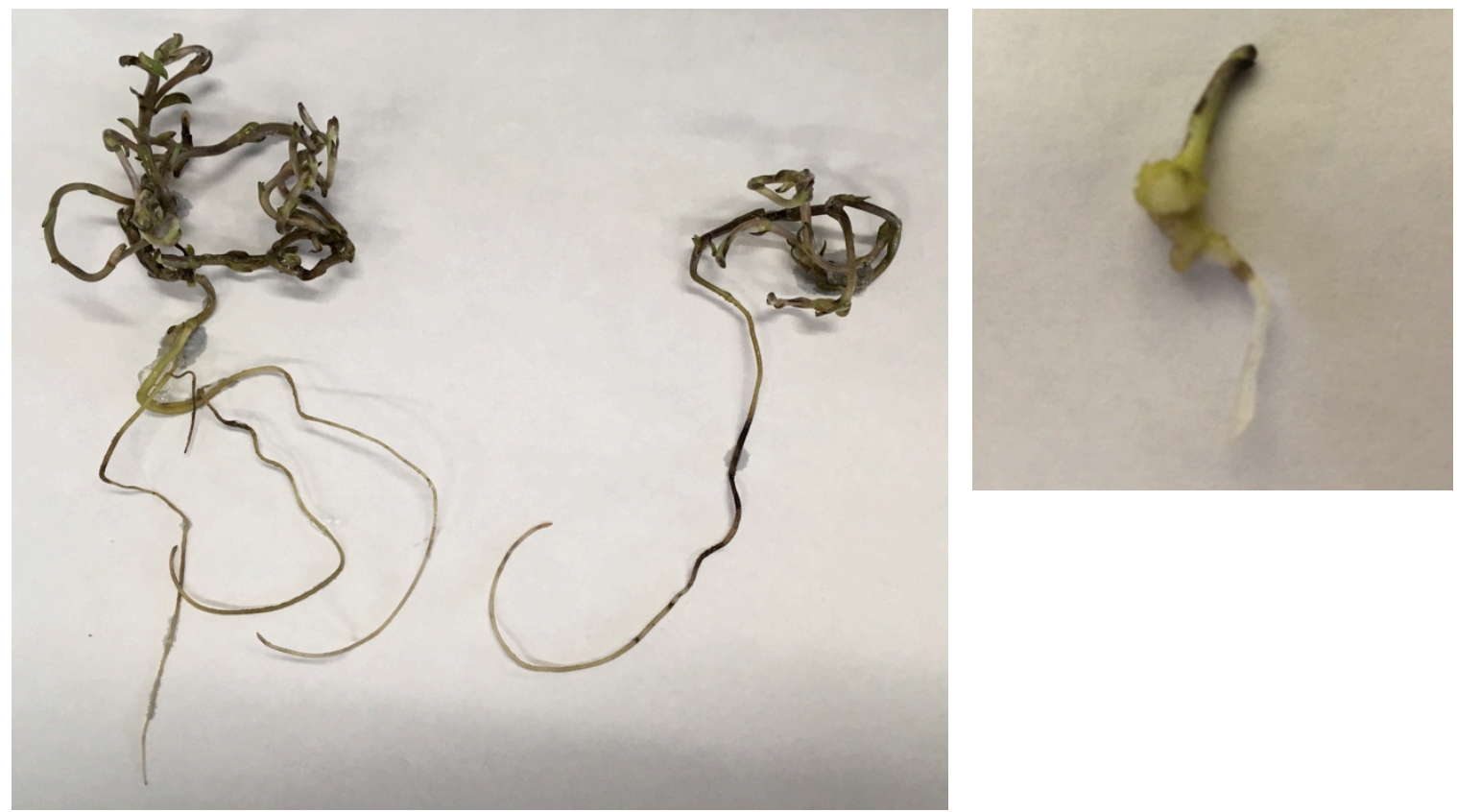

Figure 5: Shoots with attached root systems. The attachment point between roots and shoots was extremely fragile. Plants were transferred to media without any hormones, where roots grew profusely. 


\section{CHAPTER 5}

\section{CONCLUSION}

Common milkweed demonstrated a mixed response to elevated temperature conditions. Several variables, including root biomass, stem diameter, and leaf area, showed a marked decrease at a higher temperature. Number of nodes increased with temperature, and all other variables did not have a consistent response across trials. Strong trends were observed in response to water treatments. Plants experiencing drought conditions were smaller than plants in the control or excess water treatment groups. Plants given excess water were generally larger than control groups. These findings indicate that climate change induced drought will likely decrease the growth of wild $A$. syriaca populations, but excess precipitation events are unlikely to cause substantial changes. Soil salinity studies found that $A$. syriaca growth is decreased at high salt levels; however, the lowest levels demonstrated no difference from the control. This indicates that common milkweed is a moderately salt tolerant plant and therefore should not be impacted by moderate salinization of its growing habitat.

Our virus survey found extremely low levels of CMV infection $(2.5 \%)$ on wild common milkweed populations. Further, the seed transmission study found that CMV is not transmitted on $A$. syriaca seeds. These results are important for both growers and conservation efforts, as milkweeds in agricultural areas pose a low risk of spreading CMV infection to crops. We also identified challenges associated with the testing methods for CMV. A. syriaca tissue likely has a host reaction to Immunostrip 
and/or the ELISA testing methods. Growers should therefore be cautious when interpreting results from these tests.

Callus, shoots, and roots were all successfully obtained in vitro, in an effort to produce A. syriaca in tissue culture. Callus induction was obtained on Murashige and Skoog media containing $10 \mu \mathrm{M}$ BAP $+5 \mu \mathrm{M}$ NAA; shoot proliferation was obtained on media containing $1.25 \mu \mathrm{M}$ BAP $+5 \mu \mathrm{M} \mathrm{NAA}$; and root production occurred on media with $1.25 \mu \mathrm{M}$ BAP and $2.5 \mu \mathrm{M}$ NAA. These combinations of phytohormones can be used propagate $A$. syriaca as genetically identical clones to be used for future research efforts.

In general, this work gives a positive picture for the future of common milkweed in the northeast. It has demonstrated that climactic changes do not pose significant risk to milkweed populations, although decreased growth rates may occur. We also showed that this plant could withstand moderate salt levels, which means that its habitats along roadsides will not threaten the species. Further, the low levels of CMV infection mean that wild populations growing along agricultural fields will not pose a significant risk. Conservation work should continue in an effort to increase common milkweed populations. 


\section{APPENDICES}

\section{Appendix A:}

Tables 1 - 3: Total change in response variables for the climate change study for each trial. Degrees of freedom and mean squared error are shown for height $(\mathrm{cm})$, diameter $(\mathrm{mm})$, nodes, leaves, leaf:node ratio, and leaf area $(\mathrm{cm})$ for four Asclepias syriaca populations growing in two mean temperatures $\left(25^{\circ} \mathrm{C}\right.$ and $\left.30^{\circ} \mathrm{C}\right)$ and three water conditions $(10 \%, 20 \%$, and $30 \%$ soil moisture $(\mathrm{g} / \mathrm{g}))$.

Trial 1:

\begin{tabular}{|c|c|c|c|c|c|c|c|}
\hline Sources of variance & df & Height & Diameter & Nodes & Leaves & Leaf:node Ratio & Leaf Area \\
\hline Temperature & 1 & $558 \bullet$ & $6.921 * * *$ & $37.01 *$ & $207.84 * * *$ & $0.743 * * *$ & $28940 * * *$ \\
\hline Water & 2 & $3617 * * *$ & $12.373 * * *$ & $20.06 \ldots$ & $71.95 * *$ & 0.040 & $18258 * * *$ \\
\hline Population & 3 & 211 & $1.924 * *$ & $257.69 * * *$ & $125.76 * * *$ & 0.009 & $5447 * * *$ \\
\hline Temperature $\mathrm{x}$ water & 2 & 73 & 0.342 & 4.54 & 9.41 & 0.009 & 527 \\
\hline $\begin{array}{l}\text { Temperature } \mathrm{x} \\
\text { Population }\end{array}$ & 3 & 317 & $1.222 *$ & 5.44 & 6.05 & 0.003 & 843 \\
\hline Water $x$ Population & 6 & 90 & 0.315 & $20.47 *$ & $30.81 \bullet$ & $0.081 *$ & $1026 *$ \\
\hline $\begin{array}{l}\text { Temperature } \mathrm{x} \\
\text { Population } \mathrm{x} \text { Water }\end{array}$ & 6 & 128 & 0.157 & 4.93 & 24.34 & $0.075 *$ & 270 \\
\hline Error & 120 & 143 & 0.453 & 9.13 & 16.89 & 0.029 & 421 \\
\hline
\end{tabular}

Trial 2:

\begin{tabular}{|c|c|c|c|c|c|c|c|}
\hline Sources of variance & df & Height & Diameter & Nodes & Leaves & Leaf:node Ratio & Leaf Area \\
\hline Temperature & 1 & $3809 * * *$ & $2.475 *$ & $357.8 * * *$ & 4.7 & 0.063 & $10236 * * *$ \\
\hline Water & 2 & $607^{* * *}$ & $7.182 * * *$ & $68.7^{* * *}$ & $574.1 * * *$ & $0.491 \bullet$ & $16660 * * *$ \\
\hline Population & 3 & $1003 * * *$ & $2.274 * *$ & $51.5^{* *}$ & 98.8 & 0.156 & 2267 \\
\hline Temperature $\mathrm{x}$ water & 2 & 8 & $1.526 *$ & 10.1 & 16.9 & 0.072 & 1438 \\
\hline $\begin{array}{l}\text { Temperature } \mathrm{x} \\
\text { Population }\end{array}$ & 3 & 203 & 0.139 & 12.8 & 44.4 & 0.185 & 241 \\
\hline Water x Population & 6 & 61 & 0.332 & 9.7 & 55.2 & 0.146 & 1149 \\
\hline $\begin{array}{l}\text { Temperature } \mathrm{x} \\
\text { Population } \mathrm{x} \text { Water }\end{array}$ & 6 & 113 & 0.49 & 3.9 & 87.6 & 0.241 & 688 \\
\hline Error & 120 & 89 & 0.402 & 9.8 & 87.9 & 0.203 & 746 \\
\hline
\end{tabular}

Trial 3:

\begin{tabular}{llllllll}
\hline Sources of variance & df & Height & Diameter & Nodes & Leaves & Leaf:node Ratio & Leaf Area \\
\hline Temperature & 1 & $364.5^{*}$ & 1.542 & $88.67 * *$ & 0.2 & 0.0132 & $3452 *$ \\
Water & 2 & $542.6^{* * *}$ & $8.695^{* * *}$ & $121.98^{* * *}$ & $351.3 * * *$ & $0.611^{* * *}$ & $10445^{* * *}$ \\
$\begin{array}{l}\text { Population } \\
\text { Temperature x water }\end{array}$ & 3 & 62.7 & $1.793 *$ & 9.02 & 13.6 & 0.0613 & 804 \\
$\begin{array}{l}\text { Temperature x } \\
\text { Population }\end{array}$ & 3 & 139.8 & 0.289 & 4.79 & 8.2 & 0.0096 & 93 \\
$\begin{array}{l}\text { Water x Population } \\
\text { Temperature x }\end{array}$ & 6 & 44.9 & 0.584 & 1.85 & 3.9 & 0.0177 & 767 \\
$\begin{array}{l}\text { Population x Water } \\
\text { Error }\end{array}$ & 6 & 51.4 & 0.605 & 7.98 & 24.1 & 0.0619 & 704 \\
\hline
\end{tabular}


Table 4-6: Total change in response variables for the climate change study for each trial. Degrees of freedom and mean squared error are shown for stem, root, and total dry plant biomass, as well as the wet:dry biomass ratio for stems, roots, and total plant volume. Plants were grown from four Asclepias syriaca populations in two mean temperatures $\left(25^{\circ} \mathrm{C}\right.$ and $\left.30^{\circ} \mathrm{C}\right)$ and three water conditions $(10 \%, 20 \%$, and $30 \%$ soil moisture $(\mathrm{g} / \mathrm{g}))$.

Trial 1:

\begin{tabular}{|c|c|c|c|c|c|c|c|}
\hline Sources of variance & df & $\begin{array}{l}\text { Stem } \\
\text { Biomass }\end{array}$ & $\begin{array}{l}\text { Root } \\
\text { Biomass } \\
\end{array}$ & $\begin{array}{l}\text { Total } \\
\text { Biomass } \\
\end{array}$ & $\begin{array}{l}\text { Wet:dry } \\
\text { Stem }\end{array}$ & $\begin{array}{l}\text { Wet:dry } \\
\text { Roots }\end{array}$ & $\begin{array}{l}\text { Wet:dry } \\
\text { Total }\end{array}$ \\
\hline Temperature & 1 & $62.94 *$ & $310.05 * * *$ & $652.4 * *$ & 18.73 & 0.8256 & 0.735 \\
\hline Water & 2 & $79.58 * *$ & 41.13 & $229.6 * *$ & 10.05 & 0.8731 & 2.153 \\
\hline Population & 3 & $299.03 * * *$ & $113.97^{* *}$ & $782.1 * * *$ & 23.91 & 0.851 & 3.678 \\
\hline Temperature $\mathrm{x}$ water & 2 & 12.5 & 11.46 & 43.5 & 22.09 & 0.3422 & 4.069 \\
\hline $\begin{array}{l}\text { Temperature } \mathrm{x} \\
\text { Population }\end{array}$ & 3 & 13.95 & 25.25 & 74.3 & 29.55 & 0.146 & 5.379 \\
\hline Water x Population & 6 & 9.55 & 15.44 & 46.4 & 12.4 & 1.7739 & 2.633 \\
\hline $\begin{array}{l}\text { Temperature } \mathrm{x} \\
\text { Population } \mathrm{x} \text { Water }\end{array}$ & 6 & 2.28 & 3.16 & 8.8 & 30.96 & 0.2143 & 6.664 \\
\hline Error & 120 & 15.27 & 17.2 & 58.1 & 21.88 & 1.6851 & 4.532 \\
\hline
\end{tabular}

Trial 2:

\begin{tabular}{|c|c|c|c|c|c|c|c|}
\hline Sources of variance & df & $\begin{array}{l}\text { Stem } \\
\text { Biomass }\end{array}$ & $\begin{array}{l}\text { Root } \\
\text { Biomass }\end{array}$ & $\begin{array}{l}\text { Total } \\
\text { Biomass }\end{array}$ & $\begin{array}{l}\text { Wet:dry } \\
\text { Stem }\end{array}$ & $\begin{array}{l}\text { Wet:dry } \\
\text { Roots }\end{array}$ & $\begin{array}{l}\text { Wet:dry } \\
\text { Total }\end{array}$ \\
\hline Temperature & 1 & 11.17 & 0.023 & 10.19 & 0.712 & 0.059 & 0.36 \\
\hline Water & 2 & $102.76 * * *$ & $6.025 *$ & $147.49 * * *$ & $20.178 * * *$ & $4.014 *$ & $\begin{array}{l}38.11 \\
* * *\end{array}$ \\
\hline Population & 3 & $30.39 * *$ & $8.759 * *$ & $70.88 * *$ & $3.047 *$ & 3.851 & 5.15 \\
\hline Temperature $\mathrm{x}$ water & 2 & 1.66 & 0.428 & 3.37 & $3.072 *$ & 0.59 & 4.66 \\
\hline $\begin{array}{l}\text { Temperature } x \\
\text { Population }\end{array}$ & 3 & 4.41 & 2.982 & 14.07 & 0.236 & 0.927 & 0.67 \\
\hline Water x Population & 6 & 7.26 & 0.788 & 9.9 & 0.411 & 0.319 & 0.37 \\
\hline $\begin{array}{l}\text { Temperature } \mathrm{x} \\
\text { Population } \mathrm{x} \text { Water }\end{array}$ & 6 & 9.95 & 3.216 & 22.86 & 0.738 & 1.808 & 3.7 \\
\hline Error & 120 & 6.19 & 1.714 • & 13 & 0.962 & 1.358 & 2.27 \\
\hline
\end{tabular}

Trial 3:

\begin{tabular}{|c|c|c|c|c|c|c|c|}
\hline Sources of variance & df & $\begin{array}{l}\text { Stem } \\
\text { Biomass }\end{array}$ & $\begin{array}{l}\text { Root } \\
\text { Biomass }\end{array}$ & $\begin{array}{l}\text { Total } \\
\text { Biomass } \\
\end{array}$ & $\begin{array}{l}\text { Wet:dry } \\
\text { Stem }\end{array}$ & $\begin{array}{l}\text { Wet:dry } \\
\text { Roots }\end{array}$ & $\begin{array}{l}\text { Wet:dry } \\
\text { Total }\end{array}$ \\
\hline Temperature & 1 & 1.09 & $21.7 * *$ & 13.08 & $19.151^{* * *}$ & 0.744 & $2.876 *$ \\
\hline Water & 2 & $45.64 * * *$ & $5.859 \ldots$ & $70.05 * * *$ & $28.954 * * *$ & 0.492 & $\begin{array}{l}9.015 \\
* * *\end{array}$ \\
\hline Population & 3 & $1.36 \mathrm{E}+00$ & 1.533 & 5.54 & 2.123 & 0.81 & 0.462 \\
\hline Temperature $\mathrm{x}$ water & 2 & 0.82 & 2.408 & 0.81 & 2.752 & 4.112 • & 0.446 \\
\hline $\begin{array}{l}\text { Temperature } \mathrm{x} \\
\text { Population }\end{array}$ & 3 & 1.21 & 0.547 & 2.29 & 1.847 & 0.825 & 0.527 \\
\hline Water x Population & 6 & 1.42 & 2.821 & 7.71 & 0.277 & 2.232 & 0.405 \\
\hline $\begin{array}{l}\text { Temperature } \mathrm{x} \\
\text { Population } \mathrm{x} \text { Water }\end{array}$ & 6 & 5.56 & 1.603 & 11.5 & 0.484 & 0.812 & 0.219 \\
\hline Error & 120 & 4.81 & 2.192 & 10.73 & 1.452 & 1.581 & 0.62 \\
\hline
\end{tabular}


Tables 7 - 9: Change over time for the climate change study by individual trials. Degrees of freedom and mean squared error are shown for height $(\mathrm{cm})$, nodes, number of leaves, and leaf:node ratio for four Asclepias syriaca populations growing over 9 time periods in two mean temperatures $\left(25^{\circ} \mathrm{C}\right.$ and $\left.30^{\circ} \mathrm{C}\right)$ and three water conditions $(10 \%, 20 \%$, and $30 \%$ soil moisture $(\mathrm{g} / \mathrm{g}))$.

Trial 1:

\begin{tabular}{llllll}
\hline Sources of variance & $\mathrm{df}$ & Height & Nodes & Leaves & Leaf:node Ratio \\
\hline Temp & 1 & $4569 * * *$ & $17.3 .$. & 8.2 & 0.0333 \\
Pop & 3 & $321^{* *}$ & $46.3^{* * *}$ & $123.7^{* * *}$ & $0.6119 * * *$ \\
Water & 2 & $8545^{* * *}$ & $512.6^{* * *}$ & $389.3^{* * *}$ & $0.0959 * *$ \\
Time & 8 & $27421^{* * *}$ & $2734.6^{* * *}$ & $465.1 * * *$ & $1.3211 * * *$ \\
Temp:Pop & 3 & $485^{* * *}$ & $16.7^{*}$ & $54.3^{* * *}$ & $0.1341 * * *$ \\
Temp:Water & 2 & $358^{* *}$ & $22.9 * *$ & 14.7 & 0.0141 \\
Pop:Water & 6 & $312^{* * *}$ & $45^{* * *}$ & $35.1 * * *$ & 0.0279 \\
Temp:Time & 8 & $222^{* *}$ & 6 & $28.2^{* * *}$ & $0.1015 * * *$ \\
Pop:Time & 24 & 44 & 3.5 & $11.5 .$. & 0.0131 \\
Water:Time & 16 & $541 * * *$ & $36.5 * * *$ & $16 * *$ & 0.0052 \\
Temp:Pop:Water & 6 & $255^{* *}$ & $18.1 * * *$ & $47.4 * * *$ & $0.0839 * * *$ \\
Temp:Pop:Time & 24 & 37 & 0.9 & 2.4 & 0.0071 \\
Temp:Water:Time & 16 & 14 & 1.5 & 2.8 & 0.0092 \\
Pop:Water:Time & 48 & 18 & 3.1 & 5 & 0.0122 \\
Temp:Pop:Water:Time & 48 & 17 & 1.1 & 3.5 & 0.0106 \\
Residuals & 1080 & 74 & 4.6 & 7.4 & 0.0161 \\
\hline
\end{tabular}

Trial 2:

\begin{tabular}{llllll}
\hline Sources of variance & $\mathrm{df}$ & Height & Nodes & Leaves & Leaf:node Ratio \\
\hline Temp & 1 & $9499^{* * *}$ & $639^{* * *}$ & $217^{* * *}$ & 0.0013 \\
Pop & 3 & $216^{*}$ & $24.4^{* *}$ & $627.6^{* * *}$ & $2.9517^{* * *}$ \\
Water & 2 & $4581^{* * *}$ & $230.8^{* * *}$ & $104.4^{* * *}$ & 0.0198 \\
Time & 8 & $16796^{* * *}$ & $3068^{* * *}$ & $323.2^{* * *}$ & $2.1191^{* * *}$ \\
Temp:Pop & 3 & 88 & $15.2^{*}$ & 5.4 & 0.0175 \\
Temp:Water & 2 & $712^{* * *}$ & 7.1 & 9.9 & 0.0667 \\
Pop:Water & 6 & $221^{* *}$ & $30.9^{* * *}$ & 21.4 & $0.0808^{*}$ \\
Temp:Time & 8 & $342^{* * *}$ & $34.5^{* * *}$ & 20 & 0.057 \\
Pop:Time & 24 & $91^{*}$ & $10.7^{* *}$ & $68.3 * * *$ & $0.0717 * *$ \\
Water:Time & 16 & $147^{* * *}$ & 7.3 & 13.8 & 0.029 \\
Temp:Pop:Water & 6 & $490^{* * *}$ & $11.8^{* *}$ & 18.3 & $0.0702 .$. \\
Temp:Pop:Time & 24 & 11 & 2.5 & 5.6 & 0.017 \\
Temp:Water:Time & 16 & 36 & 1.9 & 6 & 0.0212 \\
Pop:Water:Time & 48 & 11 & 1.5 & 8.1 & 0.0218 \\
Temp:Pop:Water:Time & 48 & 20 & 1 & 11.6 & 0.0319 \\
Residuals & 1080 & 59 & 5.2 & 14 & 0.0344 \\
\hline
\end{tabular}


Trial 3:

\begin{tabular}{llllll}
\hline Sources of variance & df & Height & Nodes & Leaves & Leaf:node Ratio \\
\hline Temp & 1 & $598^{* *}$ & $345.6^{* * *}$ & $52.6^{*}$ & 0.048 \\
Pop & 3 & $482^{* * *}$ & $166.9^{* * *}$ & $959^{* * *}$ & $3.251^{* * *}$ \\
Water & 2 & $317^{* *}$ & 14.4 & 11.6 & 0.019 \\
Time & 8 & $6321^{* * *}$ & $1379.4^{* * *}$ & $214.5^{* * *}$ & $3.029^{* * *}$ \\
Temp:Pop & 3 & $947^{* * *}$ & $25.9^{*}$ & 11.3 & 0.02 \\
Temp:Water & 2 & $178^{*}$ & 0.4 & $30.9 .$. & $0.073 .$. \\
Pop:Water & 6 & $237^{* * *}$ & $41.1^{* * *}$ & $40.4^{* *}$ & $0.081^{* *}$ \\
Temp:Time & 8 & $55^{*}$ & $17^{*}$ & 11.3 & 0.021 \\
Pop:Time & 24 & $87^{*}$ & $24.6^{* * *}$ & $64.2^{* * *}$ & $0.118 * * *$ \\
Water:Time & 16 & 7 & 1.3 & 1.4 & 0.008 \\
Temp:Pop:Water & 6 & $447^{* * *}$ & $39.6^{* * *}$ & $39.9^{* *}$ & 0.037 \\
Temp:Pop:Time & 24 & 15 & 2.9 & 6.2 & 0.018 \\
Temp:Water:Time & 16 & 6 & 1.2 & 2.7 & 0.007 \\
Pop:Water:Time & 48 & 6 & 2.3 & 5 & 0.018 \\
Temp:Pop:Water:Time & 48 & 9 & 1.8 & 4.4 & 0.011 \\
Residuals & 1080 & 55 & 8.2 & 10.9 & 0.029 \\
\hline
\end{tabular}

Tables 10 - 12: Pairwise comparisons between water treatments and total change in response variables by individual trials. Significance codes: $\mathrm{p} \leq 0.001^{\text {' } * * *}$ ', $\mathrm{p} \leq 0.01$ '**', $\mathrm{p} \leq 0.05^{\text {'*' }}, \mathrm{p} \leq 0.10^{\prime}{ }^{\prime}$ '.

\section{Trial 1:}

\begin{tabular}{|c|c|c|c|c|c|c|c|}
\hline & Height & Diameter & Nodes & Leaves & \multicolumn{2}{|c|}{ Leaf:node Ratio } & Leaf Area \\
\hline \multicolumn{8}{|l|}{ Drought- } \\
\hline Control & $-10.802 * * *$ & $-0.700 * * *$ & $-3.208 * * *$ & $-2.395 *$ & \multicolumn{2}{|l|}{-0.023} & $-18.468 * * *$ \\
\hline \multicolumn{8}{|l|}{ Excess- } \\
\hline Control & $6.370 *$ & 0.286 & $1.291 \bullet$ & 0.687 & \multicolumn{2}{|l|}{-0.024} & $20.519 * * *$ \\
\hline \multicolumn{8}{|l|}{ Excess - } \\
\hline \multirow[t]{3}{*}{ Drought } & $17.172 * * *$ & $0.986 * * *$ & $4.5 * * *$ & $3.083 * * *$ & \multicolumn{2}{|l|}{-0.001} & $38.988 * * *$ \\
\hline & Stem & Root & Total & Wet:dry & Wet:dry & Wet:dry & \\
\hline & Biomass & Biomass & Biomass & Stem & Roots & Total & \\
\hline \multicolumn{8}{|l|}{ Drought- } \\
\hline Control & $-3.127 * * *$ & $-1.979 * * *$ & $-5.106 * *$ & 1.163 & -0.118 & 0.492 & \\
\hline \multicolumn{8}{|l|}{ Excess- } \\
\hline Control & 1.806 & 1.056 & 2.862 & -0.110 & 0.147 & 0.026 & \\
\hline \multicolumn{8}{|l|}{ Excess - } \\
\hline Drought & $4.933 * * *$ & $3.035 * *$ & $7.968 * * *$ & -1.274 & 0.265 & -0.465 & \\
\hline
\end{tabular}

Trial 2:

\begin{tabular}{lllllll}
\hline & Height & Diameter & Nodes & Leaves & Leaf:node Ratio & Leaf Area \\
\hline $\begin{array}{l}\text { Drought- } \\
\text { Control } \\
\begin{array}{l}\text { Excess- } \\
\text { Control }\end{array}\end{array}$ & $-6.997^{* *}$ & -0.250 & $-1.729 *$ & -2.75 & -0.091 & -1.734 \\
$\begin{array}{l}\text { Excess - } \\
\text { Drought }\end{array}$ & 1.593 & 0.183 & 0.125 & -2.083 & -0.105 & 10.940 \\
\hline
\end{tabular}




\begin{tabular}{lllllll}
\hline & $\begin{array}{l}\text { Stem } \\
\text { Biomass }\end{array}$ & $\begin{array}{l}\text { Root } \\
\text { Biomass }\end{array}$ & $\begin{array}{l}\text { Total } \\
\text { Biomass }\end{array}$ & $\begin{array}{l}\text { Wet:dry } \\
\text { Stem }\end{array}$ & $\begin{array}{l}\text { Wet:dry } \\
\text { Roots }\end{array}$ & $\begin{array}{l}\text { Wet:dry } \\
\text { Total }\end{array}$ \\
\hline $\begin{array}{l}\text { Drought- } \\
\text { Control }\end{array}$ & -0.945 & -0.333 & -1.279 & $-0.496 *$ & 0.049 & -0.446 \\
$\begin{array}{l}\text { Excess- } \\
\text { Control }\end{array}$ & 0.635 & 0.514 & 1.15 & -0.322 & 0.513 & 0.191 \\
$\begin{array}{l}\text { Excess - } \\
\text { Drought }\end{array}$ & $1.581 * *$ & $0.848 * *$ & $2.429 * *$ & 0.174 & 0.464 & 0.637 \\
\hline
\end{tabular}

Trial 3:

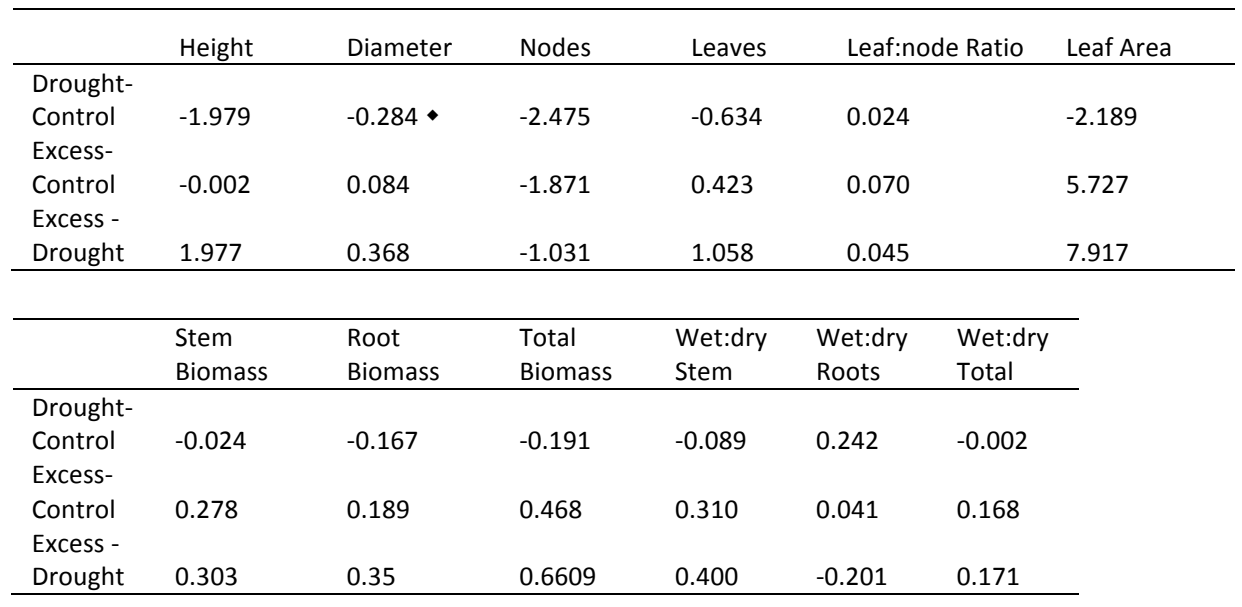

Tables 16 - 18: Pairwise comparisons between water treatments and change over time response variables by individual trials. Significance codes: $p \leq 0.001^{\prime * * *}$ ', $p \leq 0.01$ '**', $\mathrm{p} \leq 0.05^{\text {'*' }}, \mathrm{p} \leq 0.10^{\prime}{ }^{\prime}$ '.

Trial 1:

\begin{tabular}{lllll}
\hline & Height & Nodes & Leaves & Leaf:node Ratio \\
\hline $\begin{array}{l}\text { Drought- } \\
\text { Control }\end{array}$ & $-5.892 * * *$ & $-1.710 * * *$ & $-1.450 * * *$ & -0.015 \\
$\begin{array}{l}\text { Excess- } \\
\text { Control }\end{array}$ & $2.823 * * *$ & $0.489 * * *$ & $0.484^{*}$ & 0.015 \\
$\begin{array}{l}\text { Excess - } \\
\text { Drought }\end{array}$ & $8.716 * * *$ & $2.200 * * *$ & $1.934 * * *$ & $0.031 * *$ \\
\hline
\end{tabular}

Trial 2:

\begin{tabular}{|c|c|c|c|c|}
\hline & Height & Nodes & Leaves & Leaf:node Ratio \\
\hline \multicolumn{5}{|l|}{ Drought- } \\
\hline Control & $-3.778 * * *$ & $-1.192 * * *$ & $-0.902 * *$ & -0.005 \\
\hline \multicolumn{5}{|l|}{ Excess- } \\
\hline Control & $2.704 * * *$ & 0.136 & -0.113 & -0.013 \\
\hline \multicolumn{5}{|l|}{ Excess - } \\
\hline Drought & $6.483 * * *$ & $1.328 * * *$ & $0.788 * *$ & -0.008 \\
\hline
\end{tabular}

Trial 3:

\begin{tabular}{|c|c|c|c|c|}
\hline & Height & Nodes & Leaves & Leaf:node Ratio \\
\hline \multicolumn{5}{|l|}{ Drought- } \\
\hline Control & $-1.109 .$. & -0.203 & -0.231 & -0.013 \\
\hline \multicolumn{5}{|l|}{ Excess- } \\
\hline Control & 0.574 & 0.160 & 0.085 & -0.004 \\
\hline \multicolumn{5}{|l|}{ Excess - } \\
\hline Drought & $1.683 * *$ & 0.364 & 0.316 & 0.008 \\
\hline
\end{tabular}


Table 19: Change over time for soil salinity study. Degrees of freedom and mean squared error are shown for height $(\mathrm{cm})$, nodes, number of leaves, and leaf:node ratio for four Asclepias syriaca populations growing over 9 time periods and subject to four salt levels $(0,2000,6000$, and $12000 \mathrm{ppm} \mathrm{NaCl}$ solutions).

\begin{tabular}{llllll}
\hline Sources of variance & df & Height & Nodes & Leaves & $\begin{array}{l}\text { Leaf:node } \\
\text { Ratio }\end{array}$ \\
\hline Pop & 3 & $4639 * * *$ & $384.8 * * *$ & $338.7 * * *$ & 0.3187 \\
Salt & 3 & $3506 * * *$ & $198.4 * * *$ & $392.4 * * *$ & $0.5915 *$ \\
Time & 8 & $18348 * * *$ & $1566.1 * * *$ & $608.5 * * *$ & $0.605 * *$ \\
Pop:Salt & 9 & 127 & $23.6 * * *$ & $24.8 * *$ & 0.1973 \\
Pop:Time & 24 & $197 * * *$ & $14 * * *$ & $22.3 * * *$ & 0.1994 \\
Salt:Time & 24 & 107 & 6.9 & $17.2 * *$ & 0.1623 \\
Pop:Salt:Time & 72 & 13 & 1.9 & 2.2 & 0.1321 \\
Residuals & 927 & 85 & 6.2 & 8.2 & 0.2043
\end{tabular}
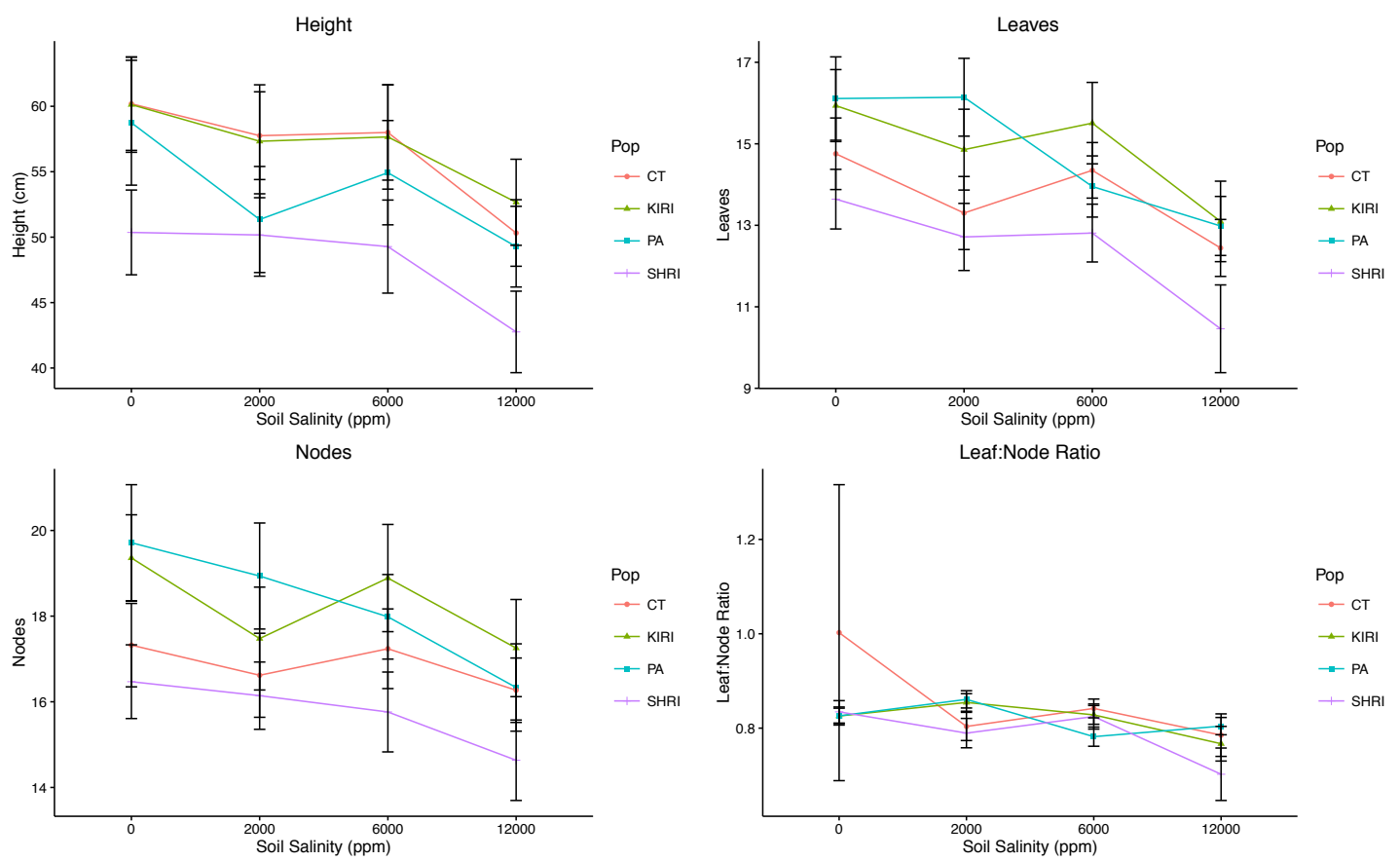

Figure 1: Population level differences for response variables at four levels of salinity. 
The following four figures show the interactions between the variables described in the figure legends. The response variables are standardized along the $\mathrm{x}$-axis for each of the three trials, which are labeled on the left in the gray bars. The y-axis is time, which is divided into nine weeklong segments. Graphs in the left column of the figure are for plants grown at $25^{\circ} \mathrm{C}$, and the right column shows plants grown at $30^{\circ} \mathrm{C}$. Plants are further divided into populations, and the black line depicts the mean.

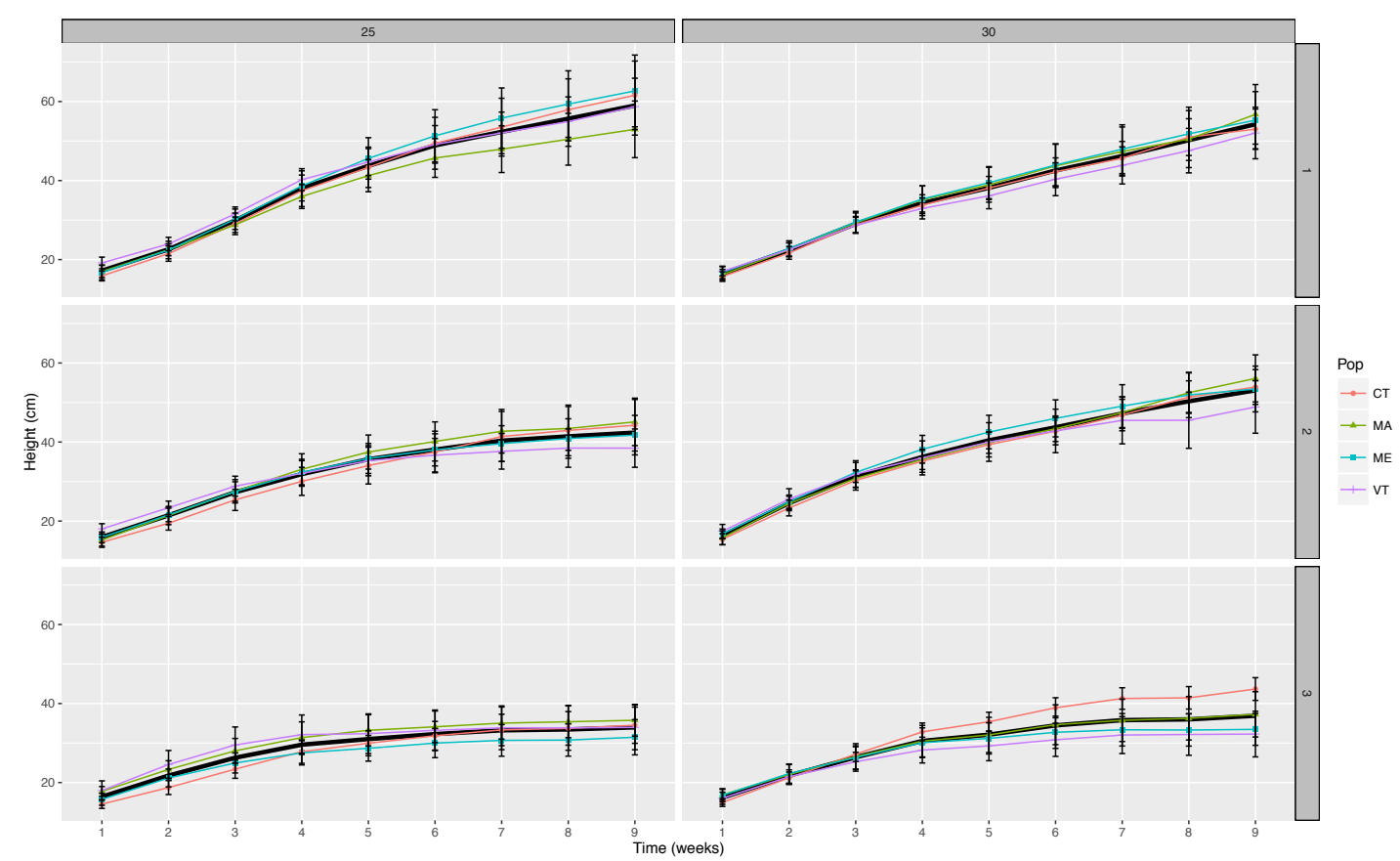

Figure 2: Height $\mathrm{x}$ Temperature $\mathrm{x}$ Population $\mathrm{x}$ Trial $\mathrm{x}$ Time.

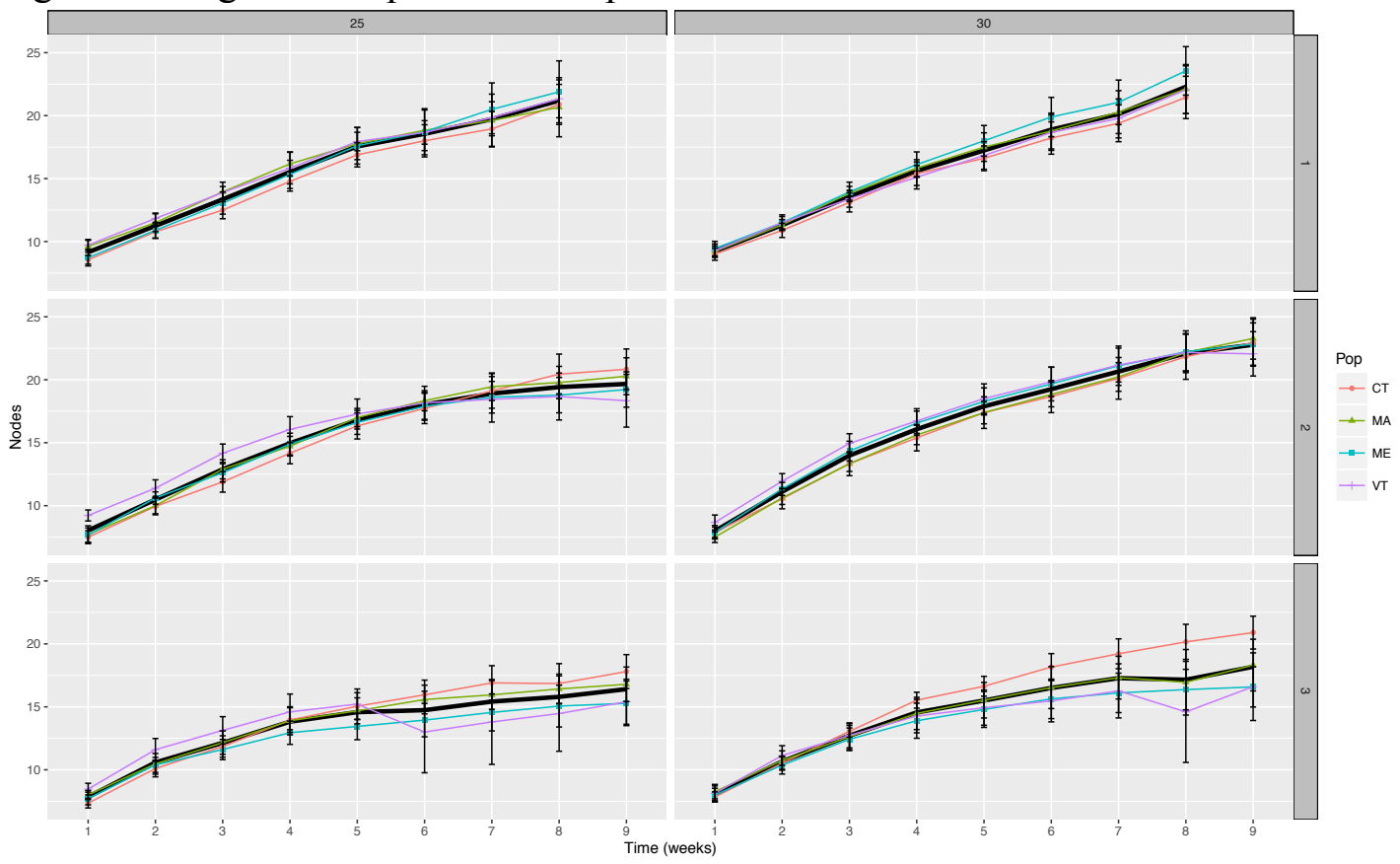

Figure 3: Nodes x Temperature x Population x Trial x Time 


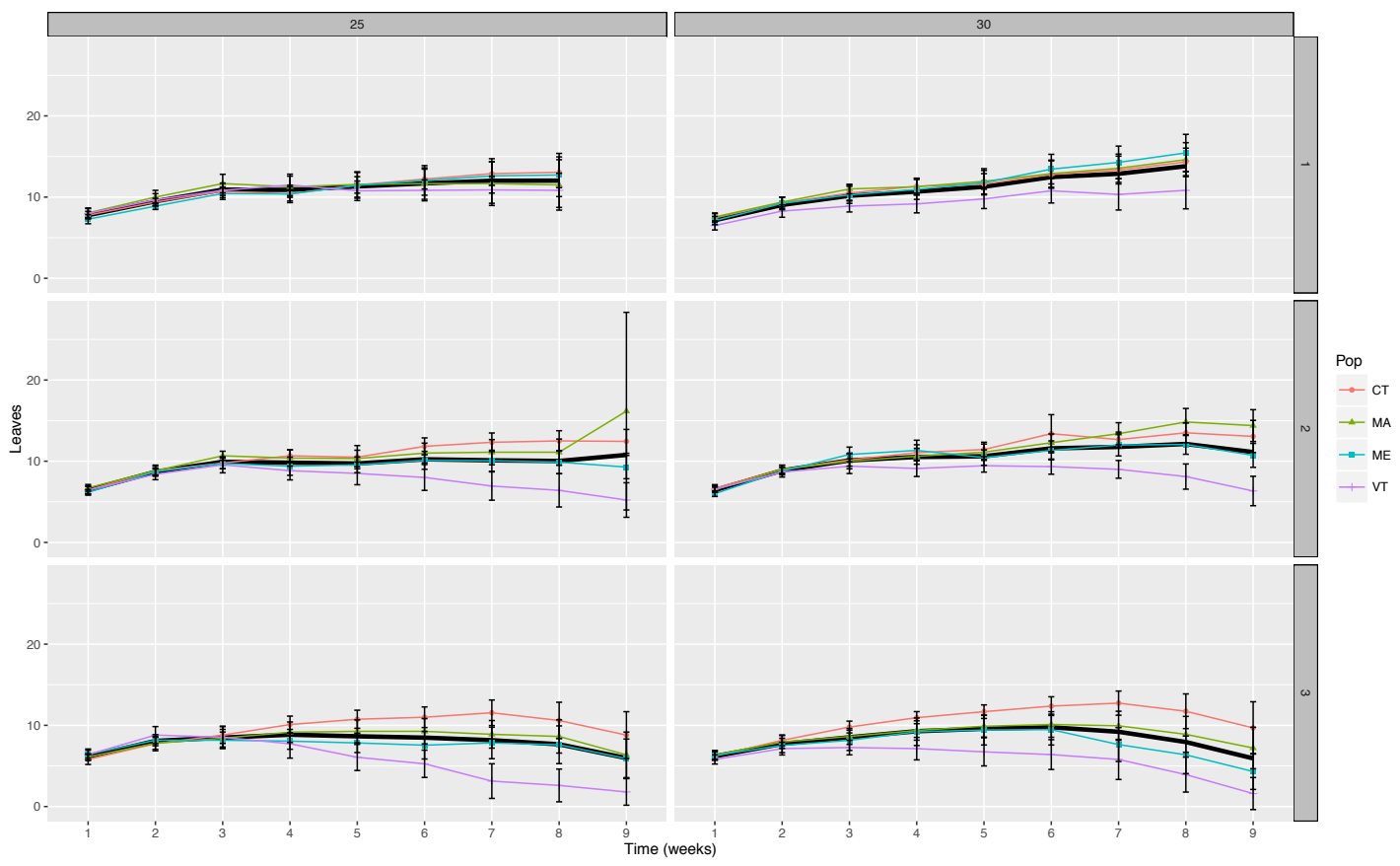

Figure 4: Leaves $\mathrm{x}$ Temperature $\mathrm{x}$ Population $\mathrm{x}$ Trial $\mathrm{x}$ Time

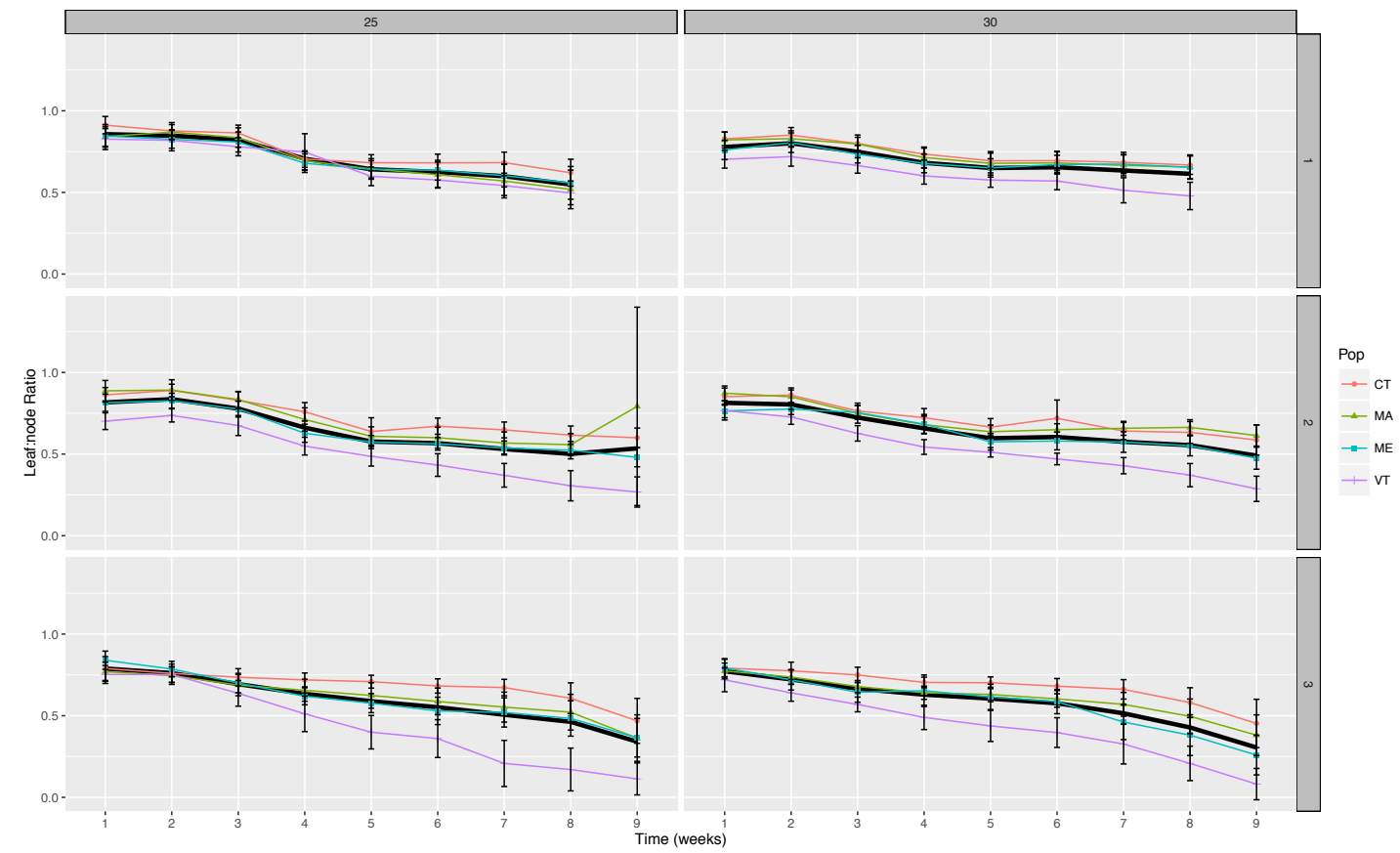

Figure 5: Leaves $\mathrm{x}$ Temperature $\mathrm{x}$ Population $\mathrm{x}$ Trial $\mathrm{x}$ Time 
The following figures depict the interactions between the variables described in the figure legends. The response variables are standardized, and each variable is divided into the three trials, labeled at the top in the gray bars. The y-axis is time, which is divided into nine weeklong segments. Each row represents a different water treatment, labeled on the left in the gray bars.

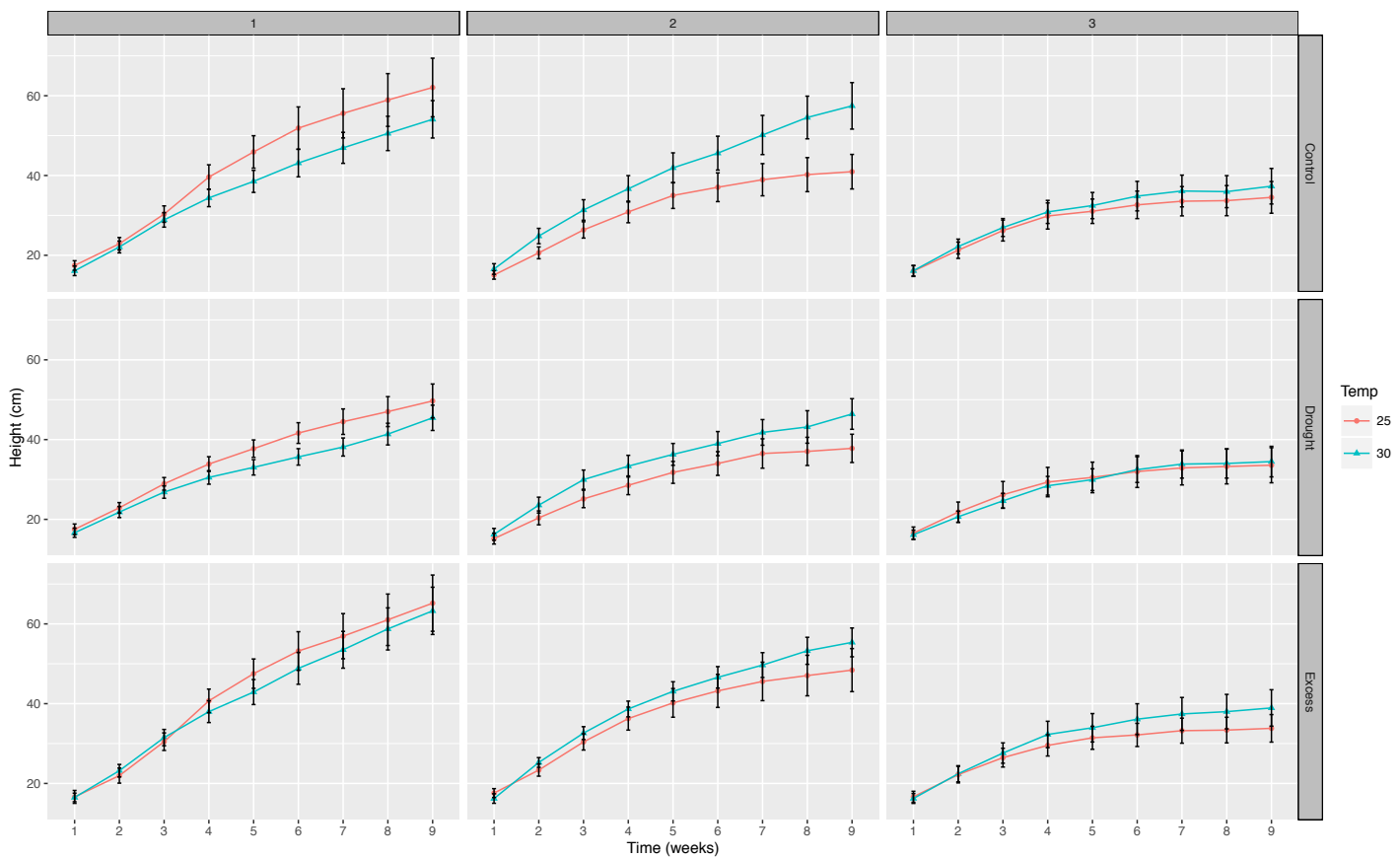

Figure 6: Height $\mathrm{x}$ Water $\mathrm{x}$ Temperature $\mathrm{x}$ Time
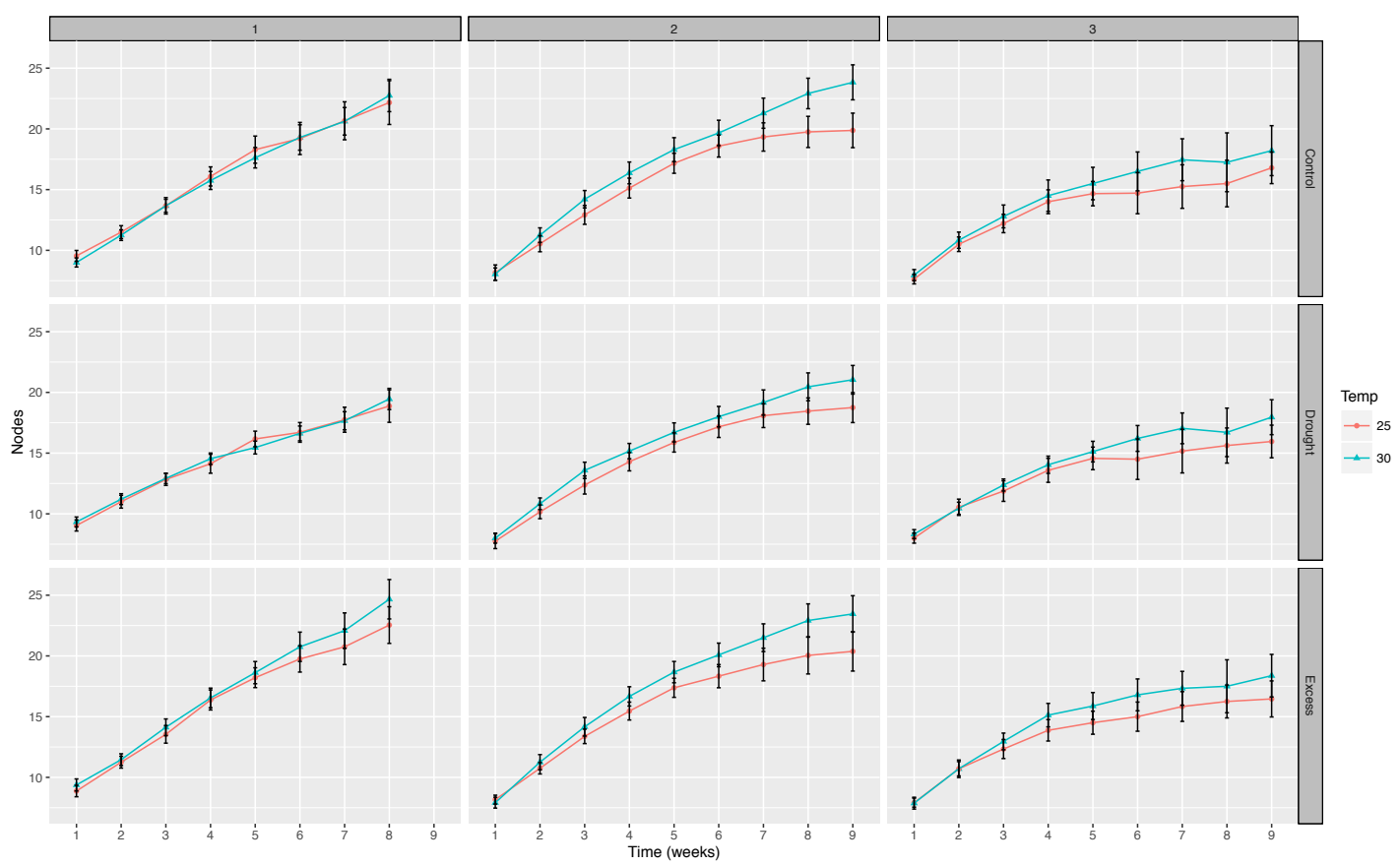

Figure 7: Nodes x Water x Temperature x Time 


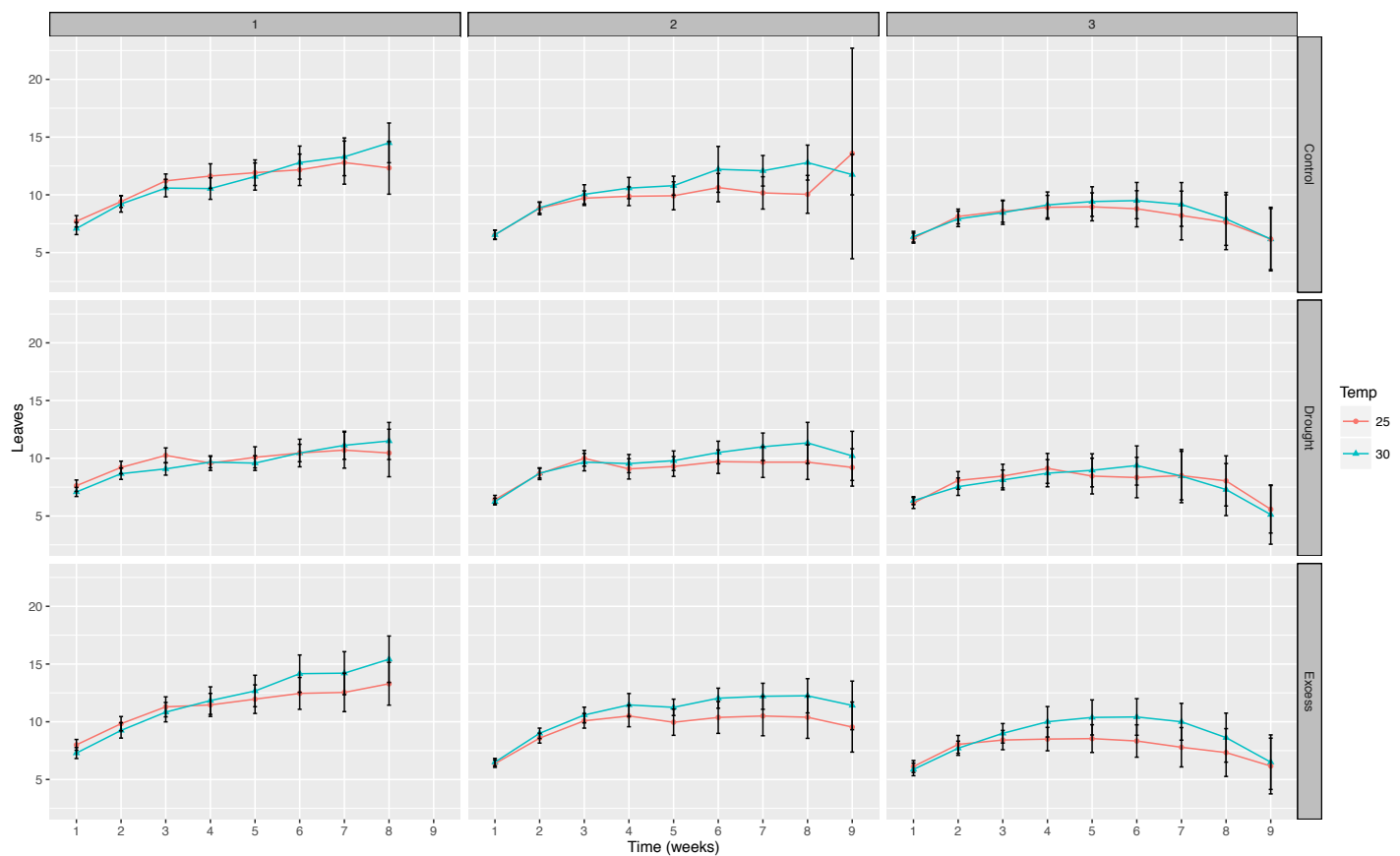

Figure 8: Number of Leaves $\mathrm{x}$ Water $\mathrm{x}$ Temperature $\mathrm{x}$ Time

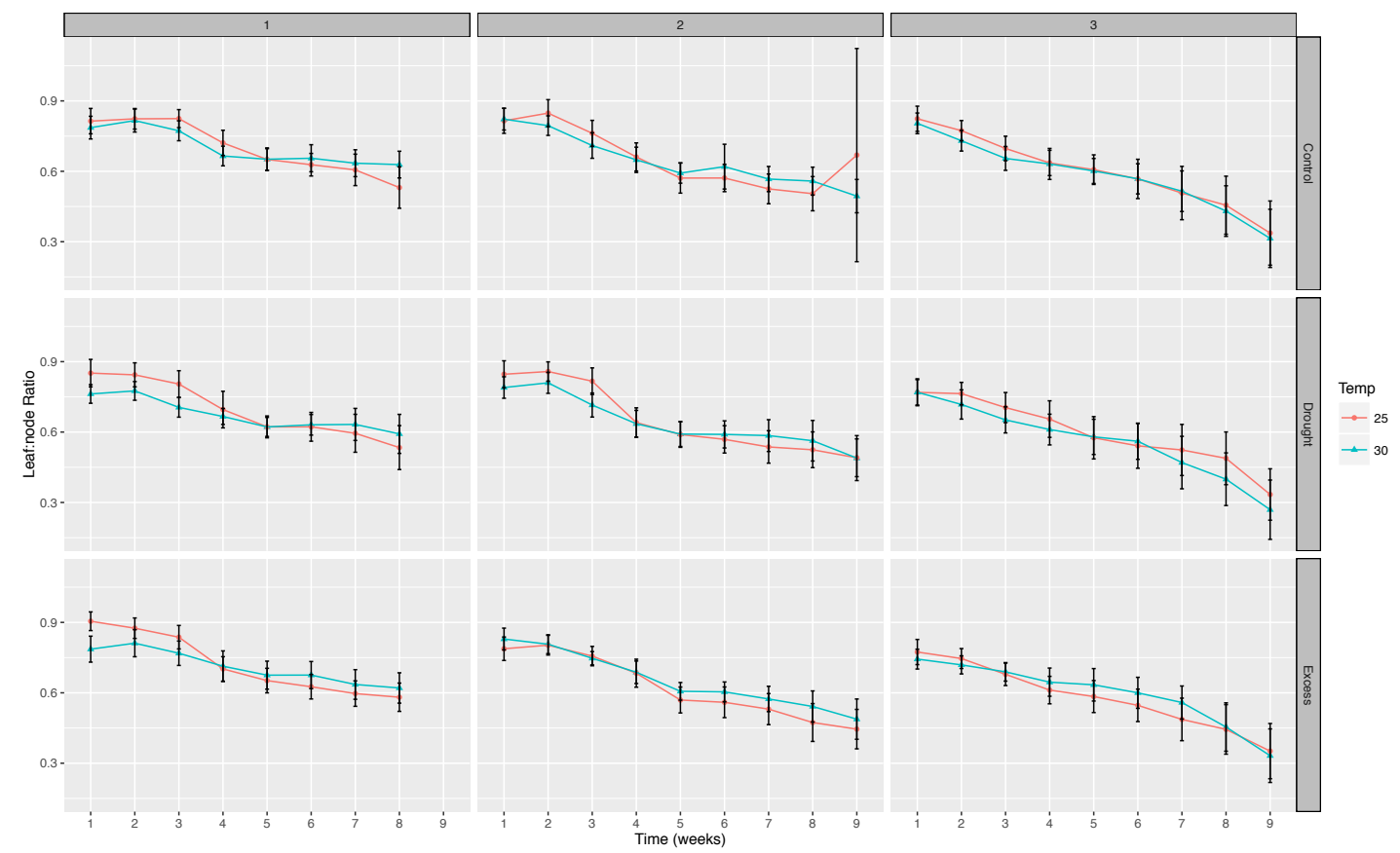

Figure 9: Leaf:node Ratio x Water x Temperature x Time 
The following figures depict the interactions between the response variable on the $\mathrm{x}$ axis, water treatments, time, and population. The response variables are standardized, and each variable is divided into the three trials, labeled at the top in the gray bars. The $\mathrm{y}$-axis is time, which is divided into nine weeklong segments. Each row represents a different water treatment, labeled on the left in the gray bars. Each individual graph is divided by four populations, and the black trend line represents the mean.

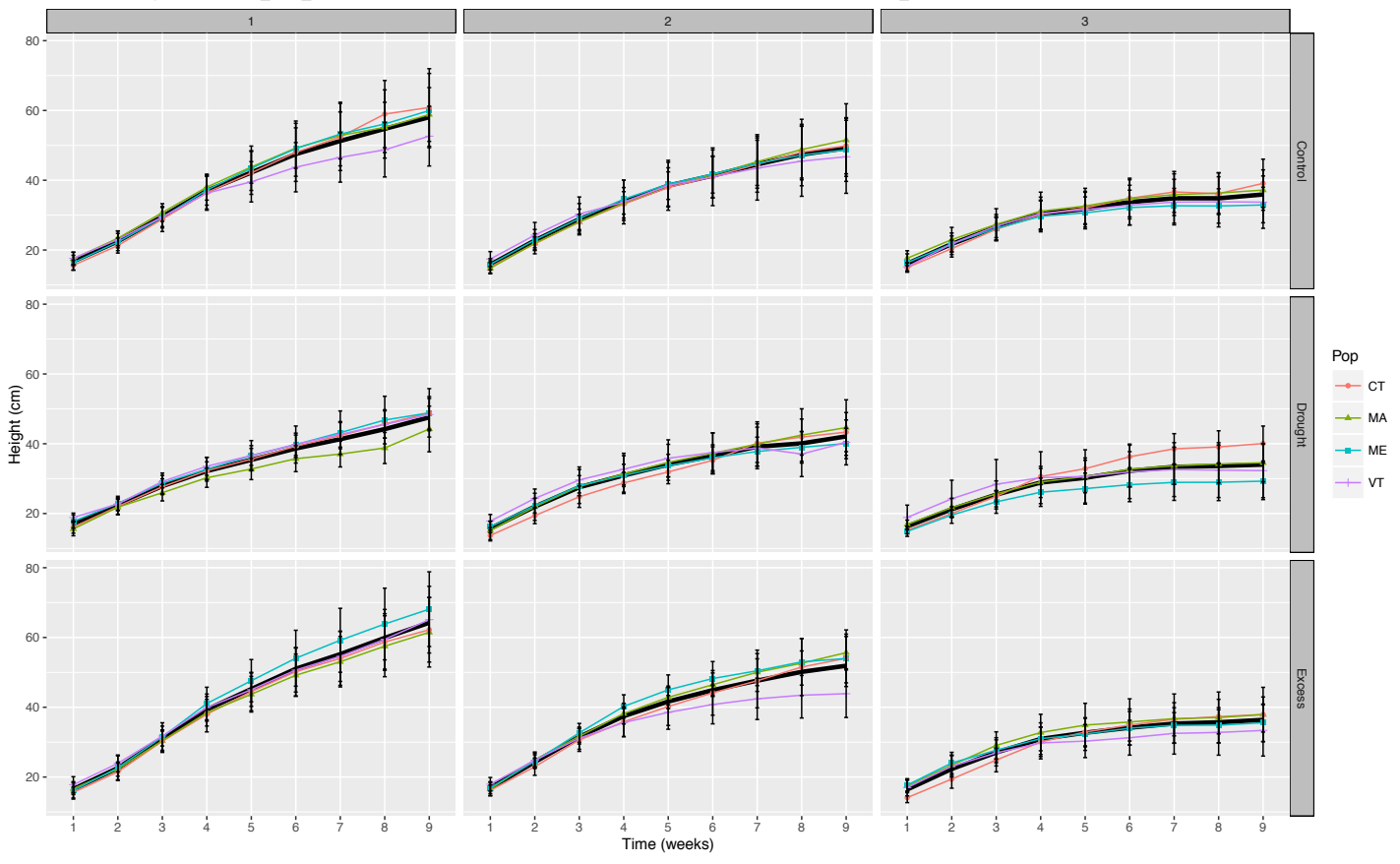

Figure 10: Height $\mathrm{x}$ Water $\mathrm{x}$ Population $\mathrm{x}$ Time

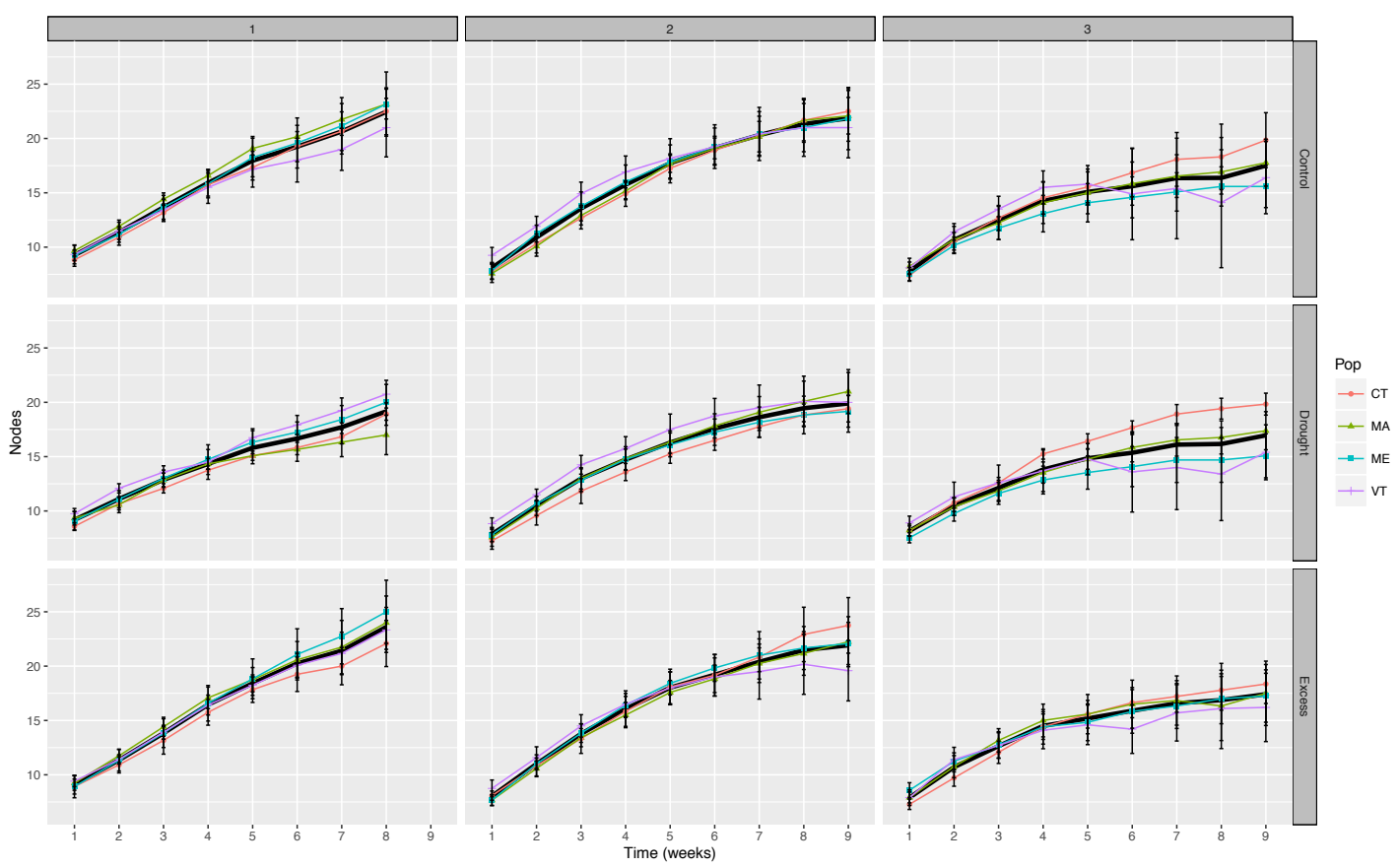

Figure 11: Nodes x Water x Population x Time 


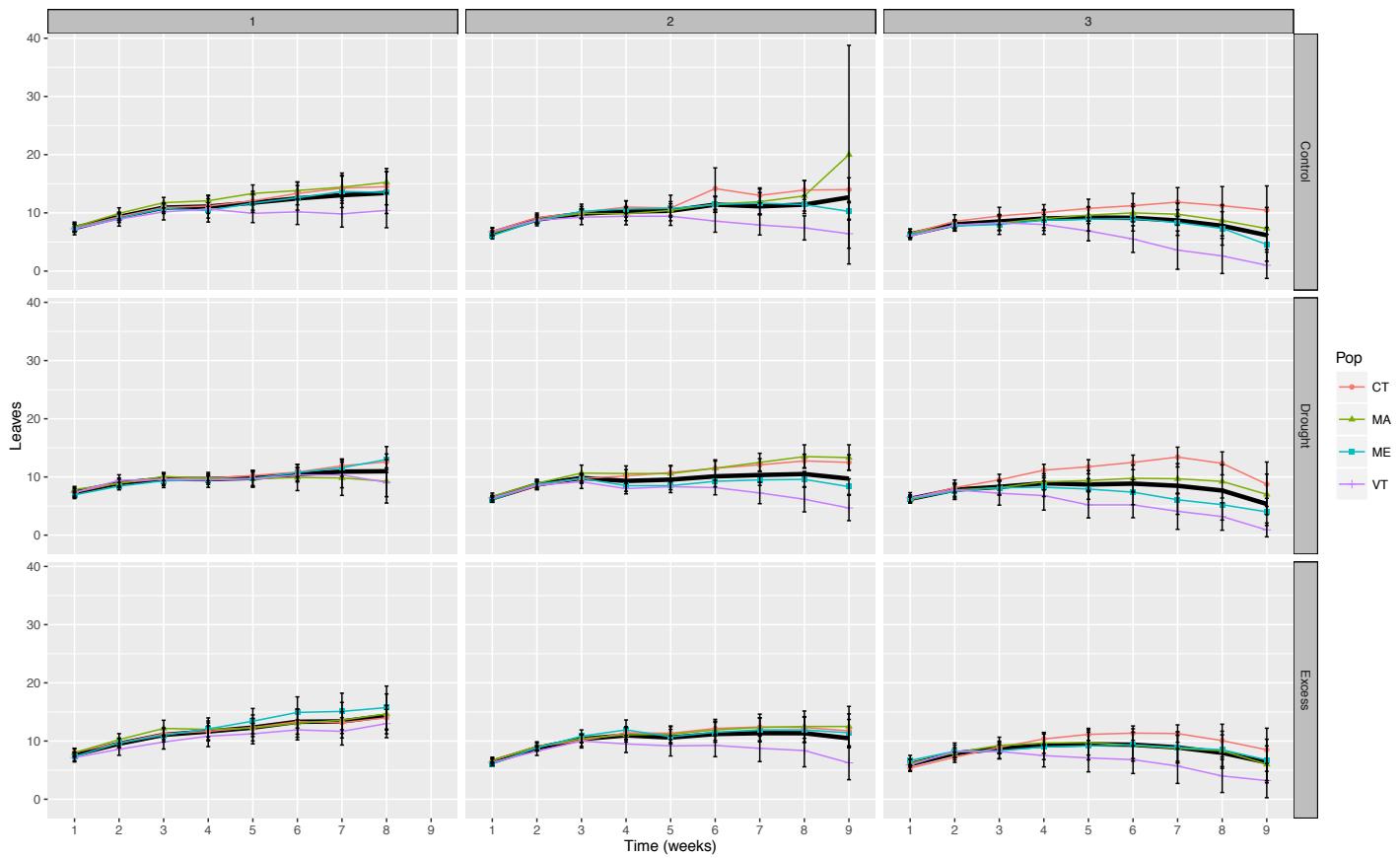

Figure 12: Number of Leaves $\mathrm{x}$ Water $\mathrm{x}$ Population $\mathrm{x}$ Time

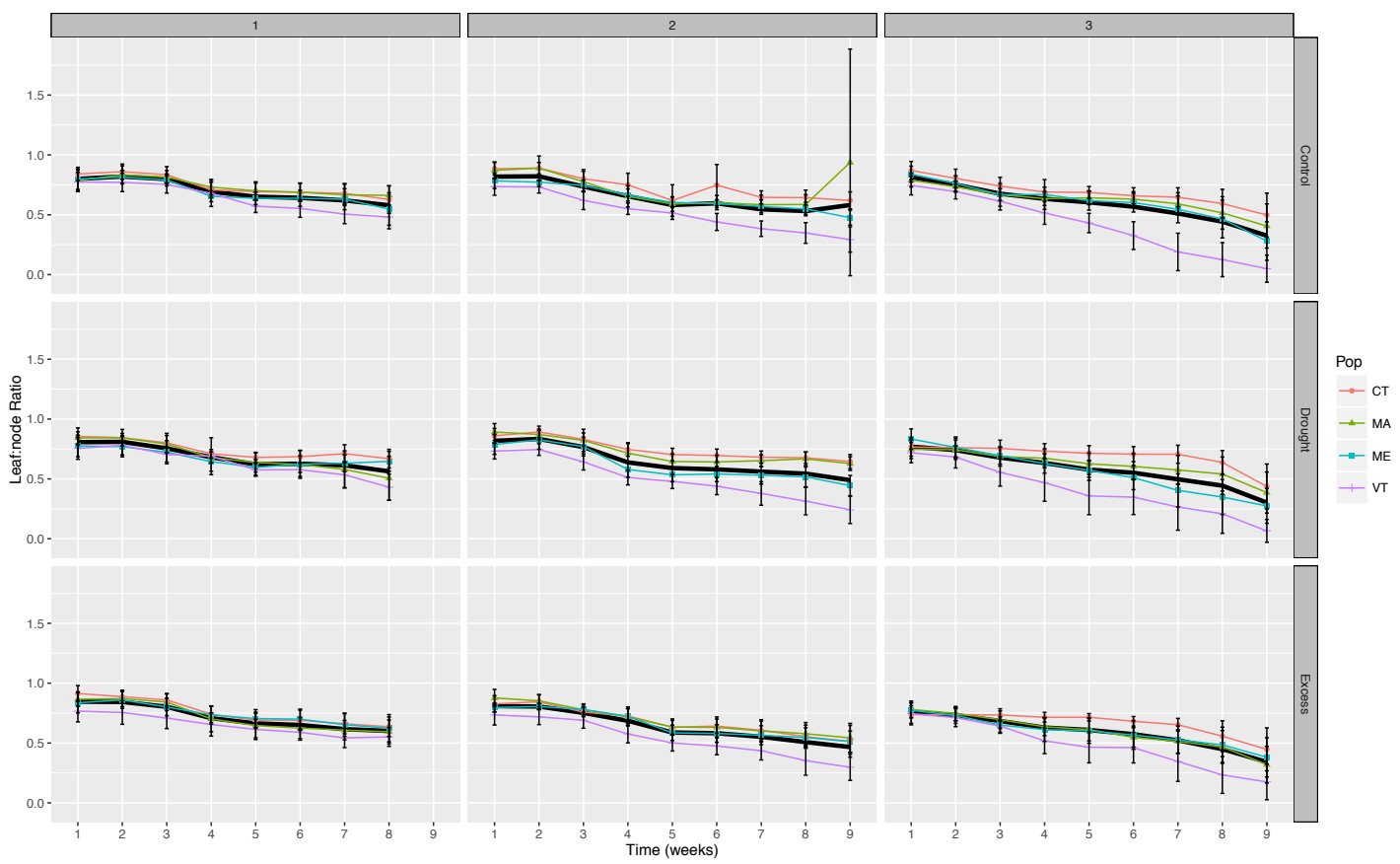

Figure 13: Leaf:node Ratio x Water x Population x Time 


\section{BIBLIOGRAPHY}

Abdul Qados, A. M. S. 2011. Effect of salt stress on plant growth and metabolism of bean plant Vicia faba (L.). Journal of the Saudi Society of Agricultural Sciences $10: 7-15$.

Agrawal, A. 2005. Natural selection on common milkweed. Evolutionary Ecology Research 7:651-667.

Ali, A., and M. Kobayashi. 2010. Seed transmission of cucumber mosaic virus in pepper. Journal of Virological Methods 163:234-237.

Aslam, M., M. Maqpool, and R. Cengiz. 2015. Drought stress in maize (Zea Mays L.): effects, resistance mechanisms, global achievements, and biological strategies. Springer Briefs in Agriculture 8:5-18.

Asseng, S., F. Ewert, P. Martre, R. P. Rotter, D. B. Lobell, D. Cammarano, B. A. Kimball, M. J. Ottman, G. W. Wall, J. W. White, M. P. Reynolds, P. D. Alderman, P. V. V Prasad, P. K. Aggarwal, J. Anothai, B. Basso, C. Biernath, A. J. Challinor, G. De Sanctis, J. Doltra, E. Fereres, M. Garcia-Vile, S. Gayler, G. Hoogenboom, L. A. Hunt, R. C. Izaurralde, M. Jabloun, C. D. Jones, K. C. Kersebaum, A. K. Koehler, C. Muller, S. N. Kumar, C. Nendel, G. O’Leary, J. E.

Olesen, T. Palosuo, E. Priesack, E. E. Rezaei, A. C. Ruane, M. A. Semenov, I.

Shcherbak, C. Stockle, P. Stratonovitch, T. Streck, I. Supit, F. Tao, P. J.

Thorburn, K. Waha, E. Wang, D. Wallach, I. Wolf, Z. Zhao, and Y. Zhu. 2015.

Rising temperatures reduce global wheat production. Nature Climate Change 5:143-147. 
Bartels, D., and R. Sunkar. 2005. Drought and salt tolerance in plants. Critical Reviews in Plant Sciences 24:23-58.

Baskin, J. M., and C. C. Baskin. 1977. Germination of common milkweed (Asclepias syriaca L.) seeds. Bulletin of the Torrey Botanical Club 104:167-170.

Beaton, L., and S. Dudley. 2004. Tolerance to salinity and manganese in three common roadside species. International Journal of Plant Science 165:37-51.

Bhowmik, P. C. 1994. Biology and control of common milkweed (Asclepias syriaca). Review in Weed Science 6:227-250.

Borders, B., and E. Lee-Mader. 2014. Milkweeds: A conservation practitioner's guide.

Brower, L. P., G. Castilleja, A. Peralta, J. Lopez-garcia, S. Diaz, D. Melgarejo, M. Missrie, and D. Melgarejo. 2002. in Practice Conservation Area Overwintering in of the Quality in a Principal Monarch Butterfly in Mexico ,. Conservation Biology 16:346-359.

Brower, L. P., D. R. Kust, E. Rendón-Salinas, E. G. Serrano, K. R. Kust, J. Miller, C. Fernandez del Rey, and K. Pape. 2004. Catastrophic winter storm mortality of monarch butterflies in Mexico during January 2002. Pages 151-166in K. Oberhauser and M. J. Solensky, editors.The monarch butterfly: biology and conserva- tion. Cornell University Press, Ithaca, NY.

Brower, L. P., O. R. Taylor, E. H. Williams, D. A. Slayback, R. R. Zubieta, and M. I. Ramírez. 2012. Decline of monarch butterflies overwintering in Mexico: Is the migratory phenomenon at risk? Insect Conservation and Diversity 5:95-100.

Bruckart, W. L., and J. W. Lorbeer. 1975. Cucumber moasic virus in weed hosts near commercial fields of lettuce and celery. Etiology 66:253-259. 
Cabot, C., J. V. Sibole, J. Barceló, and C. Poschenrieder. 2014. Lessons from crop plants struggling with salinity. Plant Science 226:2-13.

Couture, J. J., S. P. Serbin, and P. A. Townsend. 2015. Elevated temperature and periodic water stress alter growth and quality of common milkweed (Asclepias syriaca) and monarch (Danaus plexippus) larval performance. Arthropod-Plant Interactions 9:149-161.

Cramer, G., G. Alberico, and C. Schmidt. 1994. Leaf expansion limits dry matter accumulation of salt-stressed maize. Functional Plant Biology 21:663-674.

Cramer, G. L., and O. C. Burnside. 1982. Distribution and interference of common milkweed (Asclepias syriaca) in Nebraska. Weed Science Society of America $30: 385-388$.

Davis, A. K., and L. A. Dyer. 2015. Long-term trends in eastern North American monarch butterflies: A collection of studies focusing on spring, summer, and fall dynamics. Annals of the Entomological Society of America 108:661-663.

Davis, A. K., and E. Howard. 2005. Spring recolonization rate of monarch butterflies in eastern North America: new estimates from citizen-science data. Journal of the Lepidopterists' Society 59:1-5.

Dennett, M. D., J. Elston, and J. R. Milford. 1978. The effect of temperature changes on the expansion of individual leaves of Vicia faba L. Annals of Botany 42:877888.

Dill, G. M., C. A. CaJacob, and S. R. Padgette. 2008. Glyphosate-resistant crops: adoption, use and future considerations. Pest Management Science 64:326-331.

Doolittle, S. P., and M. N. Walker. 1925. Further studies on the overwintering and 
dissemination of cucurbit moasic. Journal of Agricultural Research 31:1-58.

Duffus, J. E. 1971. Role of weeds in the incidence of virus diseases. Annual Review of Phytopathology 9:319-340.

Dumroese, R. K., and T. Luna. 2013. Monarchs (Danaus plexippus) and milkweeds (Asclepias species): The current situation and methods for propagating milkweeds. Native Plants Journal 14:5-15.

El-iklil, Y., M. Karrou, and M. Benichou. 2000. Salt stress effect on epinasty in relation to ethylene production and water relations in tomato. Agronomie, EDP Sciences 20:399-406.

Escriu, F., A. Fraile, and F. García-Arenal. 2000. Evolution of virulence in natural populations of the satellite RNA of cucumber mosaic virus. Phytopathology $90: 480-485$.

Evetts, L. L., and C. Burnside. 1972. Germination and seedling development of common milkweed and other species. Weed Science 20:371-378.

Flockhart, D. T. T., J.-B. Pichancourt, D. R. Norris, and T. G. Martin. 2015. Unravelling the annual cycle in a migratory animal: breeding-season habitat loss drives population declines of monarch butterflies. Journal of Animal Ecology $84: 155-165$.

Francki, R. I. B., D. W. Mossop, and T. Hatta. 1979a. Cucumber Mosaic Virus. Association of Applied Biologists 213.

Francki, R. I. B., D. W. Mossop, and T. Hatta. 1979b. Cucumber mosaic virus. Association of Applied Biologists 213.

French, R. J., and N. C. Turner. 1991. Water deficits change dry matter partitioning 
and seed yield in narrow-leafed lupins (Lupinus angustifolius L.). Australian Journal of Agricultural Research 42:471-484.

Hartzler, R. G. 2010. Reduction in common milkweed (Asclepias syriaca) occurrence in Iowa cropland from 1999 to 2009. Crop Protection 29:1542-1544.

Hasanuzzaman, M., K. Nahar, M. M. Alam, R. Roychowdhury, and M. Fujita. 2013. Physiological, biochemical, and molecular mechanisms of heat stress tolerance in plants. International Journal of Molecular Sciences 14:9643-9684.

Hatfield, J. L. 2016. Increased temperatures have dramatic effects on growth and grain yield of three maize hybrids. Agricultural \& Environmental Letters 1:150006.

Hatfield, J. L., and J. H. Prueger. 2015. Temperature extremes: Effect on plant growth and development. Weather and Climate Extremes 10:4-10.

Heinrichs, D. H. 1970. Flooding tolerance of legumes. Canadian Journal of Plant Science 50:435-438.

Hobbs, H. A., D. M. Eastburn, C. J. D’Arcy, J. D. Kindhart, J. B. Masiunas, D. J. Voegtlin, R. A. Weinzierl, and N. K. McCoppin. 2000. Solanaceous Weeds as Possible Sources of Cucumber mosaic virus in Southern Illinois for Aphid Transmission to Pepper. Plant Disease 84:1221-1224.

Hobbs, P. R. 2007. Conservation agriculture: what is it and why is it important for future sustainable food production? The Journal of Agricultural Science 145:127.

Horton, R., G. Yohe, W. Easterling, R. Kates, M. Ruth, E. Sussman, A. Whelchel, D. Wolfe, and F. Lipschultz. 2014. Ch. 16: Northeast. Pages 371-395in J. M. Melillo and T. C. Richmond, editors.Climate Change Impacts in the United States: The Third National Climate Assessment. 
Howard, E., and A. K. Davis. 2015. Tracking the fall migration of eastern monarchs with journey north roost sightings. Pages 207-214in K. S. Oberhauser, K. R. Nail, and S. Altizer, editors.Monarchs in a changing world: biology and conservation of an iconic insect. Cornell University Press, Ithaca, NY.

Inamine, H., S. P. Ellner, J. P. Springer, and A. A. Agrawal. 2016. Linking the continental migratory cycle of the monarch butterfly to understand its population decline. Oikos 125:1081-1091.

IPCC. 2013. Summary for policymakers. Pages 1-30in T. F. Stocker, D. Qin, G.-K. Plattner, M. Tignor, S. K. Allen, J. Boschung, A. Nauels, Y. Xia, V. Bex, and P. M. Midgley, editors.Climate Change 2013: The Physical Science Basis. Contribution of Working Group I to the Fifth Assessment Report of the Intergovernmental Panel on Climate Change. Cambridge University Press, Cambridge, United Kingston and New York, NY, USA.

IPCC. 2014. Climate Change 2014: Synthesis Report. Contribution of Working Groups I, II and III to the Fifth Assessment Report of the Intergovernmental Panel on Climate Change. Page (R. K. P. and L. A. Meyer, Ed.). Geneva, Switzerland.

Jamil, A., S. Riaz, M. Ashraf, and M. R. Foolad. 2011. Gene expression profiling of plants under salt stress. Critical Reviews in Plant Sciences 30:435-458.

Jones, R. A. C., and B. A. Coutts. 1996. Alfalfa mosaic and cucumber mosaic virus infection in chickpea and lentil: Incidence and seed transmission. Annals of Applied Biology 129:491-506.

Jones, R. A., and A. S. El-Beltagy. 1989. Epinasty promoted by salinity or ethylene is 
an indicator of salt sensitivity in tomatoes. Plant, Cell \& Environment 12:813817.

Kazinczi, G., J. Horvath, and D. E. Lesemann. 2002. Perennial plants as new natural hosts of three viruses. Journal of Plant Diseases and Protection 109:301-310.

Kozlowski, T. T. 2000. Responses of woody plants to human-induced environmental stresses: Issues , problems, and strategies for alleviating stress. Critical Reviews in Plant Sciences 12:91-170.

Landis, T. 2014. Monarch waystations: propagating native plants to create travel corridors for migrating monarch butterflies. Native Plants Journal 15:5-16.

Lauer, J. 2014. Flooding effects on corn. University of Wisconsin Crop Manager $21: 42-47$.

Lavola, A., L. Nybakken, M. Rousi, J. Pusenius, M. Petrelius, S. Kellomäki, and R. Julkunen-Tiitto. 2013. Combination treatment of elevated UVB radiation, CO 2 and temperature has little effect on silver birch (Betula pendula) growth and phytochemistry. Physiologia Plantarum 149:499-514.

Lemoine, N. P. 2015. Climate change may alter breeding ground distributions of eastern migratory monarchs (Danaus plexippus) via range expansion of Asclepias host plants. PLoS ONE 10.

Mak, M., M. Babla, S. C. Xu, A. O’Carrigan, X. H. Liu, Y. M. Gong, P. Holford, and Z. H. Chen. 2014. Leaf mesophyll $\mathrm{K}+, \mathrm{H}+$ and $\mathrm{Ca} 2+$ fluxes are involved in drought-induced decrease in photosynthesis and stomatal closure in soybean. Environmental and Experimental Botany 98:1-12.

Malcolm, S. B. 1991. Cardenolide-mediated interactions between plants and 
herbivores. Pages 251-296in G. A. Rosenthal and M. R. Berenbaum, editors.Herbivores: Their interactions with secondary plant metabolites. Second edition. Academic Press, San Diego.

Malcolm, S. B., B. J. Cockrell, and L. P. Brower. 1993. Spring recolonization of eastern North America by the monarch butterfly: successive brood or single sweep migration? Pages 253-268in S. B. Malcolm and M. P. Zalucki, editors.Biology and Conservation of the Monarch Butterfly. Natural History Museum of Los Angeles County, Los Angeles.

Malcolm, S. B., and M. P. Zalucki. 1996. Milkweed latex and carenolide induction may resolve the lethal plant defence paradox. Entomologia Experimentalis et Applicata 80:193-196.

Medeiros, D. B., E. Ciriaco, H. Rafael, B. Santos, C. M. Pacheco, S. Musser, R. Jurema, and M. Custódio. 2012. Physiological and biochemical responses to drought stress in Barbados cherry. Brazilian Society of Plant Physiology 24:181192.

Milthorpe, F. L. 1959. Studies on the expansion of the leaf surface: I. The influence of temperature. Journal of Experimental Botany 10:233-249.

Mitra, R., and C.R. Bhatia. 2008. Bioenergetic cost of heat tolerance in wheat crop. Current Science 94:1049-1053.

Mueller, E. E., A. Groves, R.L., and C. Gratton. 2012. Crop and non-crop plants as potential reservoir hosts of alfalfa mosaic virus and cucumber mosaic virus for spread to commercial snap bean. Plant Disease 96:506-514.

Munns, R., and A. Termaat. 1986. Whole-plant responses to salinity. Australian 
Journal of Plant Physiology 13:143-160.

Murashige, T., and F. Skoog. 1962. A revised medium for rapid growth and bio assays with tobacco tissue cultures. Physiologia Plantarum 15:473-497.

Nezami, A., H. R. Khazaei, Z. B. Rezazadeh, and A. Hosseini. 2008. Effects of drought stress and defoliation on sunflower (Helianthus annuus) in controlled conditions. Desert 12:99-104.

Nybakken, L., R. Hörkkä, and R. Julkunen-Tiitto. 2012. Combined enhancements of temperature and UVB influence growth and phenolics in clones of the sexually dimorphic Salix myrsinifolia. Physiologia Plantarum 145:551-564.

Oberhauser, K., and A. T. Peterson. 2003. Modeling current and future potential wintering distributions of eastern North American monarch butterflies. Proceedings of the National Academy of Sciences of the United States of America 100:14063-14068.

Oberhauser, K. S., M. D. Prysby, H. R. Mattila, D. E. Stanley-Horn, M. K. Sears, G. Dively, E. Olson, J. M. Pleasants, W. K. Lam, and R. L. Hellmich. 2001. Temporal and spatial overlap between monarch larvae and corn pollen. Proceedings of the National Academy of Sciences of the United States of America 98:11913-11918.

Opina, N. L., and S. A. Miller. 2005. Evaluation of immunoassays for detection of ralstonia solanacearum, causal agent of bacterial wilt of tomato and eggplant in the Philippines. Acta Horticulturae 695:353-356.

Panter, K. E., M. H. Ralphs, J. A. Pfister, D. R. Gardner, B. L. Stegelmeier, S. T. Lee, K. D. Welch, B. T. Green, T. Z. Davis, and D. Cook. 2011. Plants poisonous to 
livestock in the western United States. Page Agriculture Information Bulletin Number 415. U.S. Department of Agriculture, Agricultural Research Service, Poisonous Plant Research Laboratory., Logan, UT.

Phippen, W. B. 2007. Production variables affecting follicle and biomass development in common milkweed. Pages 82-88in J. Janick and A. Whipkey, editors.Issues in new crops and new uses. ASHS Press, Alexandria, VA.

Pleasants, J. M., E. H. Williams, L. P. Brower, K. S. Oberhauser, and O. R. Taylor. 2016. Conclusion of no decline in summer monarch population not supported. Annals of the Entomological Society of America 109:169-171.

Pleasents, J. M., and K. S. Oberhauser. 2012. Milkweed loss in agricultural fields because of herbicide use: effect on the monarch butterfly population. Insect Conservation and Diversity 6:135-144.

Potrer, J. R., and J. W. Jones. 1977. Leaf area partitioning as an important factor in growth. Plant Physiology 59:10-14.

Pramanik, T. K., and S. K. Datta. 1986. Plant regeneration and ploidy variation in culture derived plants of Asclepias curcasavica L. Plant Cell Reports 3:219-222.

Rasmussen, J. A. 1975. Noncompetitive effects of common milkweed, Asclepias syriaca L., on germination and growth of grain sorghum. The American Midland Naturalist 94:478-483.

Reddy, S. H., M. Chakravarthi, and K. N. Chandrashekara. 2013. Effect of MS and L2 medium on callusing and regeneration from nodal explants of Asclepias curassavica ( L ). 3:294-301.

Renault, S., S. Wolfe, J. Markham, and G. Avila-Sakar. 2016. Increased resistance to a 
generalist herbivore in a salinity-stressed non-halophytic plant. AoB Plants 8:110.

Rosenzweig, C., A. Iglesius, P. R. Epstein, and E. Chivian. 2001. Climate change and extreme weather events - Implications for food production, plant diseases, and pests. Global Change \& Human Health 2:90-104.

Rosu, A., S. Danaila-Guidea, R. Dobrinoiu, F. Toma, D. T. Rosu, N. Sava, and C. Manolache. 2011. Asclepias syriaca L . - an underexploited industrial crop for energy and chemical feedstock. Romanian Biotechnological Letters 16:131-138.

Sáenz-Romero, C., G. E. Rehfeldt, P. Duval, and R. A. Lindig-Cisneros. 2012. Abies religiosa habitat prediction in climatic change scenarios and implications for monarch butterfly conservation in Mexico. Forest Ecology and Management 275:98-106.

Shlizerman, E., J. Phillips-Portillo, D. B. Forger, and S. M. Reppert. 2017. Neural integration underlying a time-compensated sun compass in the migratory monarch butterfly. Cell Reports 15:683-691.

Shrivastava, P., and R. Kumar. 2015. Soil salinity: A serious environmental issue and plant growth promoting bacteria as one of the tools for its alleviation. Saudi Journal of Biological Sciences 22:123-131.

Slayback, D. A., L. P. Brower, M. I. Ramirez, and L. S. Fink. 2007. Establishing the presence and absence of overwintering colonies of the monarch butterfly in Mexico by the use of small aircraft. American Entomologist 53:28-40.

Tack, J., A. Barkley, and L. L. Nalley. 2015. Effect of warming temperatures on US wheat yields. Proceedings of the National Academy of Sciences of the United 
States of America 112:6931-6.

Tideman, J., and J. S. Hawker. 1982. In vitro propagation of latex-producing plants. Annals of Applied Biology 49:273-279.

Tomlinson, J. 1987. Epidemiology and control of virus diseases of vegetables. Annals of Applied Biology 110:661-681.

Tomlinson, J. A., and A. L. Carter. 1970. Studies on the seed transmission of cucumber mosaic virus in chickweed (Stellaria media $</ \mathrm{i}>$ ) in relation to the ecology of the virus. Annals of Applied Biology 66:381-386.

Tomlinson, J. A., A. L. Carter, W. T. Dale, and C. J. Simpson. 1970. Weed plants as sources of cucumber mosaic virus. Ann. appl. Biol. 66:11-16.

Veteli, T. O., K. Kuokkanen, R. Julkunen-Tiitto, H. Roininen, and J. Tahvanainen. 2002. Effects of elevated $\mathrm{CO} 2$ and temperature on the herbivore defensive chemistry. Global Change Biology 8:1240-1252 ST-Effects of elevated CO2 and temper.

Vidal, O., J. López-García, and E. Rendón-Salinas. 2014. Trends in deforestation and forest degradation after a decade of monitoring in the monarch butterfly biosphere reserve in Mexico. Conservation Biology 28:177-186.

Vidal, O., and E. Rendón-Salinas. 2014. Dynamics and trends of overwintering colonies of the monarch butterfly in Mexico. Biological Conservation 180:165175.

Wason, E. L., A. A. Agrawal, and M. D. Hunter. 2013. A genetically-based latitudinal cline in the emission of herbivore-induced plant volatile organic compounds. Journal of Chemical Ecology 39:1101-1111. 
Wenkert, W., N. R. Fausey, and H. D. Watters. 1981. Flooding responses in Zea mays L. Plant and Soil 62:351-366.

Wikimedia Commons. 2010. File:USA location map - counties.svg. https://commons.wikimedia.org/wiki/File:USA_location_map_-_counties.svg.

Wilson, K. J., and P. G. Mahlberg. 1977. Investigations of laticifer differentation in tissue cultures derived from Asclepias syriaca L. Annals of Botany 41:10491054.

Woods, E. C., A. P. Hastings, N. E. Turley, S. B. Heard, and A. A. Agrawal. 2012. Adaptive geographical clines in the growth and defense of a native plant. Ecological Monographs 82:149-168.

Woodson, R. E. 1954. The North American species of Asclepias L . Annals of the Missouri Botanical Garden 41:1-211.

Wyatt, R., and S. B. Broyles. 1994. Ecology and evolution of reproduction in milkweeds. Annual Review of Ecology and Systematics 25:423-441.

Yang, S. F., and N. E. Hoffman. 1984. Ethylene biosynthesis and its regulation in higher plants. Annual Review of Plant Physiology 35:155-189.

Yang, Y., K. S. Kim, and E. J. Anderson. 1997. Seed transmission of cucumber mosaic virus in spinach. Phytopathology 87:924-931.

Zitter, T. A., and M. T. Banik. 1984. Virus diseases of Cucurbits. http://vegetablemdonline.ppath.cornell.edu/factsheets/Viruses_Cucurbits.htm. 